\title{
EVALUATION OF FLAT-PLATE PHOTOVOLTAIC/THERMAL HYBRID SYSTEMS FOR SOLAR ENERGY UTILIZATION
}

John W. Andrews

June 1981

DEPARTMENT OF ENERGY AND ENVIRONMENT

SOLAR TECHNOLOGY GROUP

BROOKHAVEN NATIONAL LABORATORY

ASSOCIATED UNIVERSITIES, INC.

UNDER CONTRACT NO. DE-AC02-76CHO0016 WITH THE UNITED STATES DEPARTMENT OF ENERGY 


\section{DISCLAIMER}

This report was prepared as an account of work sponsored by an agency of the United States Government. Neither the United States Government nor any agency thereof, nor any of their employees, nor any of their contractors, subcontractors, or their employees, makes any warranty, express or implied, or assumes any legal liability or responsibility for the accuracy, completeness, or usefulness of any information, apparatus, product, or process disclosed, or represents that its use would not infringe privately owned rights. Reference herein to any specific commercial product, process, or service by trade name, trademark, manufacturer, or otherwise, does not necessarily constitute or imply its endorsement, recommendation, or favoring by the United States Government or any agency, contractor or subcontractor thereof. The views and opinions of authors expressed herein do not necessarily state or reflect those of the United States Government or any agency, contractor or subcontractor thereof.

Printed in the United States of America

Available from

National Technical Information Service

U.S. Department of Commerce

5285 Port Royal Road

Springfield, VA 22161

NTIS price codes:

Printed Copy: A06; Microfiche Copy: A01 


\section{ABSTRACT}

The technical and economic attractiveness of combined photovoltaic/ thermal (PV/T) solar energy collectors was evaluated. The study was limited to flat-plate collectors since concentrating photovoltaic collectors require active cooling and thus are inherently $\mathrm{PV} / \mathrm{T}$ collectors, the only decision being whether to use the thermal energy or to dump it. It was also specified at the outset that reduction in required roof area was not to be used as an argument for combining the collection of thermal and electrical energy into one module. Three tests of economic viability were identified, all of which $\mathrm{PV} / \mathrm{T}$ must pass if it is to be considered a promising alternative: $\mathrm{PV} / \mathrm{T}$ must prove to be competitive with photovoltaic-only, thermal-only, and side-by-side photovoltaic-plus-thermal collectors and systems. These three tests were applied to systems using low-temperature (unglazed) collectors and to systems using medium-temperature (glazed) collectors in Los Angeles, New York, and Tampa. For photovoltaics, the 1986 DOE cost goals were assumed to have been realized, and for thermal energy collection two technologies were considered: a current technology based on metal and glass, and a future technology based on thin-film plastics. The study showed that for medium-temperature applications $P V / T$ is not an attractive option in any of the locations studied. For low-temperature applications, $\mathrm{PV} / \mathrm{T}$ appears to be marginally attractive.

\section{ACKNOWLEDGEMENTS}

I thank William Wilhelm for participation in discussions of $\mathrm{PV} / \mathrm{T}$ hardware and for information on the potential of dc motor driven compressors. I thank Paul Le Doux for his participation in these same discussions and for his zealous efforts in obtaining some of the cost data used in this report. I thank Edward Kush for his participation in the earlier PV/T discussions. 


\section{CONTENTS}

Abstract....................................

Acknowledgements................................

Tables...................................... vi

Figures........................................ vii

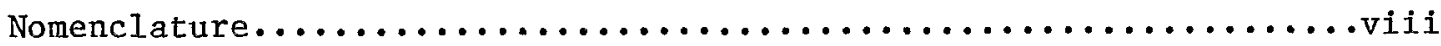

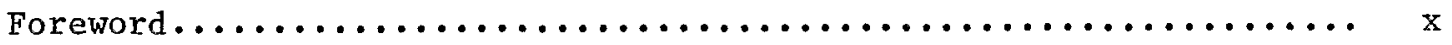

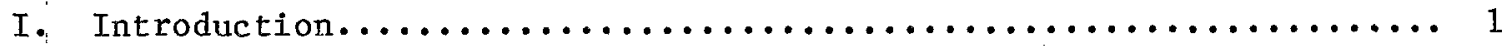

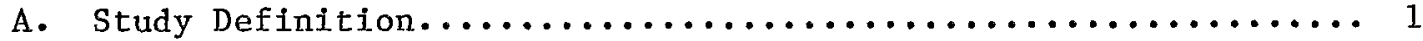

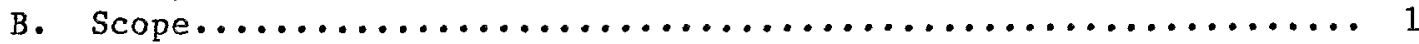

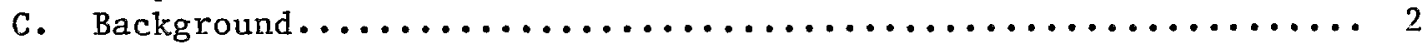

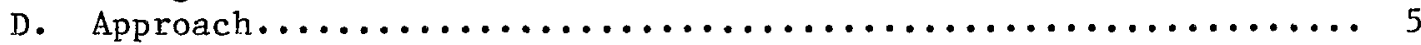

II. The Flat-Plate Solar Collector Market.................. 7

A. Low-Temperature Collectors..................... 7

B. Medium-Temperature Collectors..................... 10

III. Calculation of Thermal and Electrical Outputs.............. 12

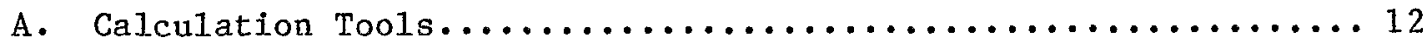

B. Summary of the Florscheutz Approach to PV/T............. 12

C. Implications for the Thermal Efficiency Curve in PV/T.......13

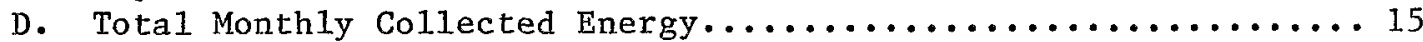

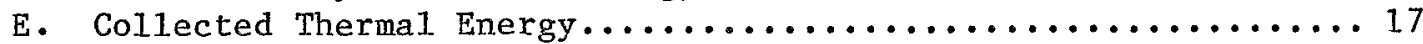

F. Collected Electrical Energy....................... 18

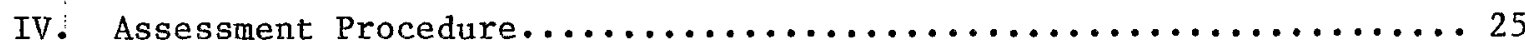

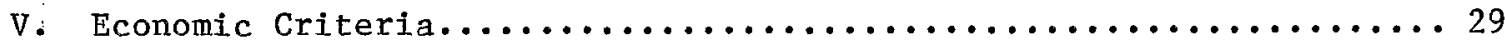

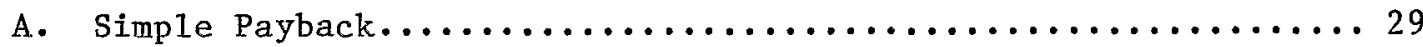

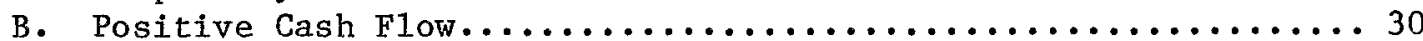

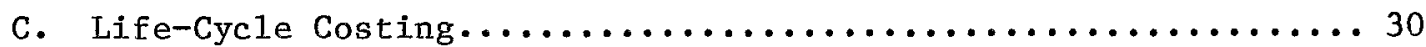

D. Selection of Target Cost/Savings Ratio................ 35

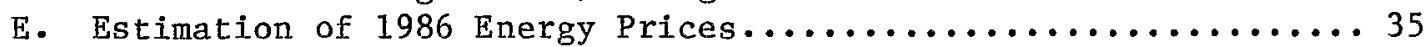

VI: Technology Issues.................................. 38

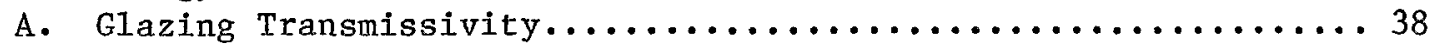

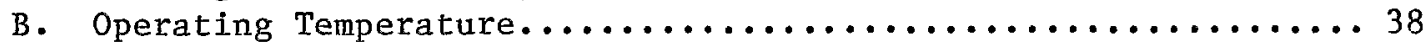

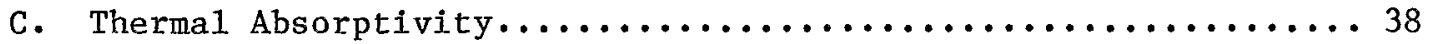

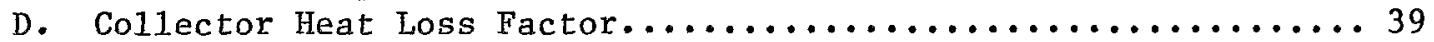

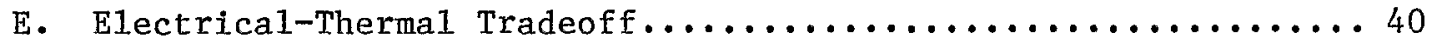

F. Lifetime Match/Mismatch........................ 40

G. Collector Area Match/Mismatch..................... 40

H. Market Area Match/Mismatch...................... 41

I. Limited Program Resources....................... 41 
VII. Incremental System Costs.....................42

A. Thermal Collector (Medium Temperature, Current

Technology) ............................... 43

B. Thermal Collector (Medium Temperature, Future

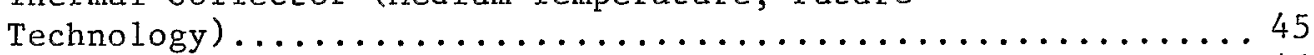

C. Thermal BOS (Medium Temperature, Current Technology......... 46

D. Thermal BOS (Medium Temperature, Future Technology.......... 49

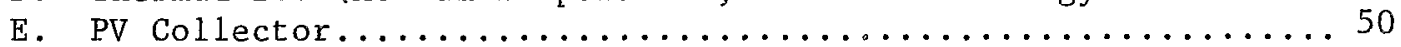

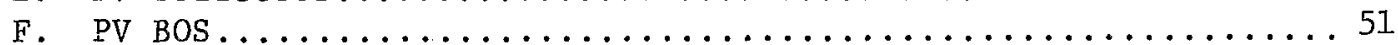

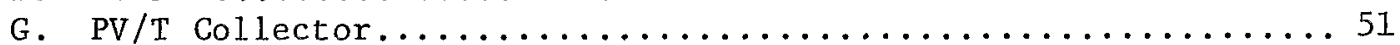

H. Summary: Medium Temperature Applications.............. 54

I. Incremental System Costs: Medium Temperature Applications.... 54

J. Low Temperature Applications: Unglazed Swimming

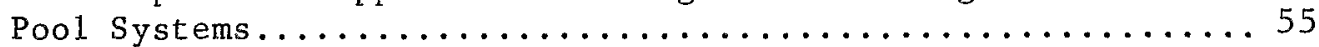

VIII. Incremental Energy Values...................... 57

A. Annual Energy Production-Hot Water Systems............. 59

B. Annual Energy Production-Space Heating/DHW.............. 61

C. Annual Energy Production-Swimming Pool Systems............ 62

D. Equivalent Electrical Energy Gain.................. 63

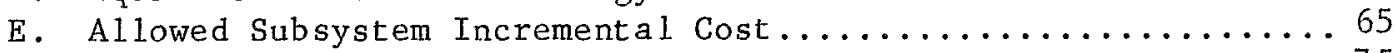

F. Comparison of $\mathrm{PV} / \mathrm{T}$ to Side-by-Side $\mathrm{PV}+\mathrm{T} \ldots \ldots \ldots \ldots \ldots \ldots \ldots \ldots$

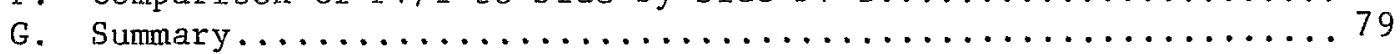

IX. Heat Pump Applications for Photovoltaics............... 80

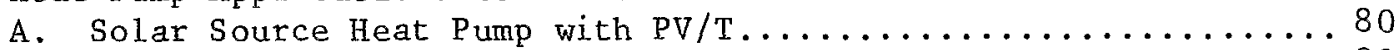

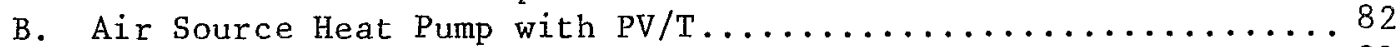

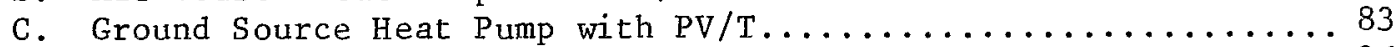

D. PV with Ground Coupling...................... 86

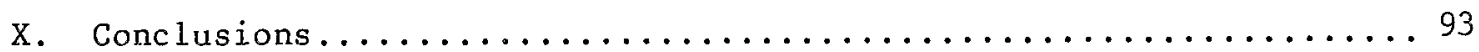

References.................................... 94 
1. Solar Collector Manufacturing Activity, 1974-1980............ 7

2. Ratios of Incremental Solar System Cost to First-Year Fuel

Savings Consistent with Zero Relative Cash Flow for the

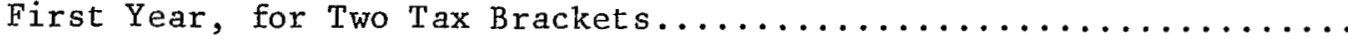

3. Present Value of Interest Tax Deductions and of Maintenance and Miscellaneous Expenses for Various Periods of Analysis........

4. First Year Maintenance Cost (as a Fraction of System First

Cost) for Which Effects of Interest Tax Deduction Cancel

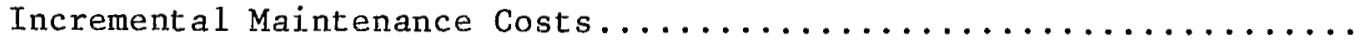

5. Values of the Present Value Function for Various Fuel Escalation

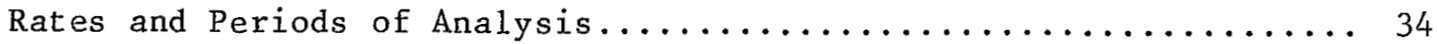

6. Calculation of Allowed System Incremental Costs............. 36

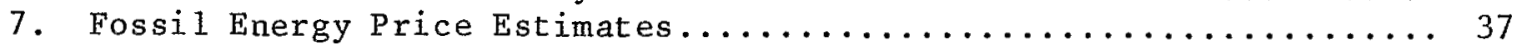

8. Market Ratios................................. 44

9. Materials Costs for Future Technology Thermal Collector......... 46

10. Overall Thermal Balance-of-System Costs, Medium Temperature, Current Technology............................ 47

11. Thermal Balance-of-System Component Costs for Domestic Hot Water System, Current Technology....................... 48

12. Thermal Balance-of-System Component Costs for Space Heating/DHW

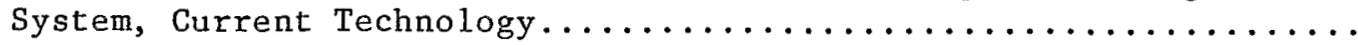

13. Thermal Balance-of-System Component Costs for Domestic Hot Water

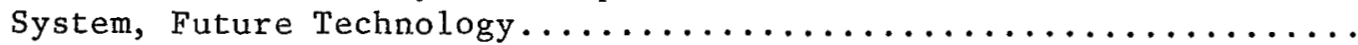

14. Thermal Balance-of-System Component Costs for Space Heating/DHW

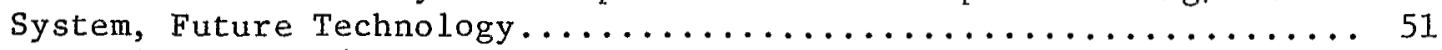

15. $\mathrm{PV}$ Savings in $\mathrm{PV} / \mathrm{T}$ Collector as Against $\mathrm{PV}$ only............. 54

16. Sumnary of Subsystem Costs, Medium-Temperature Applications....... 55

17. Incrementa1 System Costs, Medium-Temperature Applications......... 56

18. Incremental System Costs, Low-Temperature Applications......... 56

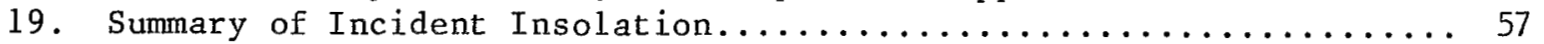

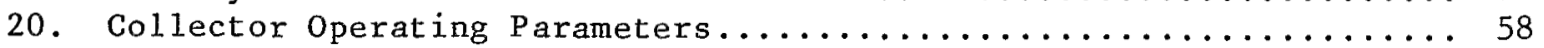

21. Summary of Energy Produced, Hot Water Application............ 59

22. Comparison of Solar Fractions Obtained by Method of Section III

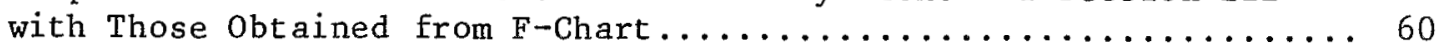

23. Summary of Energy Produced, Space Heating/DHW.............. 61

24. Summary of Energy Produced, Swimming Pool Heating............. 62

25. Equivalent Electrical Energy Gain from PV/T Against PV-Only

(Thermal Add-On) and Against Thermal-Only (PV Add-On).......... 64

26. Allowed Incremental system Costs for PV/T Against PV-Only

(Thermal Add-On) and Against Thermal-Only (PV Add-on)...........

27. Values of Energy Cost Ratio Parameter $X$ for Which the Allowed Incremental System Cost Exceeds the Calculated Incremental

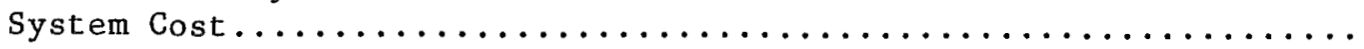

28. Example of PV Ground-Coupled Heat Pump System, New York, Electric

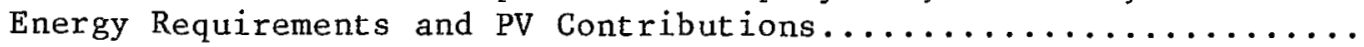

29. Estimation of Parallel Solar Assisted Heat Pump System

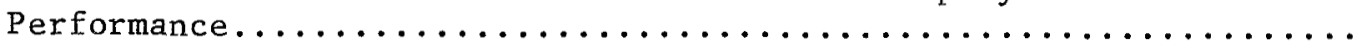


1. Primary Energy Displacement Possible Via PV/T Swimming Pool

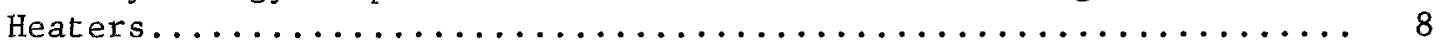

2. Primary Energy Displacement Possible Via PV/T Medium Temperature

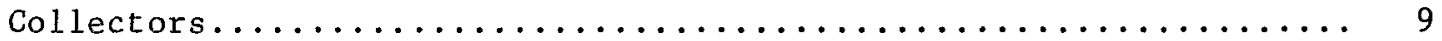

3. Comparison of Thermal Performance Comparison, PV/T With That of

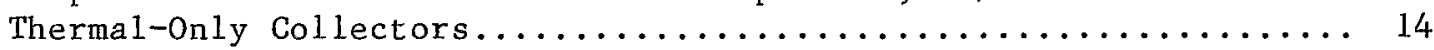

4. Typical Graph of Equivalent Electrical Energy Gain, PV/T Relative to PV-Only and Thermal-Only, Versus X, the Ratio of the Thermal Energy Price to the Electrical Energy Price (LA Hot Water)....... 26

5. Hot Water Only System Diagram (Current Technology)........... 47

6. Space Heating/DHW System Diagram (Current Technology).......... 48

7. Hot Water Only System Diagram (Advanced Technology)........... 52

8. Space Heating/DHW System Diagram (Advanced Technolgy).......... 53

9. Equivalent Electrical Energy Gain from PV/T, Domestic Hot Water,

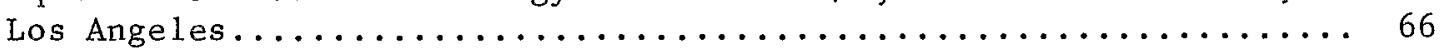

10 Equivalent Electrical Energy Gain from $\mathrm{PV} / \mathrm{T}$, Domestic Hot Water,

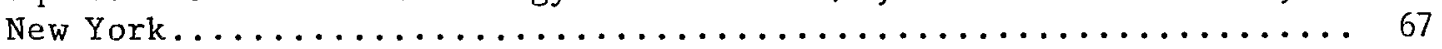

11. Equivalent Electrical Energy Gain from PV/T, Domestic Hot Water,

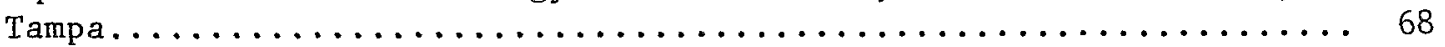

12. Equivalent Electrical Energy Gain from $P V / T$, Space Heating/DHW,

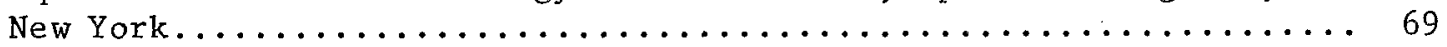

13. Equivalent Electrical Energy Gain from $P V / T$, Swimming Pool

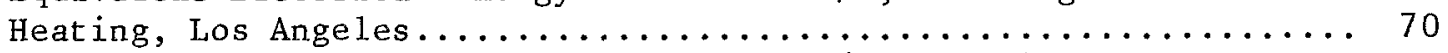

14. Equivalent Electrical Energy Gain from $P V / T$, Swinming Pool

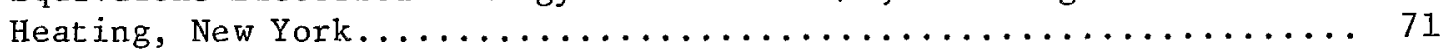

15. Equivalent Electrical Energy Gain from PV/T, Swimming Pool

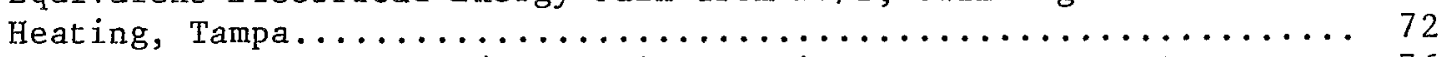

16. Energy Value Ratios, $\mathrm{PV} / \mathrm{T}$ vs. Side-by-Side $\mathrm{PV}+\mathrm{T}$, Los Angeles...... 76

17. Energy Value Ratios, $P V / T$ vs. Side-by-Side $P V+T$, New York........ 77

18. Energy Value Ratios, $P V / T$ vs. Side-by-Side $P V+T$, Tampa......... 78

19. Series Solar Assisted Heat Pump Configuration, with PV/T

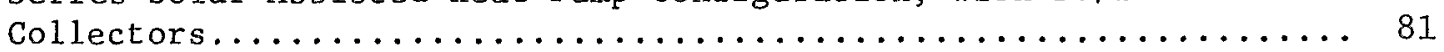

20. Parallel Solar Assisted Heat Pump Configuration, with $\mathrm{PV} / \mathrm{T}$

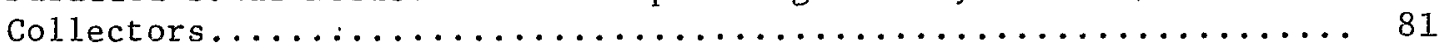

21. Contours of the Conventional Gas or Oil Furnace Efficiency Required to Save More Primary Energy Than the Best Alternative

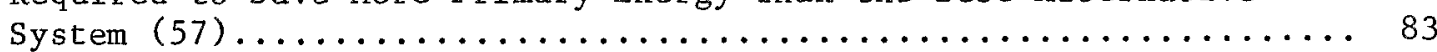

22. Ground-Coupled Solar Heat Pump Options................. 84

23. PV-Driven Ground-Coupled Heat Pump, Water-to-Air Configuration..... 88

24. PV-Driven Ground-Coupled Heat Pump, Water-to-Water Configuration... 89 
$\mathrm{A}_{\mathrm{C}}$

$\mathrm{C}$

$\mathrm{C}_{1}$

$\mathrm{C}_{2}$

d

e

$E_{C}$

$\mathrm{E}_{\mathrm{e}}$

E equiv

$\mathrm{E}_{\mathrm{t}}$

F

$\mathrm{F}^{1}$

$\mathrm{F}_{\mathrm{R}}$

$\mathrm{h}_{\mathrm{s}}$

$\mathrm{H}_{\mathrm{T}}$

$\mathrm{H}_{\max }$

$\mathrm{H}_{\mathrm{min}}$

I

$J_{c}$

m

$\mathrm{N}$

$Q_{e}$

$\mathrm{Qu}_{\mathrm{u}}$

R

S

$\mathrm{t}$

T

$\mathrm{U}_{\mathrm{L}}$

$\mathrm{X}$

$\alpha$

$\beta_{r}$
Collector area

System cost

Incremental Cost of $\mathrm{PV} / \mathrm{T}$ system over PV only

Incremental cost of $P V / T$ system over thermal only

Discount rate

Energy cost escalation rate

Collected thermal energy

Gain in electrical energy output from PV/T compared to PV only

Equivalent electrical energy gain from $\mathrm{PV} / \mathrm{T}$

Gain in thermal energy output from $\mathrm{PV} / \mathrm{T}$ compared to thermal only

First year fuel cost

Collector efficiency factor

Collector heat removal factor

Number of hours in month with sun

Insolation incident on collector surface

Maximum insolation rate on collector surface

Minimum insolation rate at which thermal energy can be collected

Total monthly insolation on collector surface

Collected electrical energy

First-year maintenance cost as fraction of system cost

Number of years in analysis

Useful electrical energy collection rate

Useful thermal energy collection rate

Ratio of $\mathrm{PV} / \mathrm{T}$ system cost to $\mathrm{PV}+\mathrm{T}$ system cost

Rate of sunlight striking the absorber

Marginal income tax rate

Temperature

Collector heat loss factor

Ratio of thermal energy price to electrical energy price

Absorber plate thermal absorptivity

Temperature coefficient of $\mathrm{PV}$ efficiency

\begin{tabular}{c} 
Units \\
\hline $\mathrm{m}^{2}$ \\
$\$$ \\
$\$ / \mathrm{m}^{2}$ \\
$\$ / \mathrm{m}^{2}$ \\
- \\
- \\
$\mathrm{kJ}$ \\
$\mathrm{GJ} / \mathrm{m}^{2}$ \\
$\mathrm{GJ} / \mathrm{m}^{2}$ \\
$\mathrm{GJ} / \mathrm{m}^{2}$ \\
$\$$ \\
- \\
- \\
$\mathrm{KJ} / \mathrm{m}^{2}-\mathrm{hr}^{\circ}{ }^{\circ} \mathrm{C}$ \\
- \\
$\mathrm{KJ} / \mathrm{m}^{2}-\mathrm{hr}$ \\
$\mathrm{KJ} / \mathrm{m}^{2}-\mathrm{hr}$ \\
$\mathrm{KJ} / \mathrm{m}^{2}-\mathrm{hr}$ \\
$\mathrm{KJ} / \mathrm{m}^{2}-\mathrm{hr}$ \\
$\mathrm{KJ} / \mathrm{m}^{2}$ \\
$\mathrm{KJ}$ \\
- \\
$\mathrm{KJ} / \mathrm{hr}$ \\
- \\
\\
-
\end{tabular}

\$

$\$ / m^{2}$

$\$ / \mathrm{m}^{2}$

$-$

GJ $/ \mathrm{m}^{2}$

$\mathrm{GJ} / \mathrm{m}^{2}$

$\mathrm{J} / \mathrm{m}^{2}$

$\$$

$-$

$\mathrm{KJ} / \mathrm{m}^{2}-\mathrm{hr}$

$\mathrm{KJ} / \mathrm{m}^{2}-\mathrm{hr}$

$\mathrm{KJ} / \mathrm{m}^{2}-\mathrm{hr}$

$\mathrm{KJ} / \mathrm{m}^{2}$

$\mathrm{KJ}$ 


\section{NOMENCLATURE}

\section{$\underline{\text { Symbo1 }}$}

$\varepsilon$

$n$

$n_{a}$

$n_{t}$

$\eta_{r}$

$\tau$

$\sim$

$\varnothing$

\section{Subscript}

a

c

e

f, $i$

$r$

s

$t$

Abbreviation

\section{APF}

BNL

BOS

CRF

COP

$\mathrm{DHW}$

DOE

HVAC

JPL

PVENER

PVF

PV I

PVMISC

PVSYS

$\mathrm{PV} / \mathrm{T}$

$\mathrm{PV}+\mathrm{T}$

TPV

\section{Definition}

Units

Fractional distance of collector

inlet temperature from ambient to stagnation

PV array efficiency

PV array efficiency at ambient temperature

Collector thermal efficiency

PV array efficiency at $28^{\circ} \mathrm{C}$ reference temperature

Glazing transmissivity

Over a symbol, indicates reference to PV/T

Empty set

\section{Definition}

Ambient

Conventiona1

Electrical

Fluid inlet

Reference

Solar

Thermal

\section{Definition}

Annual performance factor

Brookhaven National Laboratory

Balance of system

Capital recovery factor

Coefficient of performance

Domestic hot water

United States Department of Energy

Heating, ventilating and air conditioning

Jet Propulsion Laboratory

Present value of energy costs

Present value function

Present value of interest

Present value of miscellaneous and maintenance costs

Present value of system cost

Combined photovoltaic/thermal. collector

Side-by-side photovoltaic and thermal collectors

Total present value 
FOREWORD

A major objective of this study was to obtain results which may be reflected upon intensively, with an understanding of the factors which caused the results to turn out as they did. In particular, Sections IV, V, and VI attempt to develop this intuition - with which, of course, the reader may disagree. Sections I and II serve as introductory material, Section III develops the calculation procedure, Sections VII and VIII develop the results, and Section IX takes a specific look at heat pump applicatons.

A critical premise of this report is that $P V / T$ systems must be compared not only with PV-only systems to which a thermal overlay may be conceptually added, but also with thermal-only systems to which the addition of PV is contemplated. The reasons for this can be illustrated by a reductio-ad-absurdam example. Suppose a PV-only system delivered $\$ 1$ worth of energy and cost $\$ 1,000,000$. Suppose the PV/T system delivered $\$ 1,000,000$ worth of energy and cost $\$ 1,000,001$. Certain1y PV/T would look attractive relative to the PV only. But suppose further that a thermal only system delivered $\$ 999,999$ worth of energy and cost $\$ 1$. Would anyone buy the PV/T system now? of course, these are ridiculous numbers but they illustrate the point that both comparisons must be made. Furthermore, PV/T must be compared with side-by-side photovoltaic and thermal collectors as an option. 


\section{INTRODUCTION}

\section{A. Study Definition}

The Solar Technology Group at Brookhaven National Laboratory (BNL) was requested by the Jet Propulsion Laboratory (JPL) Photovoltaic Lead Center to undertake, during the period October 1980 to September 1981, a study to determine the potential economic viability of combined photovoltaic/thermal (PV/T) solar energy systems utilizing flat-plate collectors. The study was carried out during the first half of this period, and the results were presented to JPL in April 1981. This report describes these results and the analysis which led to them.

\section{B. Scope}

The objective of this study was laid down at the outset by its sponsor. This was to answer the question, "Can the collection of thermal energy in a PV/T system subsidize photovoltaics?" That is, we were asked to determine whether an added thermal collection subsystem could be more marginally costeffective than the PV-only system to which it is added, so that it would enhance the economic attractiveness of the combined system.

The study was limited to flat-plate collectors. In a flat-plate PV array, passive cooling is generally considered to be adequate; therefore, the decision whether to collect thermal energy is a design option. Concentrating PV systems (above a very low concentration ratio) require active cooling of the array and are therefore inherently PV/T, the only decision being whether to use the heat or to dump it.

Finally, we were directed not to use limited roof area as a reason for choosing the PV/T option. If $\mathrm{PV} / \mathrm{T}$ could be shown to be desirable from other considerations, then the ability of a combined $\mathrm{PV} / \mathrm{T}$ system to collect a given amount of electrical and thermal energy using a smaller array than a side-byside photovoltaic-plus-thermal system could be brought in as the clinching argument. But array area considerations could not be used as an essential pillar in the argument. Under these ground rules, in which we fully concurred, the study proceeded. 


\section{Background}

The idea of utilizing a single solar collector to satisfy both the thermal and electrical energy needs of a building is intuitively attractive, whether approached from the standpoint of a photovoltaics engineer who realizes that a considerable amount of thermal energy is available which could be obtained in addition to the electrical energy produced by the photovoltaic module, or from the standpoint of a thermal systems engineer who realizes that a portion of the thermal energy could be upgraded to higher-quality electrical energy by the addition of photovoltaics into thermal collector design.

An extensive program of $\mathrm{PV} / \mathrm{T}$ collector development and system performance modeling has been carried out under the auspices of the United States Department of Energy for several years. Work performed to date on $\mathrm{PV} / \mathrm{T}$ collectors and systems may be conveniently divided into the areas of (1) collector theory, (2) collector design, and (3) PV/T system studies.

PV/T Collector Theory. The basic work in the area of $\mathrm{PV} / \mathrm{T}$ collector theory was by Florscheutz (1), who extended the standard Hottel-Whillier model for thermal analysis of flat-plate collectors to include both the thermal and electrical outputs of a PV/T collector. The approach was to obtain modified forms of the usual collector thermal efficiency parameters which, together with the PV electrical efficiency and its temperature dependence, provide a predictive framework for use in PV/T system studies. This work was extended by Raghuraman (2-4) to take into account specific details in air- and liquid-based collector construction which caused the Florscheutz model to overestimate $\mathrm{PV} / \mathrm{T}$ thermal performance by as much as $15 \%$. Predictions from these models were found to agree well with experiments (ㅁ).

PV/T Collector Design. In the area of collector design, approaches have ranged from the simple mounting of PV cells onto the absorber plate of an existing thermal collector to sophisticated approaches intended to overcome thermal and/or electrical efficiency losses associated with the simple approach.

The simple approach has produced degradations in thermal efficiency well beyond what would be expected from the uptake of electrical energy by the 
cells (6). Primarily, these efficiency degradations stem from such things as relatively poor heat transfer through the cells to the absorber plate (2), reflection of long-wavelength radiation by the metallized back surface of the cell ( 7 ), and reduced selectivity of an absorber surface composed of photovoltaic cells relative to that obtainable in a good thermal-only selective absorber ( $(8)$. Advanced-design collectors have been proposed or developed including such design features as absorption of heat at more than one surface in air-heating ( $(9)$ and liquid-heating (10) collectors, provision of means to enhance heat transfer from a single surface (11), replacement of the metallized back surface by a grid to allow passage of long-wavelength radiation to an absorbing surface behind the cells (7), blackening of the metallized surface (11), and promotion of selectivity through the use of appropriately configured thin-film cells incorporating metal-semiconductor junctions with anti-reflective coatings ( $\underline{8})$. The results of this work suggest that considerable collector development will be required before a PV/T collector can be made with performance parameters close to those which obtainable in separate $P V$ and thermal units. The cost of the advanced designs has yet to be seriously addressed.

PV/T System Studies. Considerable work has been done on the analysis of $\mathrm{PV} / \mathrm{T}$ systems. Perhaps the largest number of papers has been published by the group at the Lincoln Laboratory of the Massachusetts Institute of Technology. In an early paper (12) it was concluded that a system employing a PV/T collector feeding electrical and thermal energy to a heat pump would in general be considerably more efficient than a stand-alone therma1-only solar system. Another paper (13) indicated that, given a choice among PV-only, thermal-only, and $\mathrm{PV} / \mathrm{T}$ collectors, optimum system performance included some $\mathrm{PV} / \mathrm{T}$ in three out of four locations. Optimum system economics required $\mathrm{PV} / \mathrm{T}$ in only one location, Boston. The study assumed an electrical efficiency for the $\mathrm{PV} / \mathrm{T}$ collector of $\sim 10 \%$ at $30^{\circ} \mathrm{C}$ collector temperature, and a therma1 efficiency of $\sim 62 \%$ at ambient collector inlet temperature. Another paper (14) held that "in general, for any system, annual system cost decreases as hybrid collectors are replaced by photovoltaic modules because of the anticipated lower cost of photovoltaic modules and the greater value of electrical energy compared to thermal energy." Two years later, the conclusion was drawn (15) 
that "where the heating load is dominant, a PV/T collector is more economical than an exclusively PV collector." The optimal system in this analysis was a parallel PV/T heat pump system, that is, a system in which the solar thermal energy is used to heat the load directly (not via the heat pump) and the electricity is used (among other things) to operate the heat pump, which uses ambient air as its source.

PV/T system studies carried out by the solar energy group at the University of Maryland (16) have concentrated on system performance sensitivity to variations in collector and storage parameters.

A study by Westinghouse Electric Corporation (17) concluded that PV/T systems would be viable with high-volume production. Installed array costs of $\$ 45 / \mathrm{m}^{2}$ for the $\mathrm{PV}$ array and $\$ 65 / \mathrm{m}^{2}$ for the combined $\mathrm{PV} / \mathrm{T}$ array were assumed (1975 dollars) for the high-volume scenario (17a). Battery storage was deemed essential for high market penetration.

A companion study $(\underline{18})$ by the General Electric Corporation arrived at a negative conclusion concerning $\mathrm{PV} / \mathrm{T}$, because "transmission losses and degraded PV output due to higher operating temperatures in the collector are apparently too severe to make this approach attractive, and it thus received a low ranking." (18a).

Finally, an in-house study performed at Sandia Laboratories (19) concluded that side-by-side photovoltaic and thermal collector arrays are more cost effective than combined $\mathrm{PV} / \mathrm{T}$ collectors. Major points cited in this study were that the side-by-side system did not in fact require much more collector area $(\sim 25 \%)$ than an equivalent PV/T system, that the combined PV/T collector did not provide significant savings in materials cost, that the combined PV/T collector needs some kind of active heat dump to prevent overheating of the cells under stagnation, that improving the selectivity of the cell surfaces results in decreased electrical output at the same time thermal output is increased, that the allowed incremental cost of adding PV to a thermal collector turns out to be lower than projected cell costs, and that in the side-by-side system the PV and thermal subsystems can be sized independently.

To summarize, considerable theoretical and experimental work has been done on PV/T collectors and systems. Two major schools of thought have 
developed. One denigrates the potential of $\mathrm{PV} / \mathrm{T}$ because of technical problems and poor benefit-to-cost ratios, while the other maintains that, at least in cold climates, the benefits of $P V / T$ will exceed the cost once the inevitable engineering problems associated with any new technology are solved.

D. Approach

The approach taken in this study was designed to conform to two major guidelines:

1. It should be relatively simple and transparent in its methodology, so that the path from assumptions to conclusions could be readily followed. A degree of complexity in the mathematical development could not be avoided, however.

2. It should consider $\mathrm{PV} / \mathrm{T}$ relative to each of the other three solar options: PV-only, thermal-only, and side-by-side PV and therma1 (PV+T). That is, $\mathrm{PV} / \mathrm{T}$ must be justified separately against each, and only if it satisfies all three criteria can it be said to be justified overall.

The methodology comprised the following steps:

1. Assess the thermal flat-plate collector market. This step provides a framework for estimating the possible energy contribution from $P V / T$ systems, and it indicates the most promising regions of the United States to choose for the study.

2. Develop an economic criterion of merit. Solar energy economics have been studied in many ways with many different assumptions, leading to widely varying conclusions. The economic criterion derived in this study is based on considerations of payback, cash flow, and life-cycle costing judged most applicable to the residential user. The criterion developed is found to be compatible with the DOE photovoltaic residential 1986 cost goals.

3. Address the technology issues inherent in $\mathrm{PV} / \mathrm{T}$. These issues comprise considerations which may lead to different (generally poorer) basic parameters (eq. absorptivity, emissivity, heat transfer) in combined $\mathrm{PV} / \mathrm{T}$ collectors than in thermal-only or PV-only ones. How to account for these potential differences is resolved at this stage.

4. Determine incremental system costs. The cost of adding thermal collection to a basic PV system and the cost of adding PV to a basic thermal 
system are (separately) determined. The ratio between the cost of a side-by-side $\mathrm{PV}+\mathrm{T}$ system and that of a combined PV/T system is determined.

5. Determine incremental energy values. Here the differences and ratios in collected energy between the same system pairs as in step 4 are determined.

6. Apply the economic criterion. Here it is determined whether the benefit calculated in step 5 is sufficient to justify the cost calculated in Step 4. The ratio $X$ between the value of thermal energy and that of electrical energy is allowed to vary as a parameter in the study. The question is asked, "Are there any values of $X$ for which $P V / T$ simultaneously passes the three tests (against PV, against thermal, against $P V+T$ ), and, if so, do these values fall in the range which is likely to be seen in practice?"

The remainder of this report follows this plan for some generic PV/T applications. At the end, specific applications involving heat pumps are taken up and related to the conclusions obtained in the foregoing sections. 


\section{THE FLAT-PLATE SOLAR COLLECTOR MARKET}

In order to assess the potential of flat-plate PV/T systems for displacing primary energy savings, a three-step process was undertaken. (1) Information on past sales of thermal-only flat-plate collectors was obtained. Future projections by recognized authors were collected. (3) A likely scenario of solar installations was generated. This information was obtained separately for two generic types of collectors, (a) unglazed, low-temperature collectors used largely for swimming pool heating, and (b) glazed, medium-temperature collectors used mostly for space and water heating. In the swimming pool case, the size and growth rate of the total residential pool market was also obtained to serve as a gross upper bound.

\section{A. Low-Temperature Collectors}

Recorded manufacturing activity for unglazed collectors used to heat swimming pools $(20)$ is shown in Table 1 . This represents a $28 \%$ annual growth rate from 1975 to 1980. The largest market areas for solar swimming pool heaters are California, Florida, and the northeastern United States. For example, for the six-month period January-June 1978, 57\% of solar pool heaters were sold in California, $21 \%$ in Florida, and $13 \%$ in New York and New Jersey (21). In the six years from 1974 to 1980 , the total number of pools grew at a

Table 1

Solar Collector Manufacturing Activity, 1974-1980, Millions of Square Feet

\begin{tabular}{lcc}
\hline & \multicolumn{2}{c}{ Collector Type } \\
\cline { 2 - 3 } Year & $\begin{array}{c}\text { Low Temperature } \\
\text { (Ung1azed) }\end{array}$ & $\begin{array}{c}\text { Medium-Temperature } \\
\text { (Glazed) }\end{array}$ \\
\hline 1974 & 1.2 & 0.2 \\
1975 & 3.0 & 0.6 \\
1976 & 3.8 & 1.9 \\
1977 & 4.8 & 5.4 \\
1978 & 5.8 & 4.8 \\
1979 & 8.3 & 5.9 \\
1980 (est.) & 11.4 & 7.0 \\
\hline
\end{tabular}




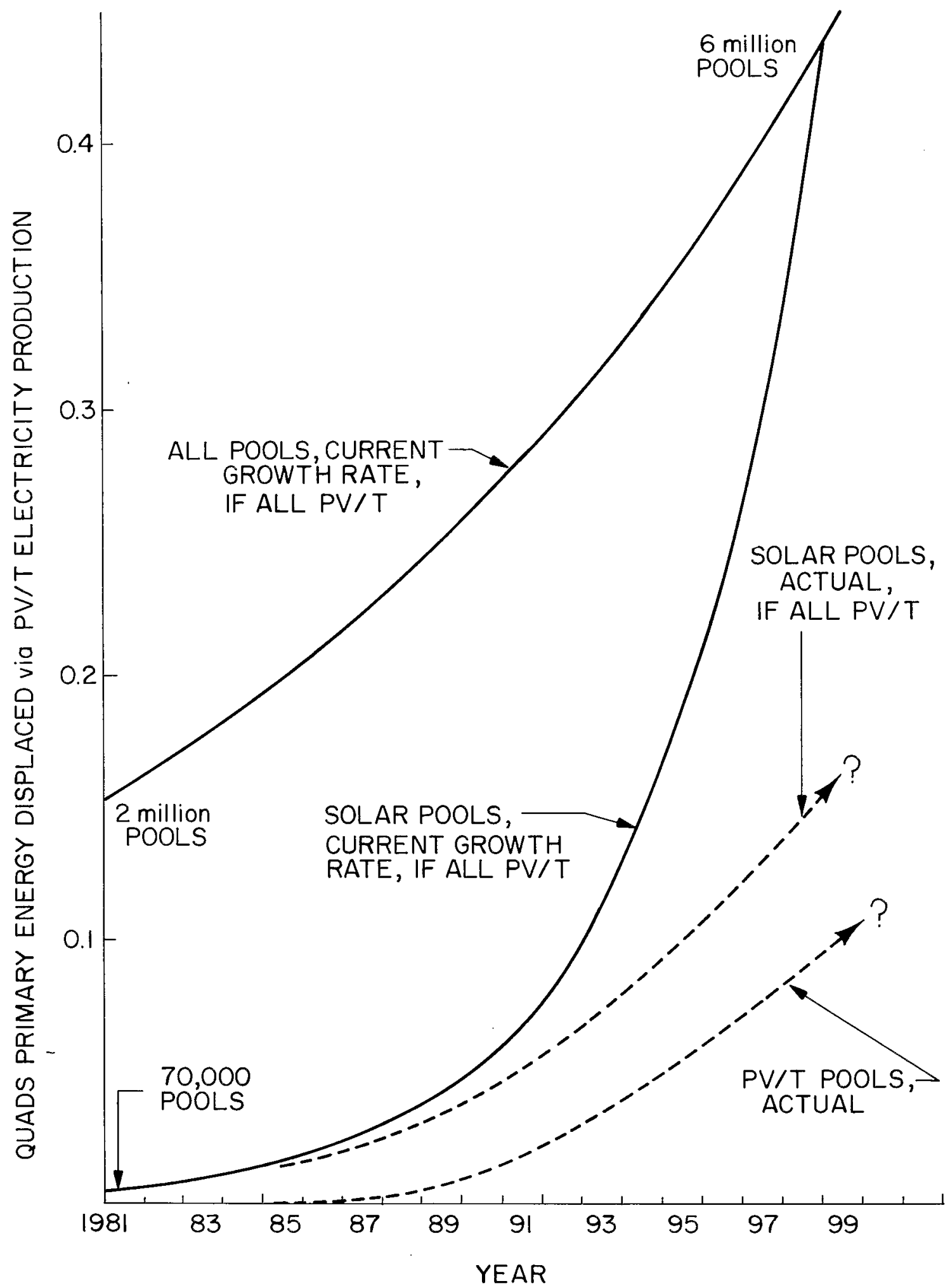

Figure 1. Primary energy displacement possible via $P V / T$ swimming pool heaters. 


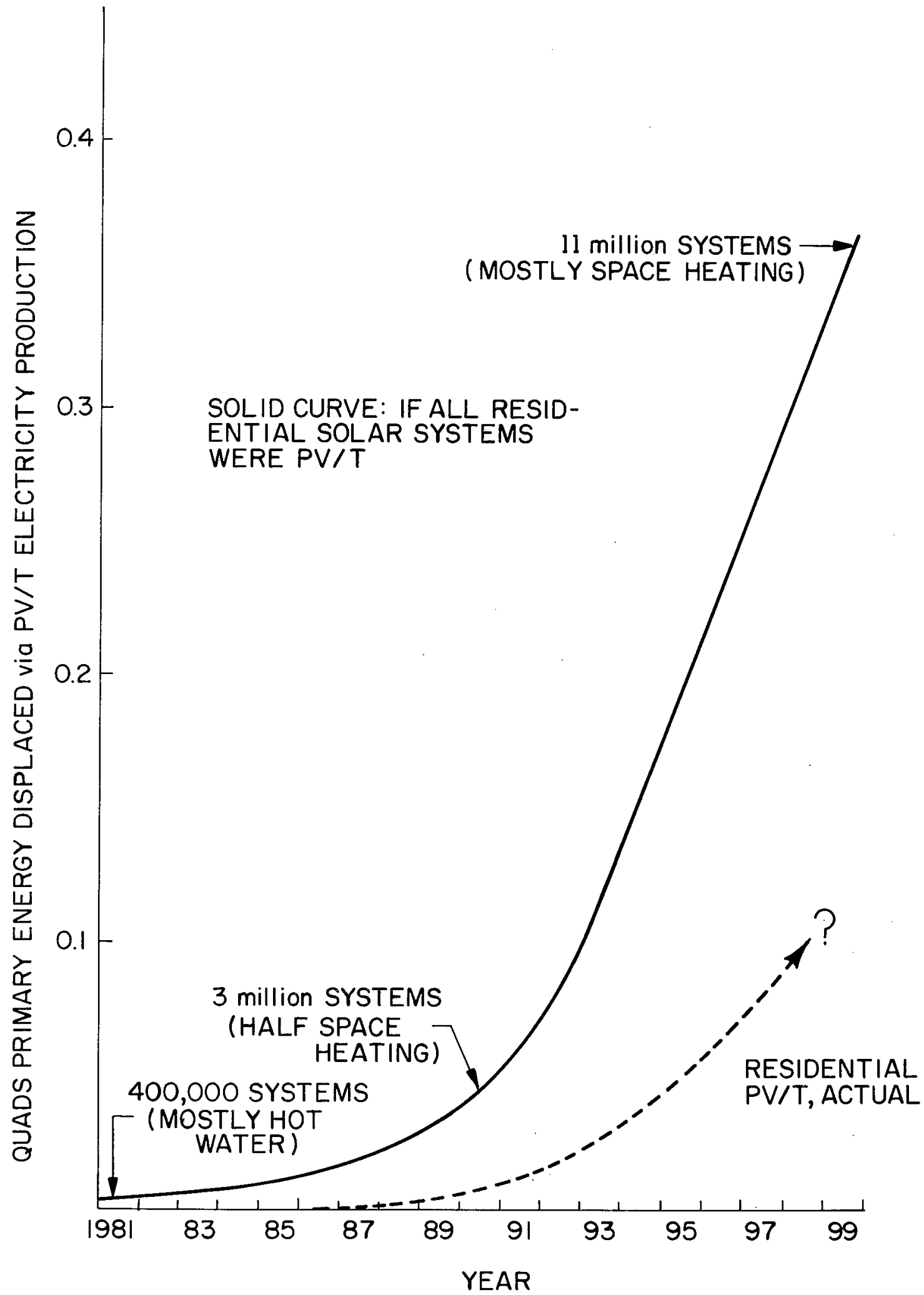

Figure 2. Primary energy displacement possible via $\mathrm{PV} / \mathrm{T}$ medium-temperature collectors. 
$6 \%$ annual rate (22). Figure 1 shows the primary energy displaced via the electricity produced by PV/T swimming pool heaters under two conditions.

1. Assume that all swimming pools have PV/T solar systems. This is clearly an unrealistic condition intended only to establish a gross upper limit.

2. Assume that all solar-heated swimming pools are $P V / T$ and that their numbers increase at the current rate. This again is unrealistic (a) because there are no $P V / T$ pools at present, and (b) because the $28 \%$ growth rate of thermal-only solar pools cannot be sustained indefinitely in the face of a $6 \%$ growth rate for all pools. The crossover of the two curves around the turn of the century reflects this.

In order to obtain a more realistic estimate, two further steps were taken. First an attempt was made to estimate the actual level of solar pool installations, but assuming all of them to be $\mathrm{PV} / \mathrm{T}$; a second estimate recognized that only a portion of them will be PV/T. Although these curves (dotted lines in Figure 1) are little more than guesses, they do give a rough indication the energy displacement obtainable from PV/T swimming pool heaters. These estimates are predicated on PV/T being a good idea. If it is not, the curves will likely remain near the zero level indefinitely. The conclusion is that the potential primary energy displacement due to the electricity produced in PV/T swimming pool heaters is 0.1 quad/yr. This includes a factor of 3 to account for power plant and transmission losses which would be saved as primary energy in addition to the electric energy produced. It does not include the thermal energy produced by the collectors.

B. Medium-Temperature Collectors

The manufacturing activity for medium-temperature collectors shown in Table 1 has involved mostly hot water heaters. A forecast of future installations was generated by using a projection of installed collector area up to 1992 (23) and extrapolating linearly beyond 1992. On the basis of this projection, which includes residential hot water and space heating/hot water systems, the primary energy displacement from the electrical energy produced by $P V / T$ medium-temperature flat-plate collectors was estimated, as shown in Figure 2. For the solid curve it is assumed that all medium-temperature solar 
actual situation, assuming $P V / T$ is a good idea for these systems. As in the swimming pool case, a factor of 3 is included to account for power plant and transmission losses, and thermal energy production is not included. A potential primary energy savings of $\sim 0.1$ quad/yr. is found for the electrical. component of $\mathrm{PV} / \mathrm{T}$ at the end of the century.

Since the primary market areas for both low- and medium-temperature collectors have till now been California, Florida, and the Northeast, the localities chosen for study were Los Angeles, Tampa, and New York. The potential contributions of low- and medium-temperature $\mathrm{PV} / \mathrm{T}$ were judged to be about equal with regard to electrical energy, and therefore, both types of systems were included in the analysis. 
III. CALCULATION OF THERMAL AND ELECTRICAL OUTPUTS

\section{A. Calculation Tools}

The calculations of thermal and electrical output from flat-plate PV/T collectors made use of two distinct formalisms. The first is that of Florscheutz (1) who modified the well-known Hottel-Whillier equations for flat-plate therma1-only collectors to include both the thermal and electrical outputs of $\mathrm{PV} / \mathrm{T}$ collectors. These equations give output rates under specified operating conditions. The second formalism $(\underline{24}, \underline{25})$ uses a specific insolation probability distribution to obtain integrated values of the energy outputs over specified time periods (months in this report). These monthly values are then summed over the year in order to make system comparisons. Each system type is characterized in the analysis by characteristic thermal operating temperatures, which are used in the calculation of thermal and electrical outputs.

B. Summary of the Florscheutz Approach to $\mathrm{PV} / \mathrm{T}$

Because of the use made in this report of Florscheutz's work, its major aspects are first summarized. Essentially, in this work, the wel1-known Hottel-Whillier equations for flat-plate thermal-only collectors are modified to take into account the effects of adding PV cells to the absorber plate of a thermal collector. The modifications generally take the form of modified values of the parameters which characterize a flat plate collector. These modified values are indicated by a tilde. Thus, the overall heat loss coefficient $U_{\mathrm{L}}$ becomes $\tilde{U}_{\mathrm{L}}$. The collector efficiency factor $F^{\prime}$ and the heat removal factor $F_{R}$ become $\tilde{F}^{\prime}$ and $\tilde{F}_{R}$. Other quantities, such as the sunlight $S$ striking the absorber and the useful thermal energy collection rate $\mathrm{Q}_{\mathrm{u}}$ are modified to $\tilde{\mathrm{S}}$ and $\tilde{\mathrm{Q}}_{\mathrm{u}}$, respectively.

Although there are indications that the method of Florscheutz may overestimate the amount of thermal energy collected, it was considered that this discrepancy, due largely to relatively poor heat transfer through the cells and the cell-absorber plate interface, may not be inherent, and that $\mathrm{PV} / \mathrm{T}$ should not be disqualified on the basis of possibly correctable deficiencies. The results obtained, then, can be viewed as a limit which may be approached by $\mathrm{PV} / \mathrm{T}$ insofar as thermal energy production is concerned. 
C. Implications for the Thermal Efficiency Curve in $\mathrm{PV} / \mathrm{T}^{\prime}$

In addition to these variables defined by Florscheutz, it is convenient to define a modified absorptivity $\alpha$ such that

$$
\tilde{\alpha}=\alpha-\eta
$$

where $\alpha$ is the collector absorptivity and $\eta$ is the efficiency of the PV array. Since $\eta$ is a function of temperature, $\tilde{\alpha}$ is not a constant. The percentage variation of $\tilde{\alpha}$ over a reasonable range of collector temperatures is sma11. For a PV array whose efficiency varies by $0.5 \% /{ }^{\circ} \mathrm{C}$, the variation in $\alpha$ over a $50^{\circ} \mathrm{C}$ temperature range is $2.5 \%$.

In terms of $\alpha$, the collector efficiency curve for the collection of thermal energy can be expressed as

$$
\begin{aligned}
\eta_{t}=\frac{\tilde{Q}_{u}}{{ }_{C} H_{T}} & =\frac{{ }_{C} \tilde{F}_{R}\left[\tilde{S}-\tilde{U}_{L}\left(T_{f, i}-T_{a}\right)\right]}{A_{C} H_{T}} \\
& =\frac{A_{C} \tilde{F}_{R}\left[S\left(1-\frac{\eta_{a}}{\alpha}\right)-\left(U_{L}-\tau H_{T} n_{r} \beta_{r}\right)\left(T_{f, i}-T_{a}\right)\right]}{A_{C} H_{T}} \\
& =\tilde{F}_{R} T \tilde{\alpha}-\tilde{F}_{R} U_{L} \frac{\left(T_{f, i}-T_{A}\right)}{H_{T}}
\end{aligned}
$$

where $\mathrm{A}_{\mathrm{C}}$ is the collector area, $\mathrm{H}_{\mathrm{T}}$ is the insolation rate on the collector surface, $\mathrm{T}_{\mathrm{f}, i}$ and $\mathrm{T}_{\mathrm{a}}$ are the collector fluid inlet temperature and ambient temperature, respectively, $N_{a}$ and $N_{r}$ are the $P V$ array efficiencies at ambient and reference temperatures, respectively, $\beta_{r}$ is the temperature coefficient of cell efficiency, $T$ is the glazing transmissivity, and the other quantities are as defined above. In deriving the third line of $\mathrm{Eq}$. (2) the relation

$$
\mathrm{S}=\tau \alpha \mathrm{H}_{\mathrm{T}}
$$

has been used. The relation (2) is identical to the standard Hotte1-Whillier efficiency curve except for the substitution of $\tilde{F}_{R}$ and $\tilde{\alpha}$ for $F_{R}$ and $\alpha$.

Figure 3 shows a schematic comparison of the thermal performance of $P V / T$ with that of thermal-only collectors. The differences in the curves can arise from the following sources:

1. The electrical energy extracted by the PV array is mostly subtracted from the thermal energy produced. 


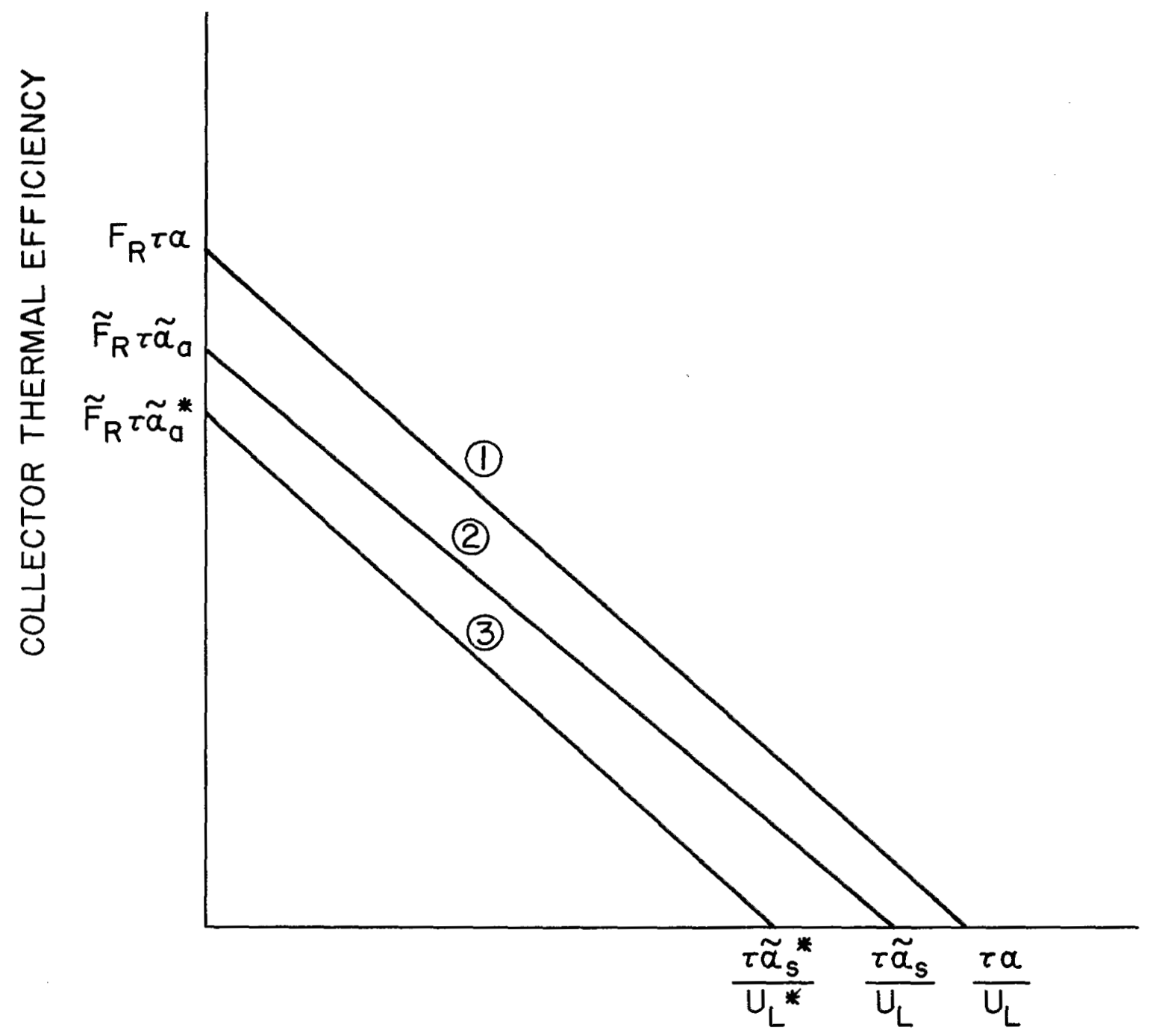

COLLECTOR INLET TEMPERATURE minUS AMBIENT TEMPERATURE INSOLATION RATE

Figure 3. Comparison of thermal performance of $\mathrm{PV} / \mathrm{T}$ with that of thermal-only collectors. Horizontal and vertical intercepts are shown. Curve 1 shows the thermal-only performance. Curve 2 shows the thermal performance of the PV/T collector assuming no difference in $\alpha$ or $\mathrm{U}_{\mathrm{L}}$ due to the presence of the cells. Curve 3 results if lower $\alpha$ and higher $U_{\mathrm{L}}$ ( $\alpha^{*}$ and $\mathrm{U}_{\mathrm{L}}{ }^{*}$ ) must be accepted in the $\mathrm{PV} / \mathrm{T}$ collector. Note: $\tilde{\alpha}_{a}$ and $\tilde{\alpha}_{s}$ are the values of $\tilde{\alpha}$ at ambient and stagnation temperatures, respectively, there being a small temperature dependence due to the variation of PV cell efficiency with temperature. 
2. A value of $\tilde{\mathrm{F}}_{\mathrm{R}}$ different from $\mathrm{F}_{\mathrm{R}}$.

3. A value of $a$ for the PV/T collector different from that for the thermal-only collector.

4. A value of $U_{L}$ for the $P V / T$ collector different from that for the thermal-only collector.

Difference 1 represents a gain of useful energy in a higher quality form (electrical) than what is given up (thermal) and so represents a net gain for $\mathrm{PV} / \mathrm{T}$. Differences 2,3 , and 4 may or may not be significant. In 2 , the value of $\tilde{F}_{R}$ would almost certainly be less than $F_{R}$ if there is a difference, since the cells could represent an additional thermal impedence, but it is hard to imagine that their presence could improve heat transfer. In 3 , the value of $\alpha$ for the $\mathrm{PV} / \mathrm{T}$ case may be significantly less than that for the therma1-only case because of possible difficulties in blackening the currentcarrying grid on the cell surfaces and because the absorptance of the active cell area may be less than that obtainable with black paint. In 4, the value of $U_{L}$ may be higher in the $P V / T$ than in the thermal-only case if the therma1-only collector has a selective coating; the potential for obtaining good selectivity in a practical $\mathrm{PV} / \mathrm{T}$ collector remains in doubt. The differences in 2, 3, and 4 represent net losses for $P V / T$ relative to thermal-only collectors which are uncompensated by any corresponding electrical energy gain. The sources and possible remedies for differences 2, 3, and 4 are discussed in section VI.

D. Total Monthly Collected Energy

An approach applied previously for combined solar heat pump systems (24, 25) to calculate the monthly collected solar thermal energy is applied here. The basis of this method is the assumption of a constant probability density for insolation intensity, given that the sun is above the horizon, from zero up to some maximum value--usually around $3410 \mathrm{~kJ} / \mathrm{m}^{2}-\mathrm{hr}\left(300 \mathrm{Btu} / \mathrm{ft}^{2}-\mathrm{hr}\right)$. That is, for any hour with sunshine, it is just as likely that the insolation rate has one value as any other within the prescribed range. In fact this distribution does not hold exactly. Many locations have a tendency for excess hours at low insolation values, together with a gradual falloff near the top of the range, so that for any reasonable cutoff there will be hours with insolation 
values above the top of the range. The sunlight received at low rates will be less effective than average, and indeed the thermal component may be complete1y uncollectable. On the other hand, sunlight at insolation rates above the cutoff will be more effective than average. The two effects thus tend to cancel out. Comparisons of collected insolation calculated by the above method with a standard thermal collector design tool, F-Chart, gave good agreement (see Section VIII). The advantage of this method is that it allows the Florscheutz equations to be integrated to give closed-form expressions for the monthly collected thermal and electrical PV/T output.

If $h_{S}$ is the number of hours with sun in the month, and $H_{\max }$ is the maximum insolation rate, then under the above assumptions the number of hours having an insolation rate between $\mathrm{H}_{\mathrm{T}}$ and $\mathrm{H}_{\mathrm{T}}+\mathrm{dH}_{\mathrm{T}}$ is $\left(\mathrm{h}_{\mathrm{S}} / \mathrm{H}_{\max }\right) \mathrm{dH}_{\mathrm{T}}$. The amount of solar thermal energy collected for these values of insolation rate is then

$$
\mathrm{dE}_{\mathrm{c}}=\frac{\mathrm{h}_{\mathrm{s}} \mathrm{dH}_{\mathrm{T}}}{\mathrm{H}_{\max }} \mathrm{Q}_{\mathrm{u}}
$$

where $Q_{u}$, the useful thermal energy collection rate, is a function of $H_{T}$ and the operating parameters of the collector. The total thermal energy collected is then

$$
E_{c}=\frac{h_{s}}{H_{\max }} \int_{0}^{\mathrm{H}^{\max }} \mathrm{Q}_{\mathrm{u}} \mathrm{dH}_{\mathrm{T}} .
$$

Similarly, the total electrical energy collected is

$$
J_{c}=\frac{{ }_{S}}{H_{\max }} \int_{0}^{\mathrm{H}} \mathrm{Q}^{\max } \mathrm{dH}^{\mathrm{T}}
$$

where $Q_{e}$ is the useful electrical output of the collector. In addition, the total insolation I received during the month at the collector aperture is

$$
I=\int_{0}^{\mathrm{H}} \mathrm{H}_{\mathrm{Tax}} \frac{\mathrm{h}_{\mathrm{s}}}{\mathrm{H}_{\max }} \mathrm{dH}_{\mathrm{T}}=\frac{\mathrm{h}_{\mathrm{S}} \mathrm{H}_{\max }}{2} \text {. }
$$

Equations (5), (6), and (7) are used in the following sections to obtain the total collected thermal and electrical energy values. 


\section{E. Collected Thermal Energy}

Equation (9) of Florscheutz (1) displays the calculated thermal output of the PV/T collector under specified operating conditions as

$$
\tilde{Q}_{u}=A_{c} \tilde{F}_{R}\left[\tilde{S}-\tilde{U}_{L}\left(T_{f, i}-T_{a}\right)\right]
$$

where $\tilde{S}=S\left(1-\eta_{a} / \alpha\right) ; \tilde{U}_{L}=U_{L}-\tau H_{T} n_{r} \beta_{r}$; and, following the discussion by Florscheutz on p. 364, $\tilde{\mathrm{F}}_{\mathrm{R}} \approx \mathrm{F}_{\mathrm{R}}$. S, the solar radiation per unit area absorbed at the absorber surface, is here taken to equal the incident radiation $\mathrm{H}_{\mathrm{T}}$ attenuated by the glazing transmissivity and absorber absorptivity, or $\mathrm{S}=\mathrm{H}_{\mathrm{T}} \tau \alpha$.

Use of the previously derived result

$$
\mathrm{dE}_{\mathrm{c}}=\left(\begin{array}{ll}
\frac{\mathrm{h}_{\mathrm{s}}}{\mathrm{H}_{\max }} & \mathrm{dH}_{\mathrm{T}}
\end{array}\right) \mathrm{Q}_{\mathrm{u}}
$$

and substitution of $\tilde{Q}_{u}$ for $Q_{u}$ as the appropriate value in a $P V / T$ collector gives

$$
\mathrm{dE}_{\mathrm{C}}=\left(\frac{\mathrm{h}_{\mathrm{S}}}{\mathrm{H}_{\max }} \mathrm{dH_{ \textrm {T } }}\right) \mathrm{A}_{\mathrm{C}} \mathrm{H}_{\mathrm{T}} \mathrm{F}_{\mathrm{R}}\left[\tau \alpha\left(1-\eta_{\alpha} / \alpha\right)-\frac{\mathrm{U}_{\mathrm{L}}\left(\mathrm{T}-\mathrm{T}_{\mathrm{a}}\right)}{\mathrm{H}_{\mathrm{T}}}+\tau \eta_{\mathrm{r}} \beta_{\mathrm{r}}\left(\mathrm{T}-\mathrm{T}_{\mathrm{a}}\right)\right]
$$

where the subscript $f, i$ has been dropped from the collector inlet temperature $\mathrm{T}$. The minimum utilizable insolation is that for which the quantity in brackets on the right side of $\mathrm{Eq}$. (8) is zero. If $\mathrm{H}_{\min }$ is the value of $\mathrm{H}_{\mathrm{T}}$ for which this holds, then

$$
H_{\min }=\frac{U_{L}(T-T a)}{\tau \alpha\left(1-\eta_{a} / \alpha+\tau \eta_{r} \beta_{r}\left(T-T_{a}\right)\right.}=\frac{U_{L}\left(T-T_{a}\right)}{\tau \tilde{\alpha}}
$$

where by definition $\tilde{\alpha} \equiv \alpha-\eta_{a}+\eta_{r} \beta_{r}\left(T-T_{a}\right)$. The quantity $\tilde{\alpha}$ is the residual thermal absorptivity after the PV energy is taken off.

The total collected thermal energy is then

$$
E_{c}=\int_{H_{\min }}^{H_{\max }} d E_{c}
$$




$$
\begin{aligned}
& =\frac{A_{c} h s}{H_{\max }} F_{R} \tau \int_{H_{\min }}^{H}\left[\alpha-\eta_{a}+\eta_{r} \beta_{r}\left(T-T_{a}\right)\right] H_{T} d H_{T}-\frac{A_{c} h_{s}}{H_{\max }} F_{R} U_{L}\left(T-T_{a}\right) \int_{H_{\text {min }}}^{H} d_{T}^{\text {max }} \\
& =\frac{A_{c} h_{S}}{H_{\max }} F_{R} \tau \tilde{\alpha}\left[\frac{H_{\max }^{2}}{2}-\frac{U_{L}^{2}\left(T-T_{a}\right)^{2}}{2 \tau^{2} \tilde{\alpha}^{2}}\right]-\frac{A_{c} h_{s}}{H_{\max }} F_{R} U_{L}\left(T-T_{a}\right)\left[H_{\max }-\frac{U_{L}\left(T-T_{a}\right)}{\tau \tilde{\alpha}}\right] \\
& =\frac{A_{C} h_{S} F_{R} \tau \tilde{\alpha} H_{\text {max }}}{2}-\frac{A_{c} h_{s} F_{R} U_{L}^{2}\left(T-T_{a}\right)^{2}}{2 H_{\max } \tau \tilde{\alpha}}-A_{c} h_{s} F_{R} U_{L}\left(T-T_{a}\right)+\frac{A_{c} h_{S} F_{R} U_{L}^{2}\left(T-T_{a}\right)^{2}}{H_{\max } \tau \tilde{\alpha}} \\
& =\frac{A_{c} h_{s} F_{R} \tau \tilde{\alpha H} H_{\max }}{2}-A_{c} h_{s} F_{R} U_{L}\left(T-T_{a}\right)+\frac{A_{c} h_{s} F_{R} U_{L}^{2}\left(T-T_{a}\right)^{2}}{2 H_{\max } \tau \tilde{\alpha}} .
\end{aligned}
$$

The total received insolation during the time period is, from Eq. (7)

$$
I=h_{s} H_{\max } / 2
$$

Then

$$
\begin{aligned}
E_{c} & =I A_{c} F_{R} \tau \tilde{\alpha}\left[1-\frac{2 U_{L}\left(T-T_{a}\right)}{\tau \tilde{\alpha} H_{\max }}+\frac{U_{L}^{2}\left(T-T_{a}\right)^{2}}{H_{\max ^{2}{ }^{2} \tilde{\alpha}^{2}}}\right] \\
& =I A_{c} F_{R} \tau \tilde{\alpha}\left[1-\frac{U_{L}\left(T-T_{a}\right)}{H_{\max } \tau \tilde{\alpha}}\right]^{2} \\
& =I A_{c} F_{R} \tau \tilde{\alpha}\left(1-\frac{T-T_{a}}{T_{m}-T_{a}}\right)^{2} \\
& =I A_{c} F_{R} \tau \tilde{\alpha}\left(\frac{T_{m}-T}{T_{m}-T_{a}}\right)^{2}
\end{aligned}
$$

where $T_{m}$ is the maximum stagnation temperature, $T_{a}+H_{\max } \tau \tilde{\alpha} / U_{L}$. This formula is the same as a formula derived for thermal-only collectors (25) except that $\alpha$ is replaced by $\tilde{\alpha}$ in the last line of $\mathrm{Eq}$. (14) and in the definition of $\mathrm{T}_{\mathrm{m}}$.

F. Collected Electrical Energy

Equation 14 of Florscheutz (1) displays the calculated electrical output of the $\mathrm{PV} / \mathrm{T}$ collector under specified operating conditions as 


$$
Q_{e}=\frac{{ }_{C} S \eta_{a}}{\alpha}\left\{I-\frac{\eta_{r} \beta_{r}}{\eta_{a}}\left[\tilde{F}_{R}\left(T_{f, i}-T_{a}\right)+\frac{\tilde{S}_{\tilde{U}}}{\tilde{U}_{L}}\left(1-\tilde{F}_{R}\right)\right]\right\}
$$

With substitutions for the tilde quantities as in Eq. (8), this becomes

$$
\mathrm{Q}_{e}=A_{c} \mathrm{H}_{\mathrm{T}} \tau \eta_{\mathrm{a}}\left\{1-\frac{\eta_{r} \beta_{r}}{\eta_{\mathrm{a}}}\left[F_{R}\left(T-\mathrm{T}_{\mathrm{a}}\right)+\frac{\mathrm{H}_{\mathrm{T}} \tau \alpha\left(1-\eta_{\mathrm{a}} / \alpha\right)\left(1-\mathrm{F}_{\mathrm{R}}\right)}{\mathrm{U}_{\mathrm{L}}-\tau I \eta_{r} \beta_{r}}\right]\right\} \text {. }
$$

A relationship similar to Eq. (9) can be shown to hold for electrical quantities, under the same assumptions upon which $\mathrm{Eq} .(9)$ was derived:

$$
\begin{aligned}
& \mathrm{dJ}_{\mathrm{c}}=\left(\frac{\mathrm{h}_{\mathrm{S}}}{\mathrm{H}_{\max }} \mathrm{dH_{ \textrm {T } }}\right) \mathrm{Q}_{\mathrm{e}} \\
& =\frac{A_{c} h_{S}}{H_{\max }} H_{T} d H_{T}\left\{\tau \eta_{a}-\tau \eta_{r} \beta_{r}\left[F_{R}\left(T-T_{a}\right)+\frac{H_{T} \tau\left(\alpha-\eta_{a}\right)\left(1-F_{R}\right)}{U_{L}-\tau H_{T} \eta_{r} \beta_{r}}\right]\right\} \text {. }
\end{aligned}
$$

For the thermal energy case, the integral was computed from $\mathrm{H}_{\mathrm{min}}$ to $H_{\text {max }}$. However, electrical energy can be collected at all insolation levels. For $\mathrm{H}_{\mathrm{T}}<\mathrm{H}_{\mathrm{min}}$, the operating temperature will not be $\mathrm{T}$ but rather will be the collector stagnation temperature, which will be less than $T$. Remember that $\mathrm{H}_{\text {min }}$ is that value of incident insolation for which $\mathrm{T}$ equals the stagnation temperature. Under stagnation

$$
\frac{T-T_{a}}{H_{T}}=\frac{\tau \tilde{\alpha}}{U_{L}}=\frac{\tau}{U_{L}}\left[\alpha-\eta_{a}+\eta_{r} \beta_{r}\left(T-T_{a}\right)\right] .
$$

Then

$$
\left(T-T_{a}\right)\left(1-\frac{\mathrm{H}_{T}{ }^{T \eta_{r} \beta_{r}}}{\mathrm{U}_{\mathrm{L}}}\right)=\frac{\mathrm{H}_{\mathrm{T}} \tau}{\mathrm{U}_{\mathrm{L}}}\left(\alpha-\eta_{a}\right)
$$

and

$$
\left(T-T_{a}\right)=\frac{H_{T} \tau\left(\alpha-\eta_{a}\right)}{U_{L}-H_{T} \tau \eta_{r} \beta_{r}}
$$

Then for $\mathrm{H}_{\mathrm{T}}<\mathrm{H}_{\mathrm{min}}$, the quantity in brackets in $\mathrm{Eq}$. (17) simplifies: 


$$
\begin{aligned}
& F_{R}\left(T-T_{a}\right)+\frac{H_{T}\left(\alpha-\eta_{a}\right)\left(1-F_{R}\right)}{U_{L}-\tau H_{T}{ }^{n}{ }_{r} r} \\
& =\frac{F_{R} H_{T} \tau\left(\alpha-\eta_{a}\right)}{U_{L}-\tau H_{T} n_{r}{ }^{\beta} r}+\frac{H_{T} \tau\left(\alpha-\eta_{a}\right)\left(1-F_{R}\right)}{U_{L}-\tau H_{T} n_{r}{ }_{r}}=\frac{H_{T} \tau\left(\alpha-\eta_{a}\right)}{U_{L}-\tau H_{T} n_{r}{ }^{\beta}} .
\end{aligned}
$$

Then

$$
\begin{aligned}
& J_{c}=\int_{0}^{H} d J_{c}^{\min }+\int_{\underline{H}_{\min }}^{H} d J_{c}^{\max } \\
& =\frac{A_{C}{ }^{h}}{H_{\max }} \int_{0}^{\mathrm{H}} \mathrm{H}_{T} \mathrm{dH}_{T}\left[\tau \eta_{a}-\tau \eta_{r}{ }_{r} \frac{\mathrm{H}_{T} \tau\left(\alpha-\eta_{a}\right)}{U_{L}-\tau H_{T} \eta_{r}{ }^{\beta} r}\right]+
\end{aligned}
$$$$
\frac{A_{C} h}{H_{\max }} \int_{H_{\min }}^{H_{T}}{ }_{T}^{\max } d H_{T}\left[\tau \eta_{a}-\tau \eta_{r} \beta_{r} F_{R}\left(T-T_{a}\right)+\frac{\tau \eta_{r} \beta_{r} H_{T} \tau\left(\alpha-\eta_{a}\right)\left(I-F_{R}\right)}{U_{L}-\tau H_{T} n_{r} \beta_{r}}\right]
$$

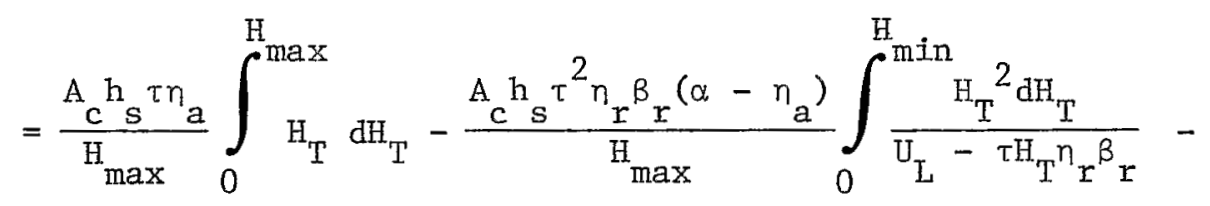$$
\frac{A_{c} h_{s} T \eta_{r} \beta_{r} F_{R}\left(T-T_{a}\right)}{H_{\max }} \int_{H_{\min }}^{H_{T}} \mathrm{H}_{T} d H_{T}-
$$

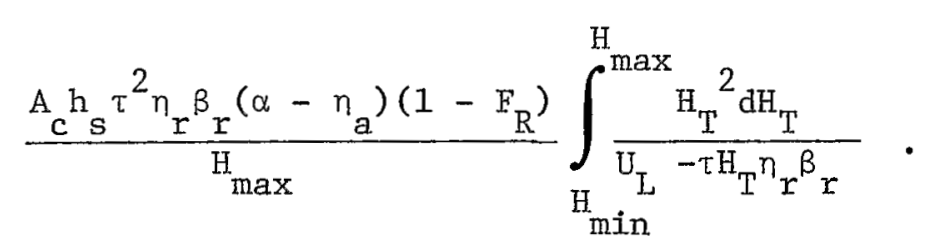

With the use of the relationship (13) linking total received insolation to maximum insolation rate, these terms reduce to 


$$
\begin{aligned}
& \mathrm{J}_{\mathrm{c}}=\mathrm{IA}_{\mathrm{c}} \mathrm{Tn}_{\mathrm{a}}- \\
& \frac{2 I A c^{\tau^{2} n_{r} \beta_{r}\left(\alpha-\eta_{a}\right)}}{H_{\max }^{2}} \int_{0}^{\mathrm{H}_{\max }} \frac{\mathrm{H}_{T}{ }^{2}{ }^{2} \mathrm{H}_{T}}{\mathrm{U}_{\mathrm{L}}-\tau \mathrm{H}_{T}{ }^{n_{r} \beta_{r}}}- \\
& \frac{2 I A_{c} \tau \eta_{r} \beta_{r} F_{R}\left(T-T_{a}\right)}{H_{\max }^{2}} \int_{H_{\text {min }}}^{H_{\text {max }}} \mathrm{H}_{T} \mathrm{dH}_{T}+
\end{aligned}
$$

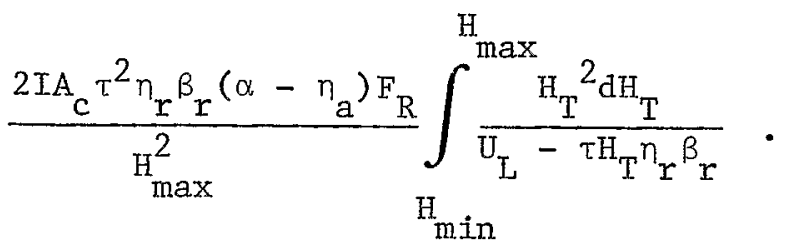

The last three terms are generally small compared with the first because of the small factor $\eta_{r} \beta_{r}$, which is typically $\sim 0.0005$. Furthermore, $\tau \mathrm{H}_{\mathrm{T}} \eta_{\mathrm{r}} \beta_{\mathrm{r}}$ is generally not more than $20 \%$ as large as $\mathrm{U}_{\mathrm{L}}$. We therefore make the approximation

$$
\frac{1}{U_{L}-\tau H_{T}{ }^{n} \beta_{r}}=\frac{1}{U_{L}}\left(\frac{1}{1-\tau H_{T} n_{r} \beta_{r} / U_{L}}\right) \approx \frac{1}{U_{L}}\left(1+\tau H_{T} n_{r} \beta_{r} / U_{L}\right)
$$

and the indefinite integral

$$
\begin{aligned}
& \int \frac{\mathrm{H}_{T}^{2}{ }^{2} H_{T}}{U_{L}-\tau H_{T} \eta_{r} \beta_{r}} \approx \frac{1}{U_{L}} \int H_{T}^{2}\left(1+\tau H_{T} \eta_{r} \beta_{r} / U_{L}\right) d H_{T} \\
& =\frac{\mathrm{H}^{3}}{3 \mathrm{U}_{\mathrm{L}}}+\frac{\tau \eta_{r}{ }^{\beta_{x} \mathrm{H}^{4}}}{4 \mathrm{U}_{\mathrm{L}}{ }^{2}}+\mathrm{C}=\frac{\mathrm{H}_{\mathrm{T}}^{3}}{3 \mathrm{U}_{\mathrm{L}}}\left(1+\frac{3 \tau \eta_{r}{ }^{\beta} \mathrm{H}_{\mathrm{T}}}{4 \mathrm{U}_{\mathrm{L}}}\right)+\mathrm{C} .
\end{aligned}
$$

Then, to a good degree of approximation,

$$
J_{c}=I A_{c} \tau \eta_{a}-I A_{c} \tau \eta_{r} \beta_{r} F_{R}\left(T-T_{a}\right)+\frac{I A_{c}{ }_{n} \beta_{r} F_{R} U^{2}\left(T-T_{a}\right)^{3}}{H_{\max }^{2} \tau \tilde{\alpha}^{2}}-
$$




$$
\begin{aligned}
& \frac{2 I A}{H_{\max }^{2}} \tau^{2} \eta_{r} \beta_{r}\left(\alpha-\eta_{a}\right)\left(I-F_{R}\right) \frac{H_{\max }^{3}}{3 U_{L}}\left(1+\frac{3 \tau \eta_{r} \beta_{r} H_{\max }}{4 U_{L}}\right)- \\
& \frac{2 I A}{H_{\max }^{2}} \eta_{r} \beta_{r}\left(\alpha-\eta_{a}\right) F_{R} \frac{U_{L}^{2}\left(T-T_{a}\right)^{3}}{3 \tau \tilde{\alpha}^{3}}\left(1+\frac{3 \eta_{r} \beta_{r}\left(T-T_{a}\right)}{4 \tilde{\alpha}}\right)
\end{aligned}
$$

where the second and third terms of Eq. (26) are the integral of the third term of Eq. (23), and the $\mathrm{F}_{\mathrm{R}}$ in the fourth term of $\mathrm{Eq} \cdot$ (26) is contributed by the upper limit of the integral of the fourth term Eq. (23).

We now make the following final approximations in the terms of Eq. (26) other than the first.

$$
\begin{aligned}
& \alpha-\eta_{\mathrm{a}} \approx \approx \text {, } \\
& \frac{3 \tau \eta_{r}{ }^{\beta} \mathrm{r}^{\mathrm{H}} \max }{4 \mathrm{U}_{\mathrm{L}}} \approx 0, \\
& \frac{3 \eta_{r}{ }_{r}\left(T-\mathrm{T}_{\mathrm{a}}\right)}{4 \tilde{\alpha}} \approx 0,
\end{aligned}
$$

We then may write

$$
\begin{aligned}
J_{c} \approx & I A_{c} \tau \eta_{a}-I A_{c} \tau \eta_{r} \beta_{r} F_{r}\left(T-T_{a}\right)+\frac{I A_{c} \eta_{r} \beta_{r} F_{R} U_{L}^{2}\left(T-T_{a}\right)^{3}}{3 H_{\max ^{2} \tau \tilde{\alpha}^{2}}} \\
& \frac{2 I A_{c} \tau^{2} \eta_{r} \beta_{r} \tilde{\alpha}\left(I-F_{R}\right) H_{\max }}{3 U_{L}} \cdot \\
= & I A_{c} \tau\left[\eta_{a}-\eta_{r} \beta_{r} F_{R}\left(T-T_{a}\right)\left(1-\varepsilon^{2} / 3\right)-\right. \\
& \left.(2 / 3) \eta_{r} \beta_{r}\left(1-F_{R}\right)\left(H_{\max } \tau \tilde{\alpha} / U_{L}\right)\right]
\end{aligned}
$$

where $\varepsilon \equiv \frac{\left(T-T_{a}\right) / H_{\max }}{\tau \tilde{\alpha} / \mathrm{U}_{L}}$. The physical interpretation of $\varepsilon$ is the fractional 
distance (in $\Delta \mathrm{T} / \mathrm{I}$ terms) of the collector operating point from ambient to stagnation under maximum insolation. Under most conditions the value of $\varepsilon$ will be $<0.5$.

Some consistency checks can be performed on this formula, based on the notion that if the cell temperature is $T$ everywhere then the energy collected from the PV array will be

$$
J_{c}=I A_{c} \tau \eta=I A_{c} \tau\left[\eta_{a}-\eta_{r} \beta_{r}\left(T-T_{a}\right)\right]
$$

The first condition to check is $F_{R}=1$ and $\varepsilon \ll 1$, such that the cell temperature is equal to the collector inlet temperature everywhere (since $\left.\mathrm{F}_{\mathrm{R}}=1\right)$ and the collector temperature always equals $\mathrm{T}\left(\varepsilon^{2} / 3 \approx 0\right.$ means that $T$ is close enough to $T_{a}$ that the low-insolation stagnation can be ignored). Substituting $\mathrm{F}_{\mathrm{R}}=1$ and $\varepsilon=0$ into Eq. (30) yields Eq. (31) as hoped for.

Other consistency checks depend on the fact that under stagnation conditions the average collector temperature weighted for solar input is $2 / 3$ as far above ambient as the maximum stagnation temperature. That is,

$$
\begin{aligned}
& \frac{\int_{0}^{\mathrm{H}} \mathrm{H}_{\mathrm{T}}^{\mathrm{max}}\left(\mathrm{T}_{\text {stagnation }}-\mathrm{T}_{\mathrm{a}}\right) \mathrm{dH_{T }}}{\int_{0}^{\mathrm{max}} \mathrm{H}_{\mathrm{T}} \mathrm{dH}_{\mathrm{T}}}=\frac{\int_{0}^{\mathrm{max}} \mathrm{H}_{\mathrm{T}}^{2} \frac{\tau \tilde{\alpha}}{\mathrm{U}_{\mathrm{L}}} \mathrm{dH}_{\mathrm{T}}}{\int_{0}^{\mathrm{H}} \mathrm{H}_{\mathrm{T}} \mathrm{dH}_{\mathrm{T}}} \\
& =\frac{\left(\frac{1}{3}\right) \frac{\tau \tilde{\alpha}}{U_{L}} H_{\max }^{3}}{\left(\frac{1}{2}\right) H_{\max }^{2}}=\frac{2}{3} \frac{\tau \widetilde{\alpha}}{U_{L}} H_{\max }=\frac{2}{3}\left(T_{m}-T_{a}\right) .
\end{aligned}
$$

If $F_{R}=0$, no thermal energy is collected and the collector is always stagnating. Substitution of $\mathrm{F}_{\mathrm{R}}=0$ into $\mathrm{Eq}$. (30) gives

$$
\begin{aligned}
J_{C} & =I A_{c} \tau\left[\eta_{a}-\frac{2}{3} \eta_{r} \beta_{r}\left(H_{\max } \tau \tilde{\alpha} / U_{L}\right)\right] \\
& =I_{c} \tau\left[\eta_{a}-\frac{2}{3} \eta_{r} \beta_{r}\left(T_{m}-T_{a}\right)\right]
\end{aligned}
$$


as expected. This condition (with $\tau=1$ ) will be used to calculate the energy output of a stand-alone $P V$ array, with a suitable value of $U_{L}$ reflecting passive cooling.

The third test condition is that for which $T-T_{a}=H_{\max } \tau \tilde{\alpha} / U_{L}$, meaning that the operating temperature is so high that the collector is always stagnating regardless of the value of $F_{R}$. Under this condition $\varepsilon=1$. Substitution of these values into $\mathrm{Eq}$. (30) yields

$$
\begin{aligned}
J_{c} & =I A_{c} \tau\left[\eta_{a}-\frac{2}{3} \eta_{r} \beta_{r} F_{R} H_{\max } \tau \tilde{\alpha} / U_{L}-\frac{2}{3} \eta_{r} \beta_{r}\left(1-F_{R}\right) H_{\max } \tau \tilde{\alpha} / U_{L}\right] \\
& =\operatorname{IA} c \tau\left[\eta_{a}-\frac{2}{3} \eta_{r} \beta_{r}\left(T-T_{a}\right)\right]
\end{aligned}
$$

as it should. 


\section{ASSESSMENT PROCEDURE}

After calculation of the electrical and thermal outputs from a PV/T system, the system still had to be assessed. The philosophy underlying this study demanded that $\mathrm{PV} / \mathrm{T}$ be compared with three alternatives: PV-only, thermal-only, and side-by-side PV and thermal collectors ( $P V+T$ ), with no credit for reduction in roof area (as explained in the Introduction).

In order to make these comparisons, it was necessary to calculate the electrical or thermal output of PV and thermal collectors in the same locations in which $P V / T$ was studied. For $P V$ only, the $P V / T$ formalism was used with $F_{R}=0$ (no heat removal), $\tau=1.0$ (no glazing), and a high value of $\mathrm{U}_{\mathrm{L}}$ appropriate for an unglazed collector with no back insulation (passive cooling). For thermal-only, the PV efficiency in the PV/T model was set equal to zero.

Using these numbers, each of the following quantities was calculated as a function of the ratio of the price (value) of thermal energy to the price (value) of electrical energy taken as a parameter:

1. Allowable $P V / T$ system cost over that of PV-only.

2. Allowable $P V / T$ system cost over that of therma1-only.

3. The ratio of the allowed $\mathrm{PV} / \mathrm{T}$ system cost to the allowed cost for side-by-side $P V+T$.

In a later section these quantities are examined in detail. Figure 4 is a typical graph showing how these comparisons are made. This graph is for a medium-temperature application (glazed collector) in Los Angeles. The solid lines are discussed here; the dashed lines are an elaboration which will be discussed later. The vertical axis on the left shows the equivalent electrical energy gain, Eequiv from PV/T over PV-only or thermal-only, which is defined as

$$
E_{\text {equiv }}=E_{e}+E_{t} X
$$

where $\mathrm{E}_{\mathrm{e}}$ is the gain (or loss if negative) in electrical energy output of $\mathrm{PV} / \mathrm{T}$ compared with PV-only or thermal-only, $E_{t}$ is the thermal energy gain (or loss) in the same comparison, and $\mathrm{X}$ is the thermal to electrical energy price ratio, plotted on the horizontal axis. 


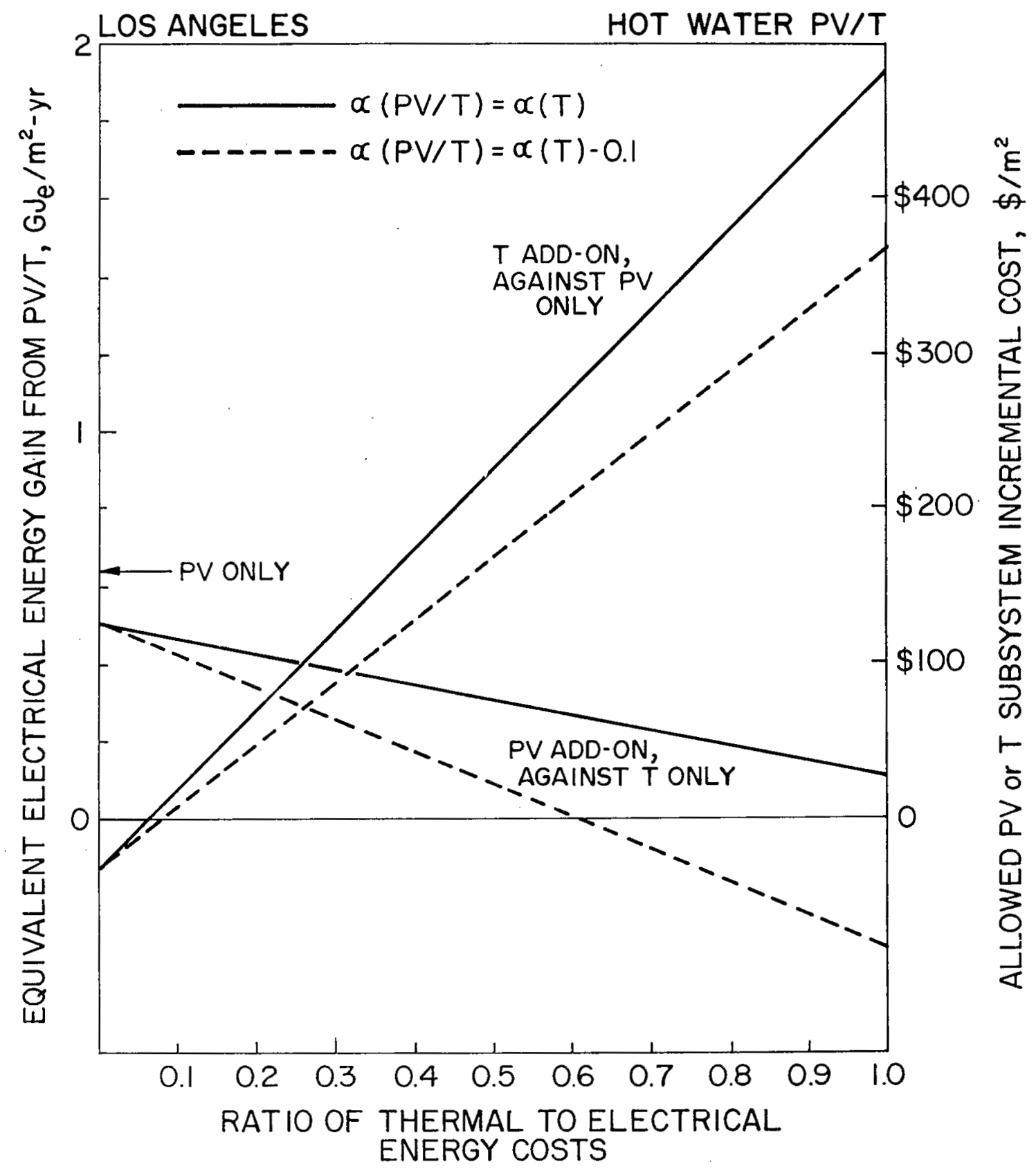

Figure 4. Typical graph of equivalent electrical energy gain, $P V / T$ relative to $\mathrm{PV}$-only and thermal-only, versus $\mathrm{X}$, the ratio of the thermal energy price to the electrical energy price (LA Hot Water). 
The most significant results of this report are implicit in these curves; therefore, it is important to understand them. The curve marked "T ADD-ON, AGAINST PV-ONLY" shows the equivalent electrical energy gain from $P V / T$ as against PV-only. If $\mathrm{X}=0$, thermal energy is worthless and the only effect of going to $\mathrm{PV} / \mathrm{T}$ from $\mathrm{PV}$ is a small loss in the amount of useful electricity produced. This is because the glazing cuts off about $8 \%$ of the incident radiation and because the higher operating temperature of the glazed collector reduces cell efficiency. As $X$ increases above zero, the thermal energy collected by the $\mathrm{PV} / \mathrm{T}$ becomes increasingly important, and for high enough values of $X$ the incremental value of adding thermal energy collection to a basic PV system becomes significant. Economics has not yet been discussed, but it can be seen that at high values of $X$ the allowed incremental cost of adding thermal to $\mathrm{PV}$ to make $\mathrm{PV} / \mathrm{T}$ goes to the $\$ 300$ to $400 / \mathrm{m}^{2}$ range. It is plausible that thermal energy collection could be added to PV for a price in. this vicinity

If one starts with a thermal energy collector, what is the value of adding PV? The line labeled "PV ADD-ON, AGAINST $T$ ONLY" addresses this . Again, suppose first that $X=0$. Then the equivalent electric energy gain from PV/T over thermal-only will be just the electicity produced by the PV/T, since the thermal energy is worthless at $\mathrm{X}=0$. This is less electricity than would be produced by PV only, as discussed above, and the gap between PV/T (over thermal-only) at $\mathrm{X}=0$ and the electricity produced by PV-only (the arrow in Figure 4) is the same as the gap between $\mathrm{PV} / \mathrm{T}$ (over $\mathrm{PV}$-only) and zero, also at $\mathrm{X}=0$ in Figure 4 .

The critical attribute of this curve is that its slope is negative. As X increases, the equivalent electrical energy gain from $\mathrm{PV} / \mathrm{T}$ over thermal-only decreases. This happens because, to a first approximation, electrical energy produced by a PV/T collector correspondingly reduces the thermal energy produced. The more valuable thermal energy becomes, the less attractive this tradeoff is. If this tradeoff were exact, the curve would have a zero intercept at $X=1$; since it is not exact, the $X=1$ intercept is positive.

These two curves may indicate a double-bind situation. If thermal energy is cheap relative to electricity, it may be attractive to add PV to a thermal-only system, but not to add thermal to a PV-only system. If thermal 
energy gets almost as expensive as electricity, the reverse may be true. It may become attractive to add thermal collection to $\mathrm{PV}$, but not to add $\mathrm{PV}$ to thermal. The requirement that both be attractive in order for $P V / T$ to be $a$ winner presents a problem. There is still the possibility, however, that both are attractive in some range of intermediate values of $\mathrm{X}$; this is examined in detail below.

The PV/T vs. PV+T comparison, which theoretically could negate the attractiveness of $\mathrm{PV} / \mathrm{T}$ even if the above two comparisons were favorable, also will be taken up later. 


\section{V . ECONOMIC CRITERIA}

The economics of solar energy systems has been analyzed in a variety of ways. Widely differing results have been obtained, ranging from broad statements that solar energy is extremely cost effective to equally broad statements that solar energy will never make it in the marketplace. The discussion below is intended to elucidate some aspects of these analyses.

To begin with, one divergence in outlook between the heating, ventilating, and air-conditioning (HVAC) industry and the solar industry needs to be pointed out. Generally, the HVAC industry requires a 3- to 5-year payback before it will consider marketing a more expensive but cheaper-to-operate heating or cooling unit. In contrast, the solar industry has typically used 20-year life-cycle costing to evaluate the economic viability of solar systems. These two criteria yield quite different results. Possibly one or the other is "right," or perhaps some number in between is right, as determined by the response of the marketplace. To investigate this further, the following approaches have been taken: (1) simple payback, (2) positive cash flow, and (3) life-cycle costing.

A. Simple Payback

Simple payback time is the period required for cumulative fuel savings to equal the extra initial outlay if a customer spends more for a novel system than for a conventional alternative. As stated above, the HVAC industry thinks in terms of 3- to 5-year payback, but the solar industry in terms of 20 years or longer. A period of 7 or 8 years has been suggested as a reasonable compromise which allows for increasing energy consciousness on the part of the public but does not diverge widely from current practice. With no allowance made for the increasing cost of energy, this would mean that the incremental solar system cost (the difference between the first cost of the solar system and that of the conventional alternative) should be no more than 8 times the first year's fuel savings. With both fuel cost escalation and the time value of money taken into account, this limiting factor might rise to about 10 . The required payback time is a matter of judgement, and this judgement can determine the entire direction of a development program; therefore, it is of interest to consider some other ways of reaching it. 


\section{B. Postive Cash Flow}

The basis of this approach to solar economics is the idea that a customer will buy a solar system if the total payments for mortgage, maintenance, and energy are less for the solar system than for the conventional one. Depending on the interest rate, this criterion could be compatible with relatively long payback periods. In order to assess this criterion, the capital recovery factors (CRF) were calculated for nine mortgages: for 10,20 , and 30 years at interest rates of 6,10 , and $14 \%$. The CRF is the ratio of the annual mortgage payment (interest plus principal) to the face amount of the loan. The loan amount is taken as the incremental solar system cost, that is, the difference between the first cost of the solar system and that of the conventional one. This is then modified by subtracting the tax savings due to the deductibility of the interest and by adding the incremental maintenance and miscellaneous costs, where these are assumed to equal $2 \%$ of the incremental system cost. The net capital recovery factor represents the amount of fuel savings required, per dollar of incremental system cost, to achieve zero initial cash flow relative to the competing conventional system. The inverse of the $\mathrm{CRF}$ is the ratio of incremental solar system cost to first-year fuel savings needed to achieve zero relative cash flow in the first year. Values of this cost-to-savings ratio are shown in Table 2. A cost/savings ratio of 10 is consistent with a 20 -year $10 \%$ loan and a marginal tax rate of $37 \%$.

\section{Life-Cycle Costing}

Life-cycle costing is a method of taking into account all the various costs and benefits which occur in the course of achieving an objective over time. A cost incurred in the future is not as great a liability as the same cost incurred now, even in the absence of inflation. Qualitatively it is human nature to defer pain as long as possible. Quantitatively, if a cost is deferred, the money set aside to pay it can earn interest in the meantime, and the longer the deferment, the more interest is earned. It may happen, however, that the further in the future a cost is deferred, the greater it will be. In an era of rising energy prices, the cost of a given amount of fuel will increase over time. A way is needed to put costs incurred at different times on an equal footing. This is accomplished by means of the present value function (PVF), which is defined $(\underline{26})$ as the amount of money that must be set 
Table 2

Ratios of Incremental Solar System Cost to First-Year

Fue1 Savings Consistent with Zero Relative Cash Flow for the

First Year, for Two Tax Brackets.

\begin{tabular}{lrcc}
\hline & & \multicolumn{2}{c}{ Cost/Savings Ratio } \\
\cline { 3 - 4 } $\begin{array}{c}\text { Lerm of } \\
\text { Loan }(\mathrm{yr})\end{array}$ & $\begin{array}{c}\text { Interest } \\
\text { Rate }(\%)\end{array}$ & $\begin{array}{c}\text { 30\% Marginal } \\
\text { Tax Rate }\end{array}$ & $\begin{array}{c}50 \% \text { Marginal } \\
\text { Tax Rate }\end{array}$ \\
\hline \multirow{2}{*}{10} & 14 & 5.9 & 7.0 \\
& 10 & 6.5 & 7.5 \\
& 6 & 7.2 & 7.9 \\
& 14 & 7.8 & 9.9 \\
& 10 & 9.3 & 11.5 \\
& 6 & 11.2 & 13.0 \\
& 14 & 8.3 & 10.8 \\
& 10 & 10.4 & 13.2 \\
& 6 & 13.3 & 15.9 \\
\hline
\end{tabular}

aside now, at an annual rate of return d, to cover over the next $\mathrm{N}$ years an annually occurring expense now costing one dollar but expected to escalate at an annual rate e:

$$
\begin{array}{rlrl}
\operatorname{PVF}(d, e, N) & =\frac{1}{d-e}\left[1-\left(\frac{1+e}{1+d}\right)^{N}\right] \quad & \text { if } d \neq e \\
& =\frac{N}{1+d} \quad \text { if } d=e .
\end{array}
$$

In evaluating the relative merits of a solar and a conventional HVAC system the present values of the various costs (or benefits) of each system are added (or subtracted) to obtain a total present value (TPV) of the lifecycle costs of each. The system having the lower TPV is the more cost effective under the given assumptions.

In the discussion below the following costs and benefits are considered:

1. System first cost.

2. Maintenance and miscellaneous costs.

3. Energy costs.

4. Tax benefits due to deductibility of interest payments.

These are the main items of concern to the residential user. In the commercial area other factors, mostly related to the tax consequences of doing 
business, must be considered. If tax subsidies (such as the solar tax credit) are available, then the solar system first cost would be taken aftersubtracting the credit.

In the calculations below, the following assumptions are made:

1. The three measures related to time value of money (discount rate, interest rate, and inflation rate) are set equal to one another. In the numerical examples this common value is taken as $10 \%$.

2. The system is assumed to be financed by a loan covering most of its cost. The down payment is taken as a nominal $20 \%$.

3. The loan term equals the life of the system.

Under these assumptions the present value of the system cost (PVSYS) is equal to the system cost $\mathrm{C}$ :

PVSYS $=\mathbf{C}$.

The present value of the maintenance and miscellaneous costs (PVMISC) is given (26a) by:

$$
\text { PVMISC }=m C \frac{N}{I+d}
$$

where $\mathrm{mC}$ is the annual maintenance and miscellaneous expense (assumed to increase with inflation), $d$ is the discount rate, and $N$ is the number of years in the analysis.

The present value of the energy costs (PVENER) is given (26a) by:

$$
\text { PVENER }=F \cdot P V F(d, e, N) \text {, }
$$

where $F$ is the energy cost incurred in the first year of operation and $e$ is the energy cost escalation rate.

The present value of the tax reduction due to deductibility of mortgage interest is (26b) equal to the marginal tax rate multiplied by the present value of the interest (PVINT):

$$
\left.t \cdot \operatorname{PVINT}=0.8 \mathrm{Ct}\left\{\left[\frac{\mathrm{Nd}}{1+\mathrm{d}}\right]\left[1-\frac{1}{1-\frac{1}{1+d} N}\right]+\right]\right\},
$$


where $t$ is the marginal income tax rate of the purchaser (federal + state state federal).

The total present value is obtained by combining the four terms:

TPV $=$ PVSYS + PVMISC + PVENER $-t \cdot$ PVINT.

The values of $t \cdot$ PVINT and PVMISC for $d=0.1$ are given in Table 3 for periods of 10 to 20 years.

Table 3

Present Value of Interest Tax Deductions and of Maintenance and Miscellaneous Expenses for Various Periods of Analysis

\begin{tabular}{ccc}
\hline Period of Analysis (yr) & $t \cdot$ PVINT & PVMISC \\
\hline 10 & $0.343 \mathrm{Ct}$ & $9.1 \mathrm{mC}$ \\
15 & $0.457 \mathrm{Ct}$ & $13.6 \mathrm{mC}$ \\
20 & $0.546 \mathrm{Ct}$ & $18.2 \mathrm{mC}$ \\
\hline
\end{tabular}

It is then possible to calculate the value of $m$ for which the second and fourth terms in Eq. (41) just cancel, for marginal tax rates of $30 \%$ and $50 \%$. These are shown in Table 4 .

Table 4

First-Year Maintenance Cost (as a Fraction $m$ of System First Cost) for Which

Effects of Interest Tax Deduction Cancel Incremental Maintenance Costs.

\begin{tabular}{ccccc} 
& & \multicolumn{2}{c}{ Period of Analysis (yr) } \\
\cline { 2 - 4 } Marginal Tax Rate & 10 & 15 & 20 \\
\hline $30 \%$ & 0.011 & 0.010 & 0.009 \\
& $50 \%$ & 0.019 & 0.017 & 0.015 \\
\hline
\end{tabular}

The $\mathrm{m}$ value is just the fraction of system first cost which is required for maintenance and miscellaneous expenses during the first year. Values of $1.5 \%(\underline{26 c)}$ and $2.0 \%(\underline{27})$ have been advanced as reasonable. This suggests that the combination PVMISC - $t$ - PVINT tends to cancel, or at least that zero is well within the range of plausible values. With this assumption, the expression for total present value becomes

$$
\begin{aligned}
\text { TPV } & =\text { PVSYS }+ \text { PVENER } \\
& =\mathrm{C}+\mathrm{F} \cdot \operatorname{PVF}(\mathrm{d}, \mathrm{e}, \mathrm{N}) .
\end{aligned}
$$


The TPV for solar (TPV $)$ is next compared with that for the conventional system $\left(T_{P V}\right)$. The threshold of solar cost effectiveness occurs when this difference equals zero:

$$
0=T P V_{S}-T P V_{c}=C_{s}-C_{c}+\left(F_{S}-F_{c}\right) \cdot \operatorname{PVF}(d, e, N) \text {. }
$$

This leads to

$$
\frac{C_{s}-C_{c}}{F_{c}-F_{s}}=\operatorname{PVF}(d, e, N)
$$

In other words, the ratio of incremental solar system cost to fuel savings at the threshold of cost effectiveness is given by the present value function as shown in Eq. (36), which can easily be calculated and is shown in Table 5. The PVF is mostly a function of the difference between $e$ and $d$; that is, adding or subtracting a small amount to both $e$ and $d$ does not alter the PVF so greatly as changing $e$ or $d$ independently.

Table 5

Values of the Present Value Function for Various Fuel Escalation Rates and Periods of Analysis

\begin{tabular}{ccccccc} 
& & \multicolumn{4}{c}{$\begin{array}{c}\text { Present Value Function } \\
\text { (Calculated for } d=0.1)\end{array}$} \\
\hline $\begin{array}{c}\text { Fuel Escalation } \\
\begin{array}{c}\text { Minus } \\
\text { Discount Rate }\end{array}\end{array}$ & $\begin{array}{c}\text { Fuel } \\
\text { Cost } \\
\text { Escalation }\end{array}$ & 5 & \multicolumn{4}{c}{ Period of Analysis (yr) } \\
\cline { 3 - 7 }-0.05 & 0.05 & 4.2 & 7.4 & 10 & 20 & 25 \\
0 & 0.10 & 4.5 & 9.1 & 13.6 & 12.1 & 13.8 \\
0.05 & 0.15 & 5.0 & 11.2 & 19.0 & 28.7 & 40.1 \\
0.10 & 0.20 & 5.5 & 13.9 & 26.9 & 47.0 & 78.0 \\
0.20 & 0.30 & 6.5 & 21.6 & 56.3 & 136.2 & 320.6 \\
\hline
\end{tabular}

The larger the PVF, of course, the more the solar system can cost. For high fuel cost escalation rates and long terms of analysis one obtains very high ratios indeed. The use of long system lifetimes such as 25 years and large fuel escalation rates such as $30 \%$ results in very high values for PVF and therefore high allowable prices for solar systems. This extreme case appears to suggest that one should rationally be willing to pay 320 times the first year's energy savings for a solar system. In addition to noting that 
this assumption means that oil would cost $\sim \$ 700$ per gallon in 2005 , one may observe as well that this apparent price freedom is limited by certain additional constraints:

1. The period of analysis should not exceed the system life. Indeed, it should probably be shorter by a sufficient period to induce purchases with the expectation of a profit. Since experience with solar systems is limited, the use of system lifetimes as long as 20 years is probably not warranted. Even 15 years may be too long.

2. The expectation of high fuel cost escalation rates will probably not be borne out as much for electricity as for fossil fuels. Fuel costs comprise only a portion of the total cost of electric power generation, and cheaper solid fuels are, in any case, expected to displace oil in electric power generation.

3. Insofar as fuel costs do escalate at a rapid rate, this will likely lead to relatively rapid innovation in photovoltaics, solar heating, and other forms of energy conservation. Thus a long-life high-cost solar system may be rendered obsolete well before the end of its service life.

D. Selection of Target Cost/Savings Ratio

The numbers in Table 5 represent a variety of possible cost goals for solar systems. Which goal is most appropriate is a matter of judgment, but, for the reasons advanced above, a value of 10 has been selected for the ratio incremental-system-cost/first-year-energy-savings, consistent with a fuel escalation rate $5 \%$ above inflation and a breakeven time of $<10$ years.

E. Estimation of 1986 Energy Prices

In order to estimate 1986 prices for both electricity and fossil fuel, a survey was taken of 1980-81 prices in the three market areas being studied. For Southern California, electricity and gas prices quoted by Southern California Edison were taken as representative (28). For Florida, Tampa Electric Co. prices were used (29). These two utilities serve the Los Angeles and Tampa areas, respectively, which were used in the study. For the Northeast, Long Island Lighting Co. electricity prices were used (30) rather than Consolidated Edison, even though New York City weather data were used, 
because LILCO prices, although above the national average, were not as extreme as those prevailing in New York City and hence were more representative of prices generally over the Northeast. Oil was used as the fossil fuel in this case, although both oil and gas are widely used.

To translate 1981 to 1986, electricity prices were escalated at a rate 5\% above inflation. The allowed cost/savings ratio of 10 was then applied to obtain an allowable incremental system cost per $\mathrm{GJ}_{\mathrm{e}}$ annual electricity savings.

The results of this process are given in Table 6 . In order to compare these results with other standard measures of system economic viability, these criteria were applied to a PV-only system in each of the three areas studied. The electricity collected per square meter was calculated by the formalism developed in the preceding section. This number was then multiplied by the allowed cost in dollars per gigajoule-electric ( $\$ / G_{e}$ ) to obtain an allowed cost in dollars per square meter $\left(\$ / \mathrm{m}^{2}\right)$. With use of a peak insolation rate

Table 6

Calculation of Allowed System Incremental Costs

\begin{tabular}{|c|c|c|c|}
\hline & os Angeles & New York & Tampa \\
\hline \multicolumn{4}{|l|}{1981 electricity price } \\
\hline \multicolumn{4}{|l|}{1986 electricity price (1981 \$) } \\
\hline$(\phi / k W h)$ & 10.2 & 12.3 & 7.5 \\
\hline$\left(\$ / G J_{e}\right)$ & 28.38 & 34.06 & 20.93 \\
\hline \multicolumn{4}{|c|}{1986 allowed incremental system cost (1981 \$) } \\
\hline$\left(\$ / G J_{e}\right)$ & 284 & 340 & 209 \\
\hline & 0.643 & 0.480 & 0.671 \\
\hline$\left(\$ / \mathrm{m}^{2}\right)$ & 183 & 170 & 140 \\
\hline$(\$ / W p)$ & 1.83 & 1.70 & 1.40 \\
\hline
\end{tabular}

of $1000 \mathrm{~W} / \mathrm{m}^{2}$, these prices can be translated to dollars per peak watt ( $\$ / \mathrm{Wp}$ ). The results of these calculations are also given in Table 6 . The resulting allowed costs of $\$ 1.83 / \mathrm{Wp}, \$ 1.70 / \mathrm{Wp}$, and $\$ 1.40 / \mathrm{Wp}$ are al1 very close to the 
1986 PV program goal (31) of $\$ 1.60 / W p$ for residential systems. Because the uncertainties in the 1986 electricity prices as calculated are larger than the differences between the above cost goals and $\$ 1.60 / \mathrm{Wp}$, the value $\$ 1.60 / \mathrm{Wp}$ for the PV-only system was used as the criterion in all three cities. This criterion was used to scale all systems, as will be seen in a later section.

For fossil fuel, the 1981 prices were 48 $/$ therm for gas in Los Angeles (28), $\$ 1.20 / g a 1$ for oil in New York (32), and 47\$/therm for gas in Tampa (29). In the analysis below, fossil energy prices were taken as a parameter. Specifically, the parameter was defined as the ratio of the price of fossil energy (delivered to the point of use) to the price of electricity. In order to estimate the most likely value of this ratio, 1981 fossil energy prices were escalated at a rate $8 \%$ above inflation. An $80 \%$ conversion efficiency was assumed. The results of these calculations are shown in Table 7 . It appears that the most likely values of this ratio will fall in the range 0.25 to 0.50 .

Table 7

Fossil Energy Price Estimates

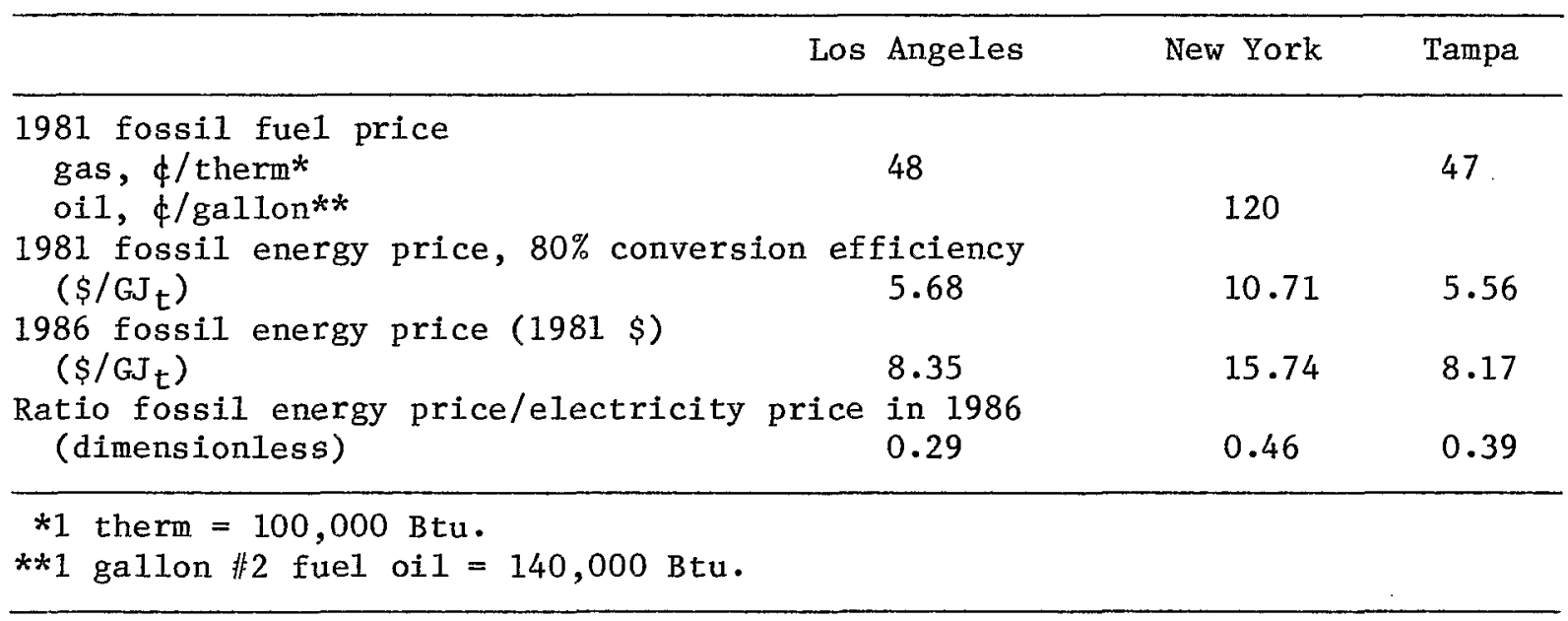




\section{TECHNOLOGY ISSUES}

Technology issues include aspects of either PV or thermal collector technology which contribute to the viability or non-viability of $P V / T$ as against PV-only; thermal-only, or side-by-side $P V+T$. These issues are discussed in the following sections.

\section{A. Glazing Transmissivity}

For medium-temperature thermal applications such as space heating or hot water, it is necessary to use glazed collectors. (Systems which employ a heat pump may be an exception; these will be considered in Section IX.) The interposition of a glazing between the incident radiation and the cells (located on the absorber plate) reduces the amount of radiation striking the cells and thus reduces the electrical energy produced by $\mathrm{PV} / \mathrm{T}$ compared with $\mathrm{PV}$-only. For low-temperature thermal applications where unglazed collectors can be used, this consideration does not apply.

B. Operating Temperature

For medium-temperature applications the average collector operating temperature is expected to be higher for $\mathrm{PV} / \mathrm{T}$ than that for a PV-only system. This will result in lowered electrical output for the PV/T collector because cell efficiency declines with increasing temperature. In addition, unless some active means of heat dumping is employed, the stagnation temperature of the PV/T collector will be much higher than that of the PV-only collector. "Cooking" the cells in this way may severely limit cell life, and this problem must be addressed even though it may have no impact on simulations of collector performance. The effect of elevated operating temperatures is thus very similar to that of glazing. For the low-temperature unglazed collector this effect is less serious, and indeed in some applications the cells may be cooled below their otherwise normal operating temperature, which improves efficiency.

\section{Thermal Absorptivity}

It is tempting to assume in simulations that the absorptivity to incident solar radiation will be the same in a PV/T collector as in a thermal-only collector. It is quite posible, however, that the $\mathrm{PV} / \mathrm{T}$ collector will suffer 
from reduced absorptivity. In the thermal collector, an optimal coating (selective or nonselective) can be used. In a $\mathrm{PV} / \mathrm{T}$ collector, the cells are necessary and one cannot just paint over them or deposit black chrome onto their surface. Absorptivity problems involve (a) the cell surface itself, and (b) the grid connections, which represent a small fraction of the cell area. Presumably any area not covered by cells could be coated in the same way as a thermal-only collector, though at higher cost per unit area. The grid connections, in principle, could be blackened or selectively coated (11), but the cost is likely to be high because the coating must be pinpointed onto the grid and kept off the cell. Still, it is possible that a process such as rotogravure printing could be used cost effectively. The major problem concerns the active cell surface itself. In order to maximize electrical efficiency, the back of a cell is normally highly reflective. This high reflectivity does not affect photons with energy above the absorption edge, since they are essentially all absorbed in the silicon. Long-wavelength photons are reflected by the metallized back and mostly pass back out of the ce11. In PV-only applications this is desirable because it reduces the operating temperature of the cell, but in a PV/T collector this represents a net loss of energy. Some means of capturing these photons is desirable, either by making most of the back surface nonreflective in a manner consistent with maintaining conductance of electrons away from the cel1, or by replacing the metallized back with a grid similar to that on the front, and providing an auxiliary absorbing surface to absorb the photons which pass through (7).

\section{Collector Heat Loss Factor}

The collector heat loss factor or $U_{L}$ value of a PV/T collector may be higher than that of a selectively coated thermal-only collector of the same geometry and with the same amount of insulation because the spectral response of the cell may not provide optimum selectivity. That is, in addition to reduced absorptivity in the visible region of the spectrum, discussed above, emissivity in the infrared may be higher than that in a selective-surface thermal-only collector. This can be due, for example, to high emissivity of the encapsulant. In this case, the collector heat loss factor will revert to a value appropriate to a nonselective collector, and thermal energy collection will be impaired. This effect will be most pronounced for the 
higher-temperature applications and relatively unimportant for low-temperature collectors. It may be possible to isolate the interior of the collector sufficiently that no additional encapsulant is needed; alternatively a very thin material ( $1 / 4$ wavelength at the blackbody peak at the temperature of operation) may be found which can be used for this purpose. In any case, both this and the previous issue represent problems to be solved.

\section{E. Electrica1-Thermal Tradeoff}

This issue was discussed above and is a consequence of heat transfer laws and conservation of energy. The impact here is that the more valuable thermal energy is, the less incrementally valuable is electrical energy, and hence the less one can spend to add a device which "trades in" thermal for electrical energy. It is this tradeoff which resulted in the downward slope in Figure 4 of the line representing the incremental value of $P V / T$ over thermal-only.

\section{F. Lifetime Match/Mismatch}

It is quite possible, indeed likely, that the optimum lifetime of the thermal portion of a PV/T collector will be different from that of the PV portion, if each is considered separately. However, in a composite unit such as this it is desirable that the system be designed, like the "one hoss shay," so that all its major components will break down at once. A 20-year solar cell in a 10-year thermal collector is clearly suboptimal, whereas it may well be possible that in a cost vs. life tradeoff the optimum life of a thermal-only collector would be 10 years. This represents a potential difficulty for $\mathrm{PV} / \mathrm{T}$ systems which may or may not be a problem in practice. A related difficulty which almost certainly will be a problem is that, even if the design lifetimes of the thermal and PV portions are the same, in a given installation they may be quite different. The breakdown of the shorter-lived subsystem may cause the other to fail; at the very least the performance of the remaining subsystem will probably be impaired.

G. Collector Area Match/Mismatch

The optimum thermal collector area may well be different from the optimum PV area. In this event, suboptimal area of one or the other would have to be used, or else a mixture of $\mathrm{PV} / \mathrm{T}$ and single-purpose collectors would be needed. At the very least this would result in system complications which 
would eliminate the "onIy one kind of collector" simplicity sometimes claimed for $\mathrm{PV} / \mathrm{T}$.

\section{H. Market Area Match/Mismatch}

The economics of solar electricity may not always follow that of solar thermal energy, although the two are no doubt correlated. Thus marketers may be faced with situations where the need for one type of energy from solar is much less than the need for the other. With side-by-side collectors, the area of one kind or another can be easily set to zero, but this is not possible with $\mathrm{PV} / \mathrm{T}$.

These three issues need not, of course, be fatal to $P V / T$, which could have a sizable market niche in spite of them. In evaluating any $\mathrm{PV} / \mathrm{T}$ program, however, they must be taken into account. At the very least, they tend to fortify the final issue, below.

\section{Limited Program Resources}

Regardless of the merits of $\mathrm{PV} / \mathrm{T}$, it is clear that an extensive engineering development program would be required to bring PV/T to a state of commercial readiness. In order to justify the necessary expenditure of resources, it must be shown not merely that $\mathrm{PV} / \mathrm{T}$ is "competitive" with other solar

options, but that it is clearly superior to them in enough applications to justify the cost of a development program. 


\section{INCREMENTAL SYSTEM COSTS}

In this section estimates are made of the incremental costs of adding thermal energy collection capability to a PV-only system and, alternatively, those of adding electric energy collection capability to a thermal-only system, to make a $\mathrm{PV} / \mathrm{T}$ system. In addition, estimates are made of the costs of a PV/T system relative to a side-by-side PV+T system of the same PV and thermal collector area. These incremental (or relative) system costs are then compared with the incremental (or relative) energy collection capability, as determined in the next section, in order to assess the economic viability of $\mathrm{PV} / \mathrm{T}$.

Each system is broken down into two subsystems, collector and balanceof-system (BOS). The collector includes the device used to collect solar energy, any internal wiring or piping, and materials and labor involved in affixing it to the building roof. BOS includes everything else needed to interface the collector to the point of delivery of the energy to the load. Thus, a thermal-only system is assumed to include a thermal collector and a thermal BOS; a PV-only system includes a PV collector and a PV BOS; and a PV/T system includes a PV/T collector, a PV BOS, and a thermal BOS.

The incremental cost $\mathrm{C}_{1}$ of $\mathrm{PV} / \mathrm{T}$ over $\mathrm{PV}$ only is thus estimated as

$$
\mathrm{C}_{1}=\mathrm{PV} / \mathrm{T} \operatorname{coll}+\mathrm{PV} \text { bos }+\mathrm{T} \text { bos }-\mathrm{PV} \operatorname{coll}-\mathrm{PV} \text { bos }
$$

where the various terms represent the costs of collector and BOS for equalarea $\mathrm{PV} / \mathrm{T}, \mathrm{PV}$, and thermal systems. This simplifies to

$$
\mathrm{C}_{1}=\mathrm{PV} / \mathrm{T} \operatorname{coll}+\mathrm{T} \text { bos }-\mathrm{PV} \operatorname{coll} \text {. }
$$

Similarly, the incremental cost $\mathrm{C}_{2}$ of $\mathrm{PV} / \mathrm{T}$ over thermal only is estimated as

$$
\begin{aligned}
\mathrm{C}_{2} & =\mathrm{PV} / \mathrm{T} \operatorname{col} 1+\mathrm{PV} \text { bos }+\mathrm{T} \text { bos }-\mathrm{T} \operatorname{coll}-\mathrm{T} \text { bos } \\
& =\mathrm{PV} / \mathrm{T} \operatorname{col} 1+\mathrm{PV} \text { bos }-\mathrm{T} \operatorname{col} 1 .
\end{aligned}
$$

It is recognized that the thermal BOS cost associated with a given area of $\mathrm{PV} / \mathrm{T}$ collector may vary from that associated with the same area of thermalonly collector, but this is considered to be a second-order effect which will not greatly alter the result. 
The ratio of $\mathrm{PV} / \mathrm{T}$ system cost to that of a side-by-side PV+T system is defined as

$$
R=\frac{P V / T \operatorname{col} 1+\mathrm{PV} \text { bos }+\mathrm{T} \text { bos }}{\mathrm{PV} \operatorname{col} 1+\mathrm{T} \operatorname{col} 1+\mathrm{PV} \text { bos }+\mathrm{T} \text { bos }} .
$$

The cost of each of these subsystems is now estimated for each of the two thermal energy temperature ranges considered, that is, medium-temperature glazed collectors $\left(>40^{\circ} \mathrm{C}\right)$ and low-temperature unglazed collectors $\left(<30^{\circ} \mathrm{C}\right)$. For the medium-temperature applications, two technologies are considered. The first is the current state-of-the-art technology comprising metal-and-glass collectors operated under pressure and freeze-protected with glycol or other antifreeze solution. The second is a proposed future technology comprising thin-film plastic collectors operated at atmospheric pressure and using ordinary water as the heat transfer fluid in a drainback mode of operation. These collectors are currently under development at Brookhaven National Laboratory, and it is of interest whether their successful development would have any effect on the economic attractiveness of $\mathrm{PV} / \mathrm{T}$.

A. Therma1 Collector (Medium Temperature, Current Technology)

The installed cost of thermal collectors varies widely. Important variables are heat transport fluid (liquid or air), number of glazings, and whether the absorber is selectively coated. For this analysis, a singleglazed, selective-surface copper-and-glass liquid-heating collector was used, because it is the most popular type and provides adequate performance for space heat and hot water without the use of double glazing. Two separate reports, one prepared by Zweigel for Continenta1 Group, Inc. (33) and the other by Booz Allen $\mu$ Hamilton (34), were used in assessing collector costs. These were used because they delved into the inner workings of the manufacturing and distribution chain, thus providing insights which proved useful in evaluating projected costs of advanced collector technologies and of balanceof-system.

The assessment methodology used in both reports was to begin with materials costs and then to consider added costs introduced at the factory and in the distribution and installation process to arrive at a final cost to the consumer. The collector materials costs as determined in these studies are tabulated below: 
Collector Materials Costs $\left(\$ / \mathrm{ft}^{2}\right)$

Continental (33) Booz Allen (34)

\begin{tabular}{lll} 
Glazing & 0.63 & 0.50 \\
Selective coating & 1.00 & N/A \\
Absorber & 2.81 & 2.13 \\
Frame and backing plate & 1.13 & 2.14 \\
Gaskets and insulation & 0.62 & 0.72 \\
\multicolumn{1}{c}{ Total } & 6.19 & 5.49
\end{tabular}

The Continental collector is selectively coated. It is not clear from their report whether or not the Booz Allen collector is selectively coated, but, since the absorber cost given does not appear high enough to admit the current cost of a selective surface (black chrome), which is $\sim \$ 1 / \mathrm{ft}^{2}$, it is assumed to be nonselective. In this case the two totals are in quite good agreement (exact if $\$ 0.70$ is taken as the difference in cost between a selective and nonselective surface). Note, however, the variations in the estimates for the various subcomponents. As a result of these considerations, the cost chosen for use was the Continental materials cost of $\$ 6.19 / \mathrm{ft}^{2}$ for the selectively coated absorber with a single glazing.

Factors by which the materials cost must be multiplied on the way to obtaining an installed cost to the customer are shown in Table 8 . Besides the Continental and Booz Allen values, the values used in this study are shown. The reasons for these choices are given below.

Table 8

Market Ratios

\begin{tabular}{lccc}
\hline \multicolumn{1}{c}{ Factor } & Continental $(\underline{33)}$ & Booz Allen (34) & This Study \\
\hline Manufacturing costs other & 1.28 & & \\
$\quad$ than materials & 1.2 & 1.31 & 1.3 \\
Manufacturer's markup & 1.2 & 1.5 & 1.4 \\
Distributor's markup & 1.75 & 1.3 & 1.25 \\
Dealer/installer markup & 3.2 & 2.9 & 1.55 \\
$\quad$ and labor & & 3.5 \\
Overall market ratio & & & 3.14 \\
\hline
\end{tabular}


For manufacturing costs other than materials, the Continental and Booz Allen values were close and appeared reasonable, and their average was taken for use.

For manufacturer's markup, the values from the two reports differed significantly. Booz Allen broke out three cost items: recovery of investment in plant and equipment, general and administration, and profit. No such breakout was given in the Continental report. Therefore more weight was given to the Booz Allen number, and a value of 1.4 was selected for use here.

For distributor's markup, the two values were fairly close, and their average was adopted.

For dealer/installer markup and labor, the Continental report took care to justify its high value on the basis of a study of labor costs as well as the dealer/installer's overhead and profit. Booz Allen, on the other hand, selected an arbitrary $\$ 2 / \mathrm{ft}^{2}$ with no further explanation. The judgement adopted here is that the Booz Allen market ratio is quite low, and the figure adopted for use is much closer to the Continental value.

The product of the four factors thus arrived at is 3.5 . Note that in each of the two cases with a significant discrepancy between the two reports our analysis indicated that the higher was likely to be closer to the truth; the overall value of 3.5 was therefore higher than the overall value obtained by either report.

Applying the overall market ratio of 3.5 to the materials cost of $\$ 6.19 /$ $\mathrm{ft}^{2}$ yields an installed collector cost of $\$ 21.67 / \mathrm{ft}^{2}$ or $\$ 233 / \mathrm{m}^{2}$. This is in the range of prices currently seen for this type of collector $(35,36)$.

B. Thermal Collector (Medium Temperature, Future Technology)

The materials costs for the Brookhaven thin-film collector have been estimated (37) and are shown in Table 9. This collector is based on the use of a thin-film laminate absorber and a thin-film glazing attached to a lightweight bent-metal frame. The thin films are stressed in a monocoque construction which adds structural strength to the panel. The absorber consists of two sheets of laminate material. Each sheet has a thin layer of a high-temperature plastic such as Du Pont Tefzel laminated to a layer of aluminum 
Table 9

Materials Costs for Future Technology Thermal Collector ( 4 x 8-ft Panel)

\begin{tabular}{lc}
\hline \multicolumn{2}{l}{ Cost } \\
\hline Frame & $\$ 4.80$ \\
Glazing film-Tedlar PVF & 8.95 \\
$\quad 0.004$ in. \$0.28/ft & \\
Absorber heat exchanger laminate & 17.92 \\
$\quad$ Tefzel/aluminum $\$ 0.56 / \mathrm{ft}^{2}$ & 12.80 \\
Adhesive, fasteners, insulation & 0.64 \\
Honeywell selective paint & $\$ 45.12$ \\
Total & \\
\hline
\end{tabular}

foil. The aluminum foil provides lateral heat transfer so that incomplete wetting can be tolerated, it provides good elastic rigidity, and because of its thermal conductivity it helps to prevent a non-uniform temperature distribution with resulting "hot spots" under stagnation. It also provides a good substrate for the selective coating. The plastic layer provides tear resistance, keeps the heat transport water away from the aluminum to prevent corrosion, and can provide a thermally nonconductive point of attachment to the collector frame. The heat transport water is introduced at the top of the panel through a manifold, flows by gravity between the twin sheets of the absorber, and emerges at the bottom into an exit manifold or trough. A lowcost selective coating under development by Honeywell Corporation under a U.S. Department of Energy contract (38) is projected to be used in this design.

\section{Thermal BoS (Medium Temperature, Current Technology)}

Overall balance-of-system costs given in the two reports for space heating/DHW systems and for hot water only systems are shown in Table 10, in terms of cost per square foot of collector. Note that these numbers refer to freeze-protected systems. In tropical and subtropical areas where freeze protection is not needed, solar DHW systems are considerably cheaper. For hot-water-only systems (Figure 5) there is a significant difference but for space heating/DHW systems (Figure 6) the two reports are in close agreement. 
appears to include it. Other differences may be due to variations in system configuration and component sizing. Overall, the Booz Allen estimate for BOS is $\sim 20 / \mathrm{ft}^{2}$ while the Continental report gives numbers ranging from $\$ 24$ to $\$ 40 / \mathrm{ft}^{2}$. Prices for solar DHW systems have been creeping upward, and $\$ 3000$ appears to be an average price in the northeastern United States. This would correspond to $\$ 50 / \mathrm{ft}^{2}$ for the system. With the collector cost estimated at $\sim \$ 22 / \mathrm{ft}^{2}$, this would correspond to a BOS cost of $\sim \$ 28 / \mathrm{ft}^{2}$. Al1 things considered, this value, or $\$ 300 / \mathrm{m}^{2}$, is thought to represent fairly well the thermal BOS cost for a solar DHW system. For the space heating/DHW system, no explicit breakout was given in the Continental report. The Booz Allen breakout is shown in Table 12 .

Table 12

Thermal BOS Component Costs for

Space Heating/DHW System, Current Technology

\begin{tabular}{lc}
\hline Item & Booz Allen $(34), 300-\mathrm{ft}^{2}$ Collector \\
\hline Storage & $\$ 2275$ \\
Pumps (4) & 579 \\
Piping & 1907 \\
Heat exchangers & 398 \\
Valves and controls & 643 \\
Misc. & 0 \\
$\quad$ Total & $\$ 5802$ \\
Cost per ft & $\$ 19.34$ \\
\hline
\end{tabular}

The overall totals given in the Booz Allen and the Continental reports are in close agreement (Table 10), and the thermal Bos cost for space heating/DHW systems was taken as their mean, $\$ 19.67 / \mathrm{ft}^{2}$ or $\$ 212 / \mathrm{m}^{2}$.

D. Therma1 BoS (Medium Temperature, Future Technology)

The use of nonpressurized thin-film collectors operating in an automatic (open drop) drainback mode with ordinary water as the heat transport fluid can make possible some significant cost reductions in the balance-of-system as well. Specifically, storage costs may be reduced by using a vented, plastic-lined vessel either made of concrete (39) or built like an above-ground swimming pool. The heat exchanger normally used between the collector and storage can be eliminated. The number of pumps can be reduced. 
The use of plastic piping becomes a possibility because the system is not pressurized and cannot experience temperature excursions above $100^{\circ} \mathrm{C}$ as could a pressurized system. Some progress in reducing the price of system controls may be experienced. A preliminary estimate of the potential for these cost. reductions has been developed. Table 13 shows estimated BOS

Table 13

Therma1 Balance-of-System Component Costs for Domestic Hot Water System, for $60-\mathrm{ft}^{2}$ Collector, Future Technology

\begin{tabular}{|c|c|c|c|c|}
\hline Item & Remarks & $\begin{array}{l}\text { Cost to } \\
\text { System } \\
\text { Manufacturer }\end{array}$ & $\begin{array}{l}\text { Market } \\
\text { Ratio }\end{array}$ & $\begin{array}{l}\text { Installed } \\
\text { Price }\end{array}$ \\
\hline Storage & $\begin{array}{l}\text { Sheet metal, } \\
\text { plastic liner, } \\
\text { insulation }\end{array}$ & $\$ 70$ & 3.5 & $\$ 245$ \\
\hline Pump & One only & 25 & 2.5 & 60 \\
\hline Piping & $\begin{array}{l}30^{\prime} 1 / 2 " \text { " CPVC, } \\
30^{\prime} 1 \text { " CPVC, } \\
\text { insulation }\end{array}$ & $\begin{array}{l}20 \\
80\end{array}$ & $\begin{array}{l}2.5 \\
2.5\end{array}$ & $\begin{array}{r}50 \\
200\end{array}$ \\
\hline Heat exchanger & $\begin{array}{l}100^{\prime} 1 / 2 " \mathrm{Cu}, \\
\text { coil immersed }\end{array}$ & 30 & 3.5 & 105 \\
\hline Controller & & 40 & 2.5 & 100 \\
\hline Check valve & & 10 & 2.5 & 25 \\
\hline Misc. & $10 \%$ & & & 140 \\
\hline Total & \multicolumn{3}{|c|}{$=\$ 15.42 / \mathrm{ft}^{2}$ or $\$ 166 / \mathrm{m}^{2}$} & $\$ 925$ \\
\hline
\end{tabular}

component costs for the hot water system (Figure 7), and Table 14 shows those for the space heating/DHW system (Figure 8). A market ratio of 2.5 was used for items that come in manufactured form ready for use on the job site; a ratio of 3.5 was used where factory or on-site fabrication of more basic materials is required. An allowance of $15 \%$ for contingency/estimation error/ miscellaneous was used to provide a margin of safety in the estimates. These estimates result in potentially achievable thermal Bos installed costs of $\$ 166 / \mathrm{m}^{2}$ for hot-water-only systems and $\$ 75 / \mathrm{m}^{2}$ for space heat/DHW systems.

E. PV Collector

The installed cost of the PV collector was taken from the DOE PV program goal for 1986 (31). This cost is $\$ 1.12$ per peak watt ( $\$ / W p)$ plus $\$ 0.11 / W p$ as 
Table 10

Overal1 Thermal Balance-of-System Costs,

Medium Temperature, Current Technology, in $\$ / \mathrm{ft}^{2}$ of Collector

\begin{tabular}{|c|c|c|}
\hline System Type & Continental (33) & Booz Allen (34) \\
\hline $\begin{array}{l}\text { Hot water only } \\
\text { Space heat/hot water }\end{array}$ & $\begin{array}{l}\$ 30-40 / \mathrm{ft}^{2 *} ; \$ 24 / \mathrm{ft}^{2 * *} \\
\$ 20 / \mathrm{ft}^{2} \text { (based on } 375 \mathrm{ft}^{2} \text { ) }\end{array}$ & $\begin{array}{l}\$ 20.60 / \mathrm{ft}^{2} \text { (based on } 60 \mathrm{ft}^{2} \text { ) } \\
\$ 19.34 / \mathrm{ft}^{2} \text { (based on } 300 \mathrm{ft}^{2} \text { ) }\end{array}$ \\
\hline
\end{tabular}

*0veral1 estimate based on stated $\$ 50-60 / \mathrm{ft}^{2}$ system cost, $\$ 20 / \mathrm{ft}^{2}$

collector cost ( $60 \mathrm{ft}^{2}$ of collector).

$* *$ Based on item-by-item breakout.

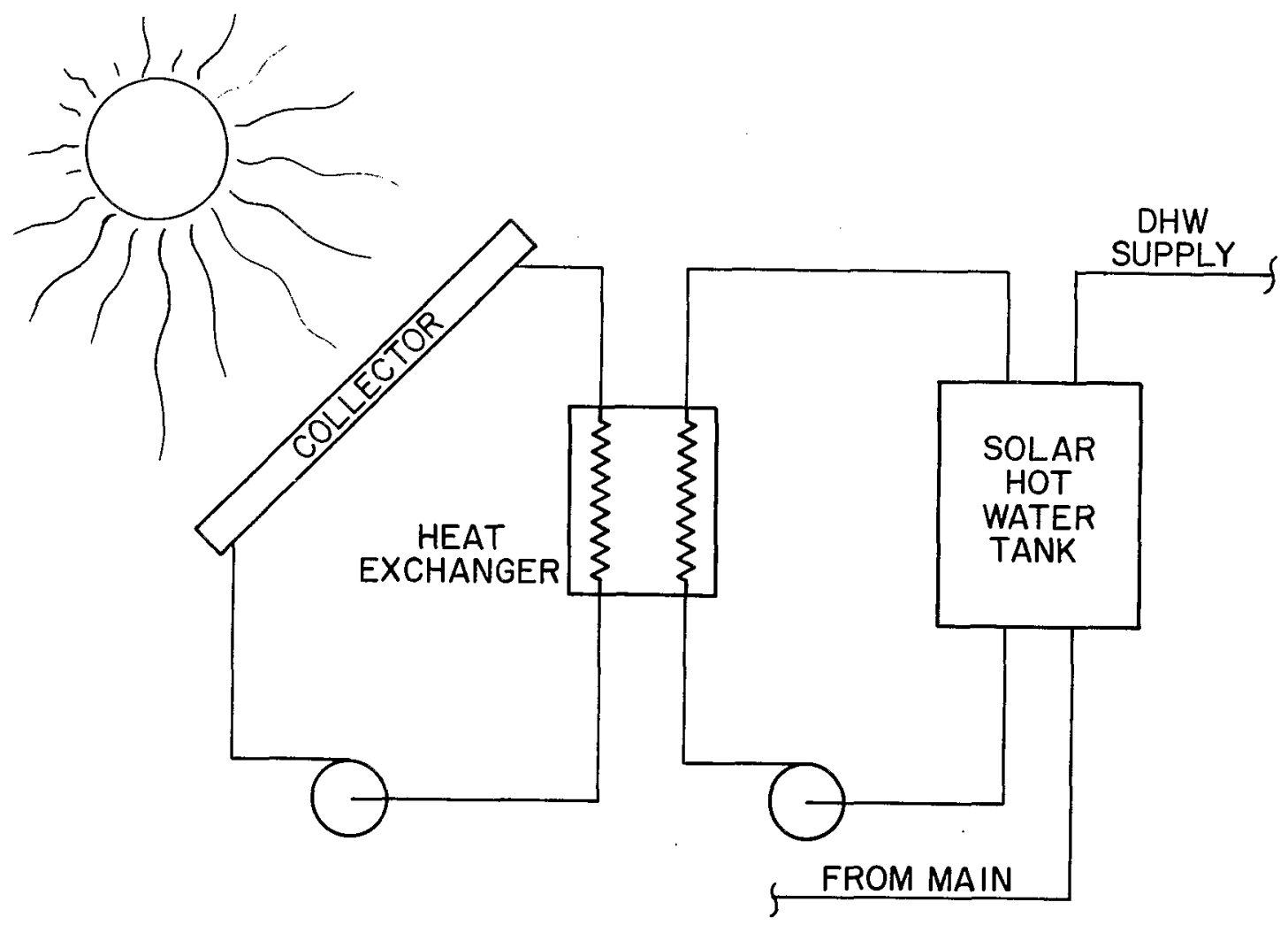

Figure 5. Hot water only system diagram (current technology).

Breakouts of BOS components for domestic hot water systems are given in Table 11. Agreement between the totals is fair, the difference being $\sim 15 \%$. However, the estimates for the individual items show considerable variation. In some cases this is explainable. For example, the Continental entry for piping clearly does not include insulation, whereas the Booz Allen estimate 
Table 11

Thermal Balance-of-System Component Costs for Domestic Hot Water System, for $60-\mathrm{ft}^{2}$ collector, Current Technology

\begin{tabular}{lcc}
\hline Item & Continental (33) & Booz Allen (34) \\
\hline Storage & $\$ 718$ & $\$ 507$. \\
Pumps (2) & 125 & 130 \\
Piping & 102 & 385 \\
Heat exchanger & Not 1 isted & 110 \\
Controls and valves & 78 & 104 \\
Misc. and other & 418 & 0 \\
$\quad$ Total & $\$ 1441$ & $\$ 1236$ \\
Cost per ft & $\$ 24.02$ & $\$ 20.60$ \\
\hline
\end{tabular}

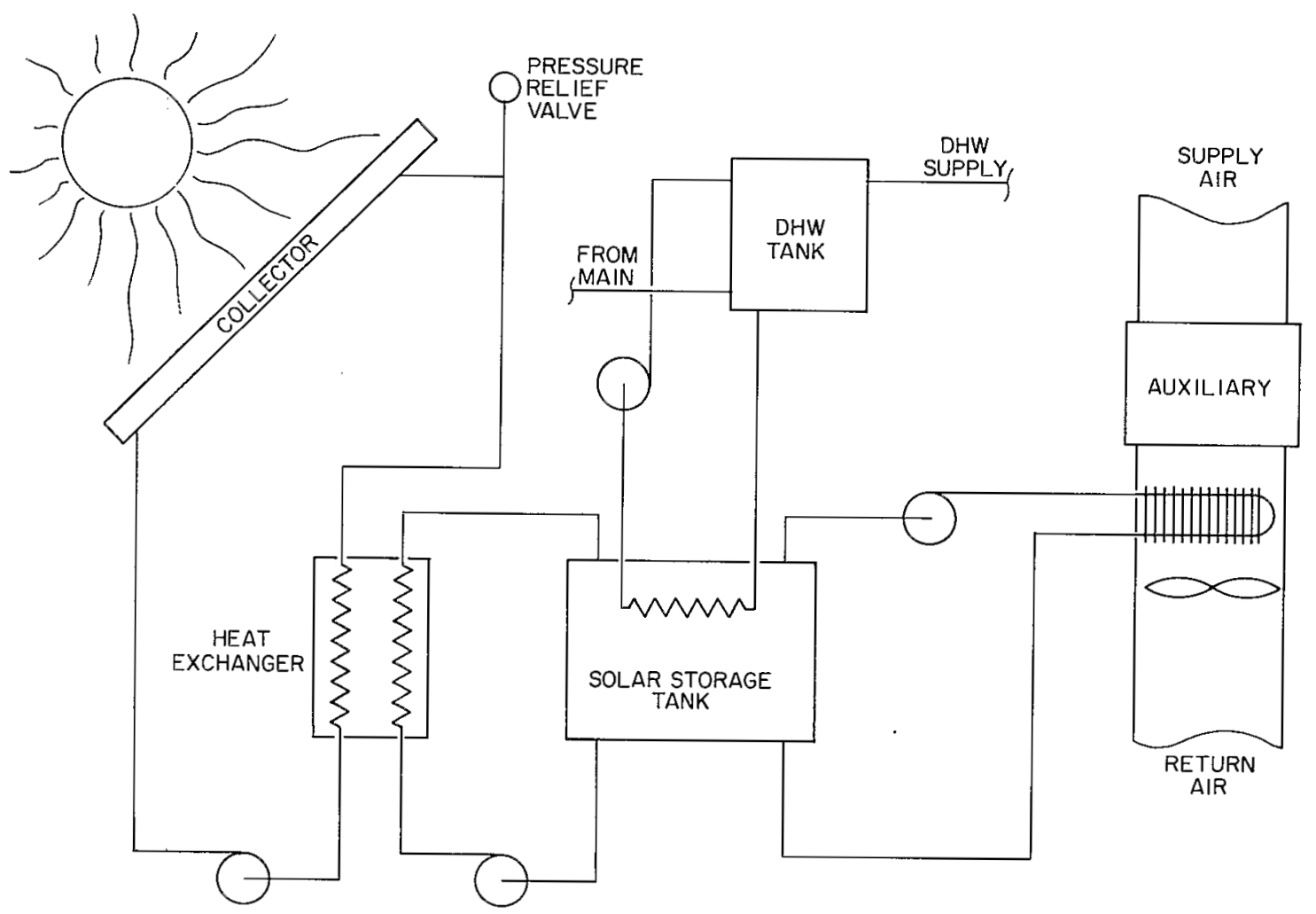

Figure 6. Space heating/DHW system diagram (current technology). 
Table 14

Thermal Balance-of-System Component Costs for Space Heating/DHW System, for $400 \mathrm{ft}^{2}$ Collector, Future Technology

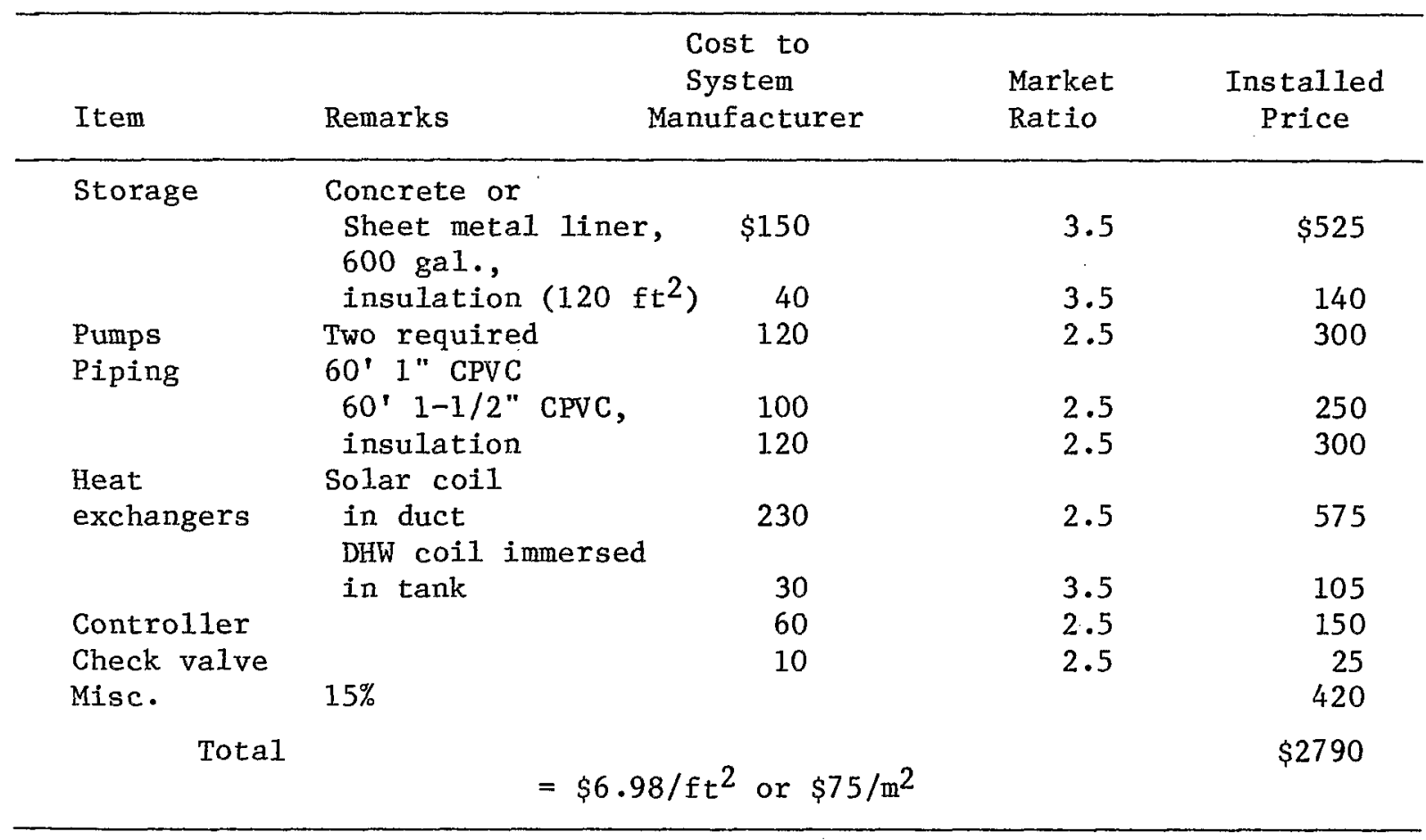

the prorated portion of indirect costs allocated to the collector, or $\$ 1.23 / \mathrm{Wp}$. At $10 \%$ nominal array efficiency and $1000 \mathrm{~W} / \mathrm{m}^{2}$ peak intensity, this is equivalent to $\$ 123 / \mathrm{m}^{2}$.

F. PV BOS

The PV BOS installed cost $(\underline{31)}$ is $\$ 0.34 / \mathrm{Wp}$ plus $\$ 0.03 / \mathrm{Wp}$ for allocated indirect costs, which is $\$ 0.37 / \mathrm{Wp}$ total. This is equivalent to $\$ 37 / \mathrm{m}^{2}$ of collector, with the same conversion procedure used as in the preceding section.

G. PV/T Collector

In order to evaluate the expected cost of a PV/T collector, two questions have been addressed:

1. Are there any savings to be realized on the $P V$ side by virtue of the $\mathrm{PV}$ being incorporated in a $\mathrm{PV} / \mathrm{T}$ collector? 


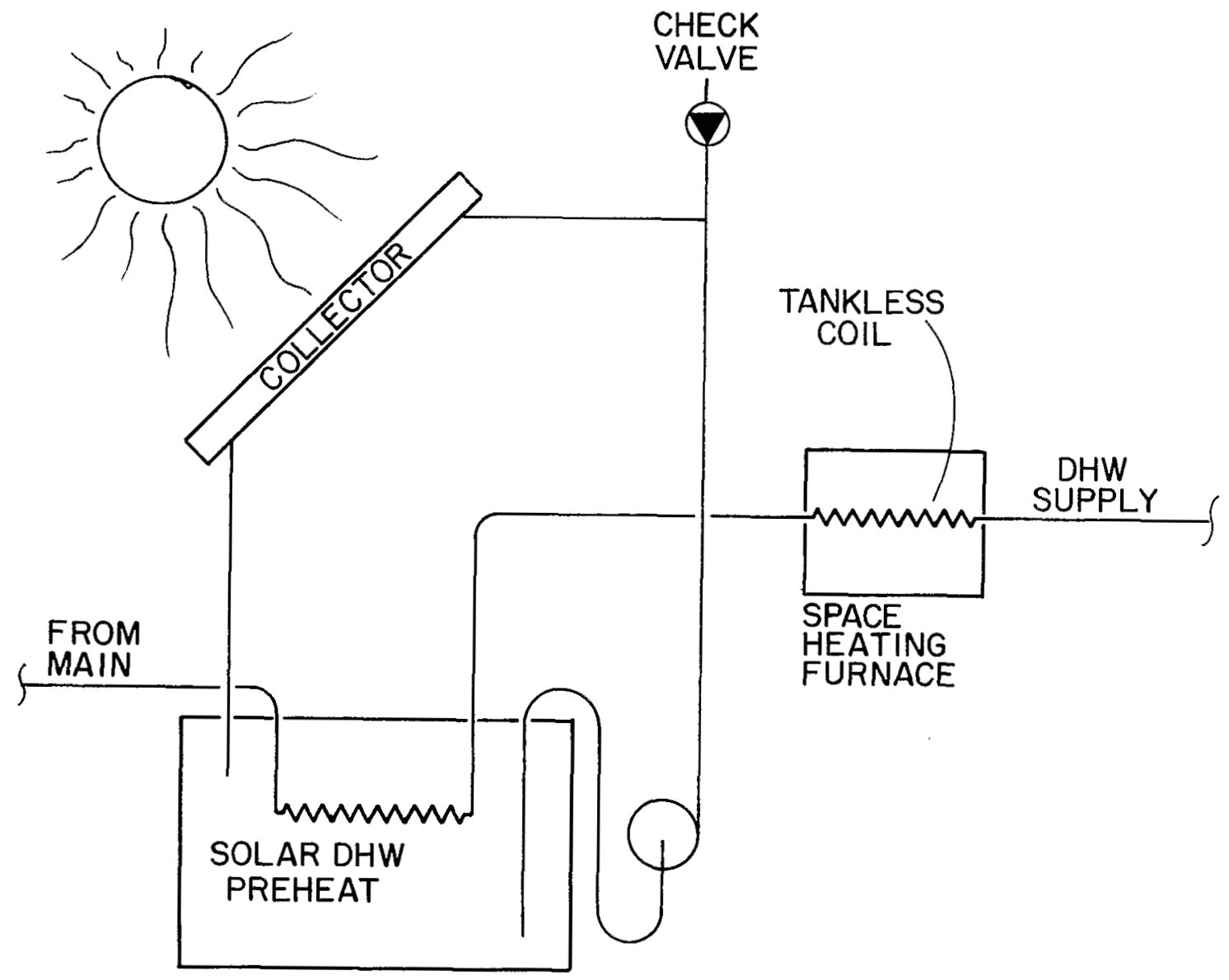

Figure 7. Hot water only system diagram (advanced technology).

2. Are there any savings to be realized on the thermal side by virtue of the thermal collection process being combined with PV in a PV/T collector?

Care must be taken not to count savings twice by charging common items like the collector frame to the thermal side in answering the first question and to the PV side in answering the second. The viewpoint taken here is that the $\mathrm{PV} / \mathrm{T}$ collector is essentially a thermal collector with attached PV cells "going along for the ride." It therefore seems unlikely that the PV/T collector will offer any savings on the thermal side. In Section VI a number of reasons why the thermal collection capability might suffer in $\mathrm{PV} / \mathrm{T}$ were discussed, such as difficulty in obtaining high absorptivity and low emissivity. It is assumed here that no savings in collector costs per unit area can be obtained on the thermal side. 


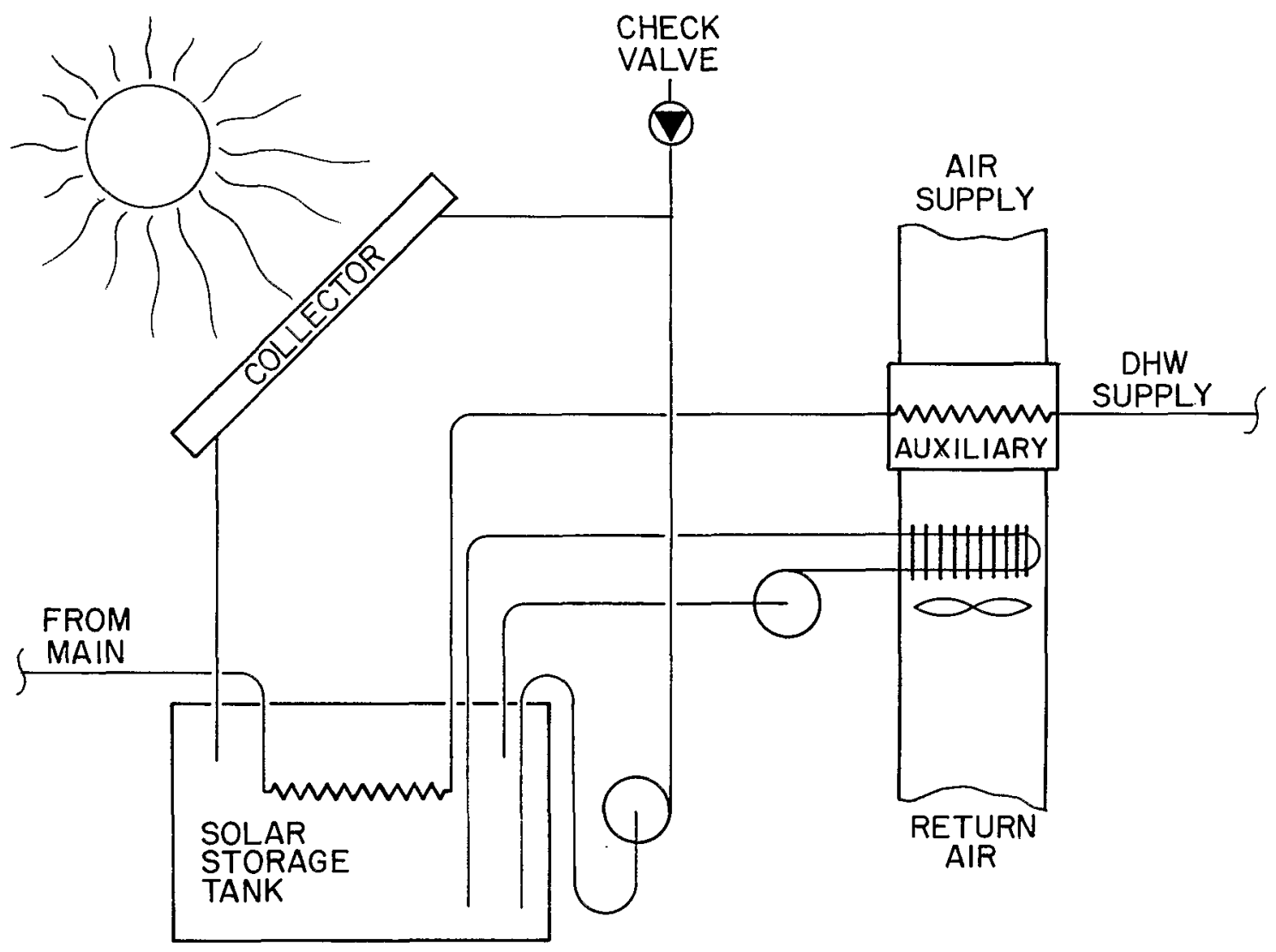

Figure 8. Space heating/DHW system diagram (advanced technology).

On the PV side, some potential savings are 1isted in Table 15 . As a result of these estimates, in computing the potential cost of $\mathrm{PV}$ in a $\mathrm{PV} / \mathrm{T}$ collector, $\$ 0.93 / \mathrm{Wp}$ or $\$ 93 / \mathrm{m}^{2}$ (rather than $\$ 1.23 / \mathrm{Wp}$ or $\$ 123 / \mathrm{m}^{2}$ ) is added to the installed cost of the thermal-only collector to obtain the installed cost of the $\mathrm{PV} / \mathrm{T}$ collector. Thus, for a current-technology medium-temperature $\mathrm{PV} / \mathrm{T}$ collector, the resulting cost is $\$ 233 / \mathrm{m}^{2}+\$ 93 / \mathrm{m}^{2}=\$ 326 / \mathrm{m}^{2}$. For the futuretechnology medium-temperature $\mathrm{PV} / \mathrm{T}$ collector, the cost is $\$ 53 / \mathrm{m}^{2}+\$ 93 / \mathrm{m}^{2}=$ $\$ 146 / \mathrm{m}^{2}$. This estimate may be low in that the $\$ 93 / \mathrm{m}^{2}$ was predicated in part on sharing the marketing and distribution costs with the thermal subsystem, and $\$ 53 / \mathrm{m}^{2}$ leaves little leeway for such sharing; nevertheless, it is allowed to stand, as a lower limit. 
Table 15

PV Savings in PV/T Collector as Against PV-Only ( $\$ / \mathrm{Wp})$

\begin{tabular}{|c|c|c|c|}
\hline Item & PV-0n1y (31) & $\mathrm{PV}$ in $\mathrm{PV} / \mathrm{T}$ & Explanation of Difference \\
\hline $\begin{array}{l}\text { PV collector, } \\
\text { FOB mfg. }\end{array}$ & 0.70 & 0.65 & $\begin{array}{l}\text { Module fabrication not } \\
\text { required (save } \$ 0.10 \text { ) } \\
\text { but cells must be } \\
\text { secured to absorber (add } \\
\$ 0.05) \text {. }\end{array}$ \\
\hline $\begin{array}{l}\text { Marketing and } \\
\text { distribution }\end{array}$ & 0.21 & 0.10 & $\begin{array}{l}\text { Half these costs borne by } \\
\text { thermal side of system }\end{array}$ \\
\hline Installation & 0.17 & 0.03 & $\begin{array}{l}\text { Not much more expensive } \\
\text { to install } \mathrm{PV} / \mathrm{T} \text { than } \mathrm{T}- \\
\text { only ( } \$ 0.03 \text { for minor } \\
\text { variation). }\end{array}$ \\
\hline Field wiring & 0.04 & 0.04 & Same. \\
\hline Subtotal & 1.12 & 0.82 & \\
\hline $\begin{array}{l}\text { Allocated portion } \\
\text { of indirects }\end{array}$ & 0.11 & 0.11 & Same. \\
\hline Tota1 & 1.23 & 0.93 & \\
\hline
\end{tabular}

H. Summary: Medium-Temperature Applications

The cost estimates obtained in the foregoing sections are summarized in Table 16.

I. Incremental System Costs: Medium Temperature Applications

It is now possible to calculate the incremental system costs defined earlier:

1. Cost of PV/T over PV only.

2. Cost of PV/T over thermal only.

3. Ratio of $\mathrm{PV} / \mathrm{T}$ cost to side-by-side $\mathrm{PV}+\mathrm{T}$ cost.

These costs are shown in Table 17. Note that in the second case, cost of PV/T over thermal-only, the value is the same for all systems. In each system the incremental cost is the $\$ 37 / \mathrm{m}^{2}$ for the PV BOS plus the $\$ 93 / \mathrm{m}^{2}$ cost of adding $\mathrm{PV}$ to the thermal collector to make a PV/T collector. The wide variation of numbers in the first case, cost of $\mathrm{PV} / \mathrm{T}$ over $\mathrm{PV}$-on $1 \mathrm{y}$, is due to the wide variation in thermal collector and BOS costs from system to system. 
Table 16

Summary of Subsystem Costs, Medium-Temperature Applications

\begin{tabular}{llr}
\hline Subsystem & Technology & Installed Cost $\left(\$ / \mathrm{m}^{2}\right)$ \\
\hline Thermal collector & Current & 233 \\
& Future & 53 \\
Therma1 BOS - DHW & Current & 300 \\
& Future & 166 \\
Therma1 BOS - space & Current & 212 \\
heat/DHW & Future & 75 \\
PV Collector & 1986 Residential & 123 \\
PV BOS & 1986 Residential & 37 \\
PV/T collector & Thermal-Current & 326 \\
& Thermal-Future & 146 \\
\hline
\end{tabular}

The numbers in Table 17 will be used in Section VIII to evaluate the economic attractiveness of $\mathrm{PV} / \mathrm{T}$ for medium-temperature applications.

J Low Temperature Applications: Unglazed Swimming Pool Systems

The economic potential of $\mathrm{PV} / \mathrm{T}$ systems utilizing unglazed collectors operating at low temperatures was also analyzed. Such applications would mitigate some of the drawbacks encountered at higher temperatures, such as the effect of the glazing in reducing incident radiation, the loss of cell efficiency at higher temperatures, and the loss of selectivity likely to be encountered in a PV/T absorber. The principal application of unglazed collectors at present is for heating swimming pools. Such systems generally use low-cost plastic collectors and have low BOS costs because no storage is needed and they have no complex central modes or flow routings. Installed collector costs tend to run $\sim \$ 6 / \mathrm{ft}^{2}$ and the balance-of-system $\sim \$ 2 / \mathrm{ft}^{2}$ installed (40). These costs are equivalent to $\$ 65 / \mathrm{m}^{2}$ and $\$ 22 / \mathrm{m}^{2}$ respective1y. To estimate the cost of an unglazed PV/T collector, the $\$ 93 / \mathrm{m}^{2}$ incremental PV cost is added to the $\$ 65 / \mathrm{m}^{2}$ thermal collector cost to obtain a $\$ 158 / \mathrm{m}^{2} \mathrm{PV} / \mathrm{T}$ collector cost. PV collector and BOS costs remain at $\$ 128 / \mathrm{m}^{2}$ and $\$ 37 / \mathrm{m}^{2}$ respectively. By using these values, it is possible to prepare a table of incremental costs similar to Table 17, but with only one entry for each case rather than four since one technology and one system application have been considered rather than two of each. The values obtained, shown in Table 18, will be used in section VIII to evaluate the economics of a PV/T swimming pool system. 
Table 17

Incremental System Costs, Medium Temperature Applications, $\$ / \mathrm{m}^{2}$ Collector

\begin{tabular}{|c|c|c|c|c|}
\hline & & \multirow[b]{2}{*}{ Application } & \multicolumn{2}{|c|}{ Technology } \\
\hline & & & Current & Advanced \\
\hline I. & $\begin{array}{l}\text { Cost of } \mathrm{PV} / \mathrm{T} \text { over } \mathrm{PV} \text {-only } \\
(\mathrm{PV} / \mathrm{T} \operatorname{col} 11+\mathrm{T} \text { box }-\mathrm{PV} \operatorname{col} 1)\end{array}$ & $\begin{array}{l}\text { Hot water only } \\
\text { Space heat/DWH }\end{array}$ & $\begin{array}{l}503 \$ / \mathrm{m}^{2} \\
415\end{array}$ & $\begin{array}{r}189 \\
98\end{array}$ \\
\hline II. & $\begin{array}{l}\text { Cost of } \mathrm{PV} / \mathrm{T} \text { over thermal-on1y } \\
(\mathrm{PV} / \mathrm{T} \operatorname{col} 1+\mathrm{PV} \text { box }-\mathrm{T} \operatorname{col1})\end{array}$ & $\begin{array}{l}\text { Hot water on1y } \\
\text { Space heat/DHW }\end{array}$ & $\begin{array}{l}130 \$ / \mathrm{m}^{2} \\
130\end{array}$ & $\begin{array}{l}130 \\
130\end{array}$ \\
\hline III. & $\begin{array}{l}\text { Ratio of } \mathrm{PV} / \mathrm{T} \text { cost to } \\
\text { cost of side-by-side } \mathrm{PV}+\mathrm{T} \\
\frac{(\mathrm{PV} / \mathrm{T} \operatorname{col} 1+\mathrm{PV} \text { bos }+\mathrm{T} \text { bos })}{(\mathrm{PV} \operatorname{col} 1+\mathrm{T} \operatorname{col} 1+\mathrm{PV} \text { bos }+\mathrm{T} \text { b }}\end{array}$ & $\begin{array}{l}\text { Hot water only } \\
\text { Space heat/DHW } \\
\text { bos) }\end{array}$ & $\begin{array}{l}0.96 \\
0.95\end{array}$ & $\begin{array}{l}0.92 \\
0.90\end{array}$ \\
\hline
\end{tabular}

Table 18

Incremental System Costs, Low-Temperature Applications, $\$ / \mathrm{m}^{2}$ Collector

\begin{tabular}{|c|c|c|c|}
\hline & & Application & $\begin{array}{l}\text { Technology } \\
\text { Current }\end{array}$ \\
\hline I. & $\begin{array}{l}\text { Cost of } \mathrm{PV} / \mathrm{T} \text { over } \mathrm{PV} \text { only } \\
(\mathrm{PV} / \mathrm{T} \operatorname{coll}+\mathrm{T} \text { bos }-\mathrm{PV} \operatorname{col} 1)\end{array}$ & Swimming pool & $57 \$ / \mathrm{m}^{2}$ \\
\hline II. & $\begin{array}{l}\text { Cost of } \mathrm{PV} / \mathrm{T} \text { over thermal only } \\
(\mathrm{PV} / \mathrm{T} \operatorname{coll}+\mathrm{PV} \text { bos }-\mathrm{T} \text { coll) }\end{array}$ & Swimming pool & $130 \$ / \mathrm{m}^{2}$ \\
\hline III. & $\begin{array}{l}\text { Ratio of } P V / T \text { cost to } \\
\text { cost of side-by-side } P V+T\end{array}$ & Swimming pool & 0.86 \\
\hline & $\frac{\mathrm{PV} / \mathrm{T} \operatorname{coll}+\mathrm{PV} \text { bos }+\mathrm{T} \text { bos }}{(\mathrm{PV} \operatorname{coll}+\mathrm{T} \operatorname{col} 1+\mathrm{PV} \text { bos }+\mathrm{T} \text { bos })}$ & & \\
\hline
\end{tabular}




\section{INCREMENTAL ENERGY VALUES}

In this section the energy inputs are calculated by the methods of Section III for PV/T systems as well as PV-only and thermal-only systems. Once these values are obtained, it is possible to calculate an equivalent electrical energy gain from PV/T relative to PV-only and to thermal-only. As explained in Section IV, in these calculations thermal energy is related to an amount of electrical energy equivalent in value by means of a multiplication factor $x$, the ratio of the value of thermal energy to the value of electrical energy. The value of $X$ is treated as a parameter in the analysis which follows. That is, the question is asked, "Are there any values of $\mathrm{X}$ for which $\mathrm{PV} / \mathrm{T}$ is justified economically, and, if so, do these values include those likely to be experienced in the real world?"

In order to do the calculations, weather and insolation data are needed as well as the solar collector parameters. The incident insolation values used in this study are shown in Table 19. The values for. Los Angeles and

Table 19

Summary of Incident Insolation, $\mathrm{GJ} / \mathrm{m}^{2}$

\begin{tabular}{lccc}
\hline Month & $\begin{array}{c}\text { Los Angeles } \\
\left(30^{\circ} \text { tilt }\right)\end{array}$ & $\begin{array}{c}\text { New York } \\
\left(40^{\circ} \text { ti.1t }\right)\end{array}$ & $\begin{array}{c}\text { Tampa } \\
\left(30^{\circ} \text { tilt }\right)\end{array}$ \\
\hline Jan. & 0.459 & 0.320 & 0.605 \\
Feb. & 0.491 & 0.330 & 0.582 \\
Mar. & 0.562 & 0.444 & 0.692 \\
Apr. & 0.710 & 0.502 & 0.667 \\
May & 0.600 & 0.477 & 0.683 \\
Jun. & 0.590 & 0.494 & 0.611 \\
Jul. & 0.741 & 0.564 & 0.601 \\
Aug. & 0.726 & 0.618 & 0.603 \\
Sep. & 0.613 & 0.439 & 0.603 \\
Oct. & 0.553 & 0.413 & 0.640 \\
Nov. & 0.488 & 0.291 & 0.628 \\
Dec. & 0.461 & 0.230 & 0.576 \\
Total & 6.994 & 5.122 & 7.491 \\
kWh/m ${ }^{2}$ & 1943 & 1423 & 2081 \\
Btu/ft & 615,000 & 450,000 & 660,000 \\
\hline
\end{tabular}


New York were taken from Lunde and Brown (41), and those for Tampa were calculated from data given by Wynn and Johnson (42) since Lunde and Brown gave no values for Florida. The collector parameters used are shown in Table 20. For the thermal-only medium-temperature collector, these parameters correspond approximately to those of a single-glazed selective-surface collector. The

Table 20

Collector Operating Parameters

Thermal Only

$\begin{array}{lrc}\mathrm{F}_{\mathrm{R}} & 0.80 & 0.80 \\ \tau & 0.92 & 1.0 \\ \alpha & 0.95 & 0.95 \\ \mathrm{U}_{\mathrm{L}}\left(\mathrm{kJ} / \mathrm{hr}-\mathrm{m}^{2}{ }^{\circ}{ }^{\circ} \mathrm{C}\right) & 21.85 & 80\end{array}$

PV On1y

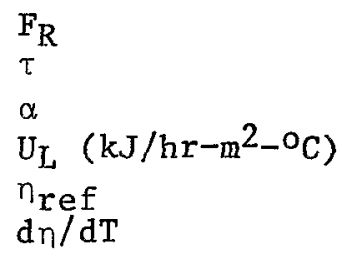

$$
\begin{aligned}
& 0 \\
& 1.0 \\
& 0.6 \\
& 80
\end{aligned}
$$

$10 \%$ at $28^{\circ} \mathrm{C}$ cell temperature $-0.0005$

$\underline{\mathrm{PV} / \mathrm{T}}$

\begin{tabular}{lrc}
$F_{\mathrm{R}}$ & 0.80 & 0.80 \\
$\tau$ & 0.92 & 0.92 \\
$\alpha$ & 0.95 or 0.85 & 0.95 or 0.85 \\
$\mathrm{U}_{\mathrm{L}}\left(\mathrm{kJ} / \mathrm{hr}-\mathrm{m}^{2}-{ }^{\circ} \mathrm{C}\right)$ & 21.85 & 80 \\
$n_{\mathrm{r} e f}$ & $10 \%$ at $28^{\circ} \mathrm{C}$ & $10 \%$ at $28^{\circ} \mathrm{C}$ \\
$\mathrm{d}_{n} / \mathrm{dT}$ & -0.0005 & -0.0005 \\
\hline
\end{tabular}

PV-only collector was simulated by setting $\tau=1$ (no glazing), $F_{R}=0$ (no heat remova1), and $\mathrm{U}_{\mathrm{L}}=80^{\circ} \mathrm{kJ} / \mathrm{hr}-\mathrm{m}^{2}{ }^{\circ} \mathrm{C}$ and $\alpha=0.60$ (passive cooling). The latter conditions result in a cell temperature $27^{\circ} \mathrm{C}$ above ambient at a peak insolation of $1000 \mathrm{~W} / \mathrm{m}^{2}$. For the PV/T collector, two cases were considered, one in which the absorptivity was the same as in the thermal-only case ( $\alpha=$ 0.95 ) and one in which the absorptivity was less $(\alpha=0.85)$. This was done to assess the impact of the the reduction in absorptivity which may be difficult or impossible to eliminate in PV/T collectors. The possible difficulty of 
higher emissivity in $P V / T$ systems was not dealt with explicitly. If this should prove to be an insurmountable problem, then $\mathrm{PV} / \mathrm{T}$ systems would be less attractive than predicted here for any applications where the collector temperature is significantly above ambient.

The PV operating characteristics include a system efficiency of $10 \%$ at $28^{\circ}$ cell temperature and a temperature coefficient of efficiency of -0.0005 per ${ }^{\circ} \mathrm{C}$. Thus the cell efficiency drops to zero $200^{\circ} \mathrm{C}$ above ambient, but the cells would not be operated anywhere near that high at temperatures for reasons of cell life as well as efficiency.

A. Annua1 Energy Production-Hot Water Systems

The annual energy production for domestic hot water systems is shown in Table 21. These calculations were done with an assumed average collector temperature of $60^{\circ} \mathrm{C}$. The $\mathrm{PV}$-only and T-only values are given for comparison. In the case of $P V / T$, where the thermal energy is used to heat water, the energy produced is seen to be a function of absorptivity. As a check on the methods of section III, the value of energy produced by the therma1-on1y system was compared with that obtained from F-Chart (42), which calculates solar thermal energy collected in space heating and domestic hot water systems.

Table 21

Summary of Energy Produced (GJ/m 2 ), Hot Water Application

\begin{tabular}{lccc}
\hline & $\begin{array}{c}\text { Los Angeles } \\
\left(30^{\circ} \text { tilt }\right)\end{array}$ & $\begin{array}{c}\text { New York } \\
\left(40^{\circ} \text { tilt }\right)\end{array}$ & $\begin{array}{c}\text { Tampa } \\
\left(30^{\circ} \text { tilt }\right)\end{array}$ \\
\hline $\begin{array}{l}\text { Total incident } \\
\text { PV-Only* }\end{array}$ & 6.994 & 5.122 & 7.491 \\
T-Only & 0.643 & 0.480 & 0.671 \\
PV/T $\alpha=0.95$ & 2.459 & 1.679 & 2.945 \\
$\quad \begin{array}{l}\text { Electric } \\
\text { Thermal }\end{array}$ & 0.512 & 0.376 & 0.540 \\
PV/T $\quad \begin{array}{l}\text { Q }=0.85 \\
\quad \text { Electric } \\
\text { Thermal }\end{array}$ & 2.068 & 1.400 & 2.513 \\
\hline
\end{tabular}

*System efficiency $10 \%$ at $28^{\circ} \mathrm{C}$ cell temperature. 
The latter calculations were done for an annual hot water load of $20 \times 10^{6}$ Btu ( 21.1 GJ) partially met by a solar system having $60 \mathrm{ft}^{2}\left(5.57 \mathrm{~m}^{2}\right)$ of collector area. The solar fractions obtained by each procedure for each location are given in Table 22. The differences in annual solar fraction between the two methods range from 0 to $10 \%$. Since the accuracy of F-Chart is itself $\sim 10 \%$, the agreement is good.

Table 22

Comparison of Solar Fractions Obtained by Method of Section III (f), with those Obtained from F-Chart ( $f *$ ) (Thermal-only collector, domestic hot water, $60 \mathrm{ft}^{2}$ )

\begin{tabular}{|c|c|c|c|c|c|c|}
\hline \multirow{3}{*}{ Month } & \multirow{2}{*}{\multicolumn{2}{|c|}{ Los Angeles }} & \multirow{2}{*}{\multicolumn{2}{|c|}{$\begin{array}{l}\text { Location } \\
\text { New York }\end{array}$}} & \multirow{2}{*}{\multicolumn{2}{|c|}{ Tampa }} \\
\hline & & & & & & \\
\hline & $\mathrm{f}$ & $\mathrm{f}^{*}$ & $\mathrm{f}$ & $\overline{f^{*}}$ & $f$ & $f^{*}$ \\
\hline Jan. & 0.47 & 0.52 & 0.22 & 0.28 & 0.65 & 0.71 \\
\hline Feb. & 0.56 & 0.67 & 0.26 & 0.37 & 0.71 & 0.80 \\
\hline Mar. & 0.57 & 0.64 & 0.34 & 0.47 & 0.78 & 0.80 \\
\hline Apr. & 0.78 & 0.84 & 0.48 & 0.60 & 0.85 & 0.84 \\
\hline May & 0.65 & 0.70 & 0.52 & 0.56 & 0.87 & 0.83 \\
\hline Jun. & 0.68 & 0.73 & 0.60 & 0.64 & 0.84 & 0.80 \\
\hline Jul. & 0.85 & 0.85 & 0.72 & 0.70 & 0.81 & 0.76 \\
\hline Aug. & 0.87 & 0.84 & 0.77 & 0.75 & 0.81 & 0.76 \\
\hline Sep. & 0.73 & 0.77 & 0.54 & 0.56 & 0.82 & 0.79 \\
\hline Oct. & 0.64 & 0.63 & 0.42 & 0.47 & 0.80 & 0.78 \\
\hline Nov. & 0.54 & 0.60 & 0.25 & 0.30 & 0.75 & 0.79 \\
\hline Dec. & 0.46 & 0.53 & 0.18 & 0.16 & 0.64 & 0.68 \\
\hline Total & 0.65 & 0.69 & 0.44 & 0.49 & 0.78 & 0.78 \\
\hline
\end{tabular}

The annual energy production totals as in Table 21 show that the total energy production in the $P V / T$ system with $\alpha=0.95$ is slightly greater than the thermal energy collected in the thermal-only system. To zero order, the $\mathrm{PV} / \mathrm{T}$ collector "trades in" thermal energy for electrical energy on a one-for-one basis. More accurately, slightly more electrical energy is collected than thermal energy is given up.

With $\alpha^{\prime}=0.85$ in the $\mathrm{PV} / \mathrm{T}$ collector, less total energy is collected in the PV/T system than in the baseline thermal-only system with $\alpha=0.95$. Even in this case it is possible that $\mathrm{PV} / \mathrm{T}$ would be attractive, since electricity is generally more valuable than thermal energy. The viability of $P V / T$ is addressed in a later part of this section. 
B. Annual Energy Production - Space Heating/DHW

The use of $\mathrm{PV} / \mathrm{T}$ for combined space heating/DHW was examined in New York. The other two locations were judged to have space heating loads too low to be of interest. Rather than keying the simulation to a specfic heating load, it was assumed that the collectors operating at $40^{\circ} \mathrm{C}$ were fully utilized in November through April, and that in May through October there was no heating load and a hot water load of $0.05 \mathrm{GJ}$ per month per square meter of collector, which was fully met. This would correspond to a monthly hot water load of 1.7 GJ for a $34-\mathrm{m}^{2}$ system. These assumptions involve approximations, but, since the objective is to cross-compare the various systems, these approximations were judged to be adequate. The annual energy production figures are shown in Table 23. Note that in this case the total energy produced by $P V / T$ with $\alpha=0.95$ is significantly greater than that produced by the thermal-only system. This is because the thermal collection capability is underutilized inthe summer and therefore electricity produced by the PV during that time does not detract from the thermal energy actually used. How this affects the analysis will be seen shortly.

Table 23

Summary of Energy Produced (GJ/m²), Space Heating/DHW

\begin{tabular}{lc} 
& New York $\left(40^{\circ}\right.$ tilt $)$ \\
\hline Total Incident & 5.122 \\
PV Only & 0.480 \\
T On1y* & 1.139 \\
PV $/ \mathrm{T}, \alpha=0.95$ & \\
Electric & 0.389 \\
Thermal* & 1.003 \\
PV T $\alpha=0.85$ & 0.394 \\
Electric & 0.860 \\
Thermal* & \\
\hline
\end{tabular}

*Thermal energy utilized Nov.-Apr. for space heat/DHW year round. 
C. Annual Energy Production - Swimming Pool Heating

The annual energy production in the swimning pool application was calculated for a collector operating temperature of $25^{\circ} \mathrm{C}$. It was assumed that in Los Angeles heat from the collectors was fully utilized in November through May and not needed at all the rest of the year; in New York, heat was fully utilized in April through June and in September and october and not at all in the other months; and in Tampa heat was fully utilized in october through April and not needed the rest of the year. Information from Fafco Inc. (43) was used in making these selections. In the southern locations heat is needed in the winter to allow year-round use of the outdoor pool. In New York, the collectors are used to extend the season into spring and fall only, the winter being too $\operatorname{cold}$.

The annual energies produced by the various systems are shown in Table 24. The total energy produced by $\mathrm{PV} / \mathrm{T}$ with $\alpha=0.95$ is significantly greater than the heat produced by the thermal-only system. In this case, electricity produced during the time the thermal energy is not needed does not subtract from the thermal energy collected. This effect is similar to that observed in the space heating case, although the details are different.

\begin{tabular}{|c|c|c|c|}
\hline \multicolumn{4}{|c|}{ Summary of Energy Produced $\left(\mathrm{GJ} / \mathrm{m}^{2}\right)$, Swimming Pool Heating } \\
\hline & $\begin{array}{l}\text { Los Angeles } \\
\left(30^{\circ} \text { tilt }\right)\end{array}$ & $\begin{array}{l}\text { New York } \\
\left(40^{\circ} \text { tilt }\right)\end{array}$ & $\begin{array}{c}\text { Tampa } \\
\left(30^{\circ} \text { tilt }\right)\end{array}$ \\
\hline Total Incident & 6.994 & 5.122 & 7.491 \\
\hline PV-only & 0.643 & 0.480 & 0.671 \\
\hline T-only* & 1.962 & 1.360 & 3.017 \\
\hline \multicolumn{4}{|l|}{$\mathrm{PV} / \mathrm{T}, \quad \alpha=0.95$} \\
\hline Electic & 0.662 & 0.495 & 0.700 \\
\hline Thermal* & 1.665 & 1.177 & 2.663 \\
\hline \multicolumn{4}{|l|}{$\mathrm{PV} / \mathrm{T}, \quad \alpha=0.85$. } \\
\hline Electric & 0.667 & 0.499 & 0.704 \\
\hline Therma1* & 1.377 & 0.999 & 2.315 \\
\hline
\end{tabular}

*Nov.-May in LA; Apr.-Jun. and Sep.-Oct. in NY; Oct.-Apr. in Tampa. 


\section{Equivalent Electrical Energy Gain}

The equivalent electrical energy gain from $P V / T$ is now calculated relative to $\mathrm{PV}-o n 1 \mathrm{y}$ and to thermal-only. The equivalent electrical energy gain $E_{1}$ from $P V / T$ relative to PV-only (that is, for thermal add-on) is

$$
E_{1}=E_{e}(P V / T)-E_{e}(P V)+E_{t}(P V / T) \cdot X
$$

where $E_{e}(P V / T)$ and $E_{t}(P V / T)$ are the electrical and thermal outputs from $P V / T$, $E_{e}(P V)$ is the electrical output from the PV-only system, and $X$ is the ratio of thermal to electrical energy prices defined previously. The equivalent electrical energy gain $E_{2}$ from $P V / T$ relative to thermal-only (that is, for $P V$ add-on) is

$$
E_{2}=E_{e}(P V / T)+\left[E_{t}(P V / T)-E_{t}(T)\right] \cdot X
$$

where $E_{t}(T)$ is the thermal output from the thermal-only system. The equations for $E_{1}$ and $E_{2}$ are given in Table 25 for each of the situations of interest.

The straight lines resulting from these equations are plotted in Figures 9 through 15 (1eft-hand ordinate), with solid lines for $\alpha=0.95$ and dashed lines for $\alpha=0.85$. The equivalent electrical energy gain from adding thermal energy collection to a PV system has a negative intercept (for the mediumtemperature applications) and a positive slope. The intercept is negative because less electrical energy is collected in a PV/T collector than in a PVonly collector of equal area. If thermal energy is worthless $(X=0)$, then the equivalent electrical energy for each system is just the electrical energy itself; hence, the negative intercept represents the amount by which the $\mathrm{PV} / \mathrm{T}$ electricity production is less than that of PV only. The slope is positive because no thermal energy is collected in a PV-only system, and therefore the thermal energy collected by the PV/T represents an increasingly valuable increment as $\mathrm{X}$ increases.

The line for the equivalent electrical energy gain from adding PV to a thermal-only system has a positive intercept and a negative slope. The positive intercept shows just the electrical energy collected by the $\mathrm{PV} / \mathrm{T}$ system, since for $\mathrm{X}=0$ the equivalent electrical energy collected by the thermal-only system is zero. 
Table 25

Equivalent Electrical Energy Gain from PV/T Against

PV Only (Thermal Add-On) and Against Thermal Only (PV Add-On).

\begin{tabular}{|c|c|c|c|c|}
\hline $\begin{array}{l}\text { System } \\
\text { Type }\end{array}$ & Location & $\begin{array}{l}\text { Subsystem } \\
\text { Added On }\end{array}$ & $\begin{array}{c}\mathrm{PV} / \mathrm{T} \\
\text { Absorbtivity }\end{array}$ & $\begin{array}{l}\text { Equation For Equivalent } \\
\text { Electrical Energy Gain } \\
\quad\left(\mathrm{GJ} / \mathrm{m}^{2} \text { Collector }\right)\end{array}$ \\
\hline \multirow[t]{12}{*}{ DHW } & LA & $\mathrm{T}$ & 0.95 & $E_{1}=-0.131+2.068 X$ \\
\hline & & & 0.85 & $E_{1}=-0.126+1.611 X$ \\
\hline & & PV & 0.95 & $E_{2}=0.512-0.391 X$ \\
\hline & & & 0.85 & $E_{2}=0.517-0.848 X$ \\
\hline & $\mathrm{NY}$ & $\mathrm{T}$ & 0.95 & $E_{1}=-0.104+1.400 X$ \\
\hline & & & 0.85 & $E_{1}=-0.100+1.078 X$ \\
\hline & & PV & 0.95 & $E_{2}=0.376-0.279 X$ \\
\hline & & & 0.85 & $E_{2}=0.380-0.601 X$ \\
\hline & $\mathrm{TA}$ & $\mathrm{T}$ & 0.95 & $E_{1}=-0.131+2.513 X$ \\
\hline & & & 0.85 & $E_{1}=-0.121+2.009 x$ \\
\hline & & PV & 0.95 & $E_{2}=0.540-0.432 X$ \\
\hline & & & 0.85 & $E_{2}=0.550-0.936 X$ \\
\hline \multirow[t]{4}{*}{$\mathrm{SH} / \mathrm{DHW}$} & $\mathrm{NY}$ & $\mathrm{T}$ & 0.95 & $E_{1}=0.091+1.003 X$ \\
\hline & & & 0.85 & $E_{1}=0.086+0.860 X$ \\
\hline & & PV & 0.95 & $E_{2}=0.389+0.136 X$ \\
\hline & & & 0.85 & $E_{2}=0.394-0.279 X$ \\
\hline \multirow[t]{12}{*}{$\mathrm{SPH}$} & LA & $\mathrm{T}$ & 0.95 & $E_{1}=0.019+1.665 X$ \\
\hline & & & 0.85 & $E_{1}=0.024+1.377 X$ \\
\hline & & PV & 0.95 & $E_{2}=0.662-0.297 X$ \\
\hline & & & 0.85 & $E_{2}=0.667-0.585 X$ \\
\hline & NY & $\mathrm{T}$ & 0.95 & $E_{1}=0.015+1.177 X$ \\
\hline & & & 0.85 & $E_{1}=0.019+0.999 \mathrm{X}$ \\
\hline & & PV & 0.95 & $E_{2}=0.495-0.183 \mathrm{X}$ \\
\hline & & & 0.85 & $E_{2}=0.499-0.361 X$ \\
\hline & TA & $\mathrm{T}$ & 0.95 & $E_{1}=0.029+2.663 X$ \\
\hline & & & 0.85 & $E_{1}=0.033+2.315 X$ \\
\hline & & PV & 0.95 & $E_{2}=0.700-0.354 X$ \\
\hline & & & 0.85 & $E_{2}=0.704-0.702 X$ \\
\hline
\end{tabular}

$\mathrm{DHW}=$ domestic hot water; $\mathrm{SH} / \mathrm{DHW}=$ space heat/domestic hot water; $\mathrm{SPH}=$ swimming pool heating; LA = Los Angeles; NY = New York; TA = Tampa; $T=$ thermal add-on; $\mathrm{PV}=$ photovoltaic add-on; $\mathrm{E}_{1}$ and $\mathrm{E}_{2}$ defined in Eqs. (49) and (50).

Why the negative slope? Since this negative slope is the crux of this report's argument, it is essential that it be understood. In calculating the equivalent electrical energy gain from $\mathrm{PV} / \mathrm{T}$ relative to thermal-only, two things must be accounted for. The first is, the electricity produced by the $\mathrm{PV}$ in the $\mathrm{PV} / \mathrm{T}$ system, which is a gain for $\mathrm{PV} / \mathrm{T}$ and is represented by the positive vertical intercept. The second is the thermal energy given up in 
order to get the electrical energy. Less thermal energy is collected in the $\mathrm{PV} / \mathrm{T}$ system than in the thermal-only system. Therefore, the more valuable thermal energy becomes relative to electricity (the higher the value of $X$ ), the greater the weight of this reliquished thermal energy, and the less the net equivalent electrical energy gain. In other words, the slope of the line is negative.

E. Allowed Subsystem Incremental Cost

On each of Figures 9 through 15, the electric energy production of the PV-only system is shown on the left-hand ordinate. In Section $V$ it was argued that the allowed first cost of the PV-only system was approximately $\$ 1.60 / \mathrm{Wp}$ in each location, by the economic criterion adopted in this report. For simplicity and ease of interpretation, and because the uncertainty in electricity cost projections to 1986 exceeds by a wide margin the differences between the allowed costs obtained in section $V$ and the PV program goal of $\$ 1.60 / \mathrm{Wp}$, it was decided to peg the allowed cost of the PV-only system in each location at exact $1 \mathrm{y} \$ 1.60 / \mathrm{Wp}$. With the nomina1 $10 \%$ array efficiency and 1000 $\mathrm{W} / \mathrm{m}^{2}$ peak intensity, this translates to $\$ 160 / \mathrm{m}^{2}$ for the $\mathrm{PV}$-only system. This provides a conversion factor between equivalent electrical energy gain and allowed incremental system cost in each location:

for Los Angeles, $\$ 160 / \mathrm{m}^{2} \div 0.643 \mathrm{GJ} / \mathrm{m}^{2}=\$ 249 / \mathrm{GJ}$,

for New York, $\$ 160 / \mathrm{m}^{2} \div 0.480 \mathrm{GJ} / \mathrm{m}^{2}=\$ 333 / \mathrm{GJ}$,

for Tampa, $\$ 160 / \mathrm{m}^{2} \div 0.671 \mathrm{GJ} / \mathrm{m}^{2}=\$ 238 / \mathrm{GJ}$.

These conversion factors are used to calibrate the right hand ordinates of Figures 9 through 15, which give the allowed incremental system costs $C_{1}$ and $\mathrm{C}_{2}$ corresponding to the equivalent electrical energy gains $\mathrm{E}_{1}$ and $\mathrm{E}_{2}$. The criterion thus becomes: "Is the proposed addition of thermal energy collection to a PV-only system, or of PV to a thermal-only system, more or less attractive economically than PV itself on a stand-alone basis?"

The equations for the allowed incremental system costs $C_{1}$ and $C_{2}$ equivalent to the lines in Figures 9 through 15 are shown in Table 26 . It is possible to calculate those values of $X$ for which the allowed incremental system cost in Table 26 exceeds the estimated incremental system cost in Tables 17 or 18 (Section VII). These calculations are shown in Table 27, for 


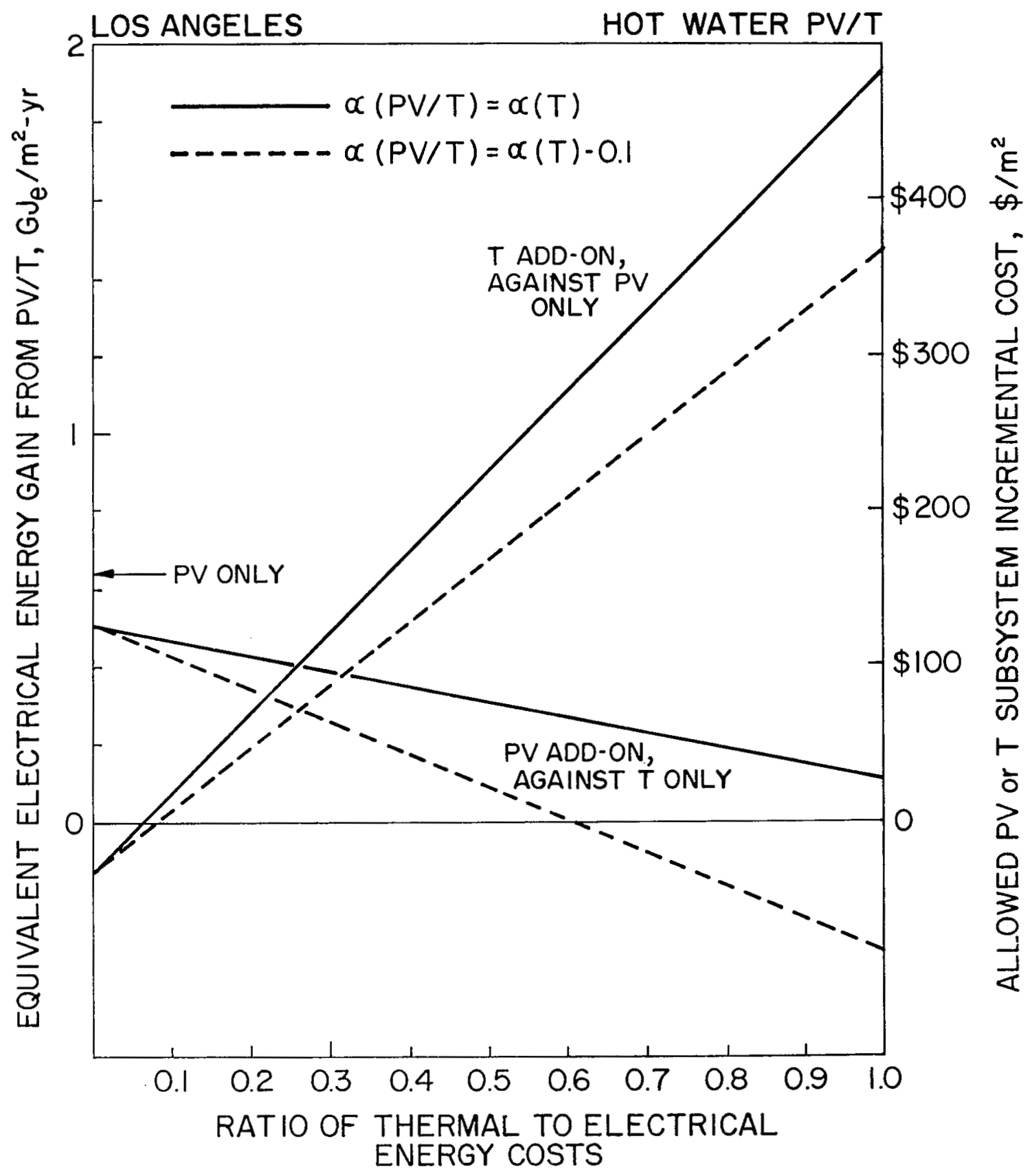

Figure 9. Equivalent electrical energy gain from $\mathrm{PV} / \mathrm{T}$, domestic hot water, Los Angeles. 


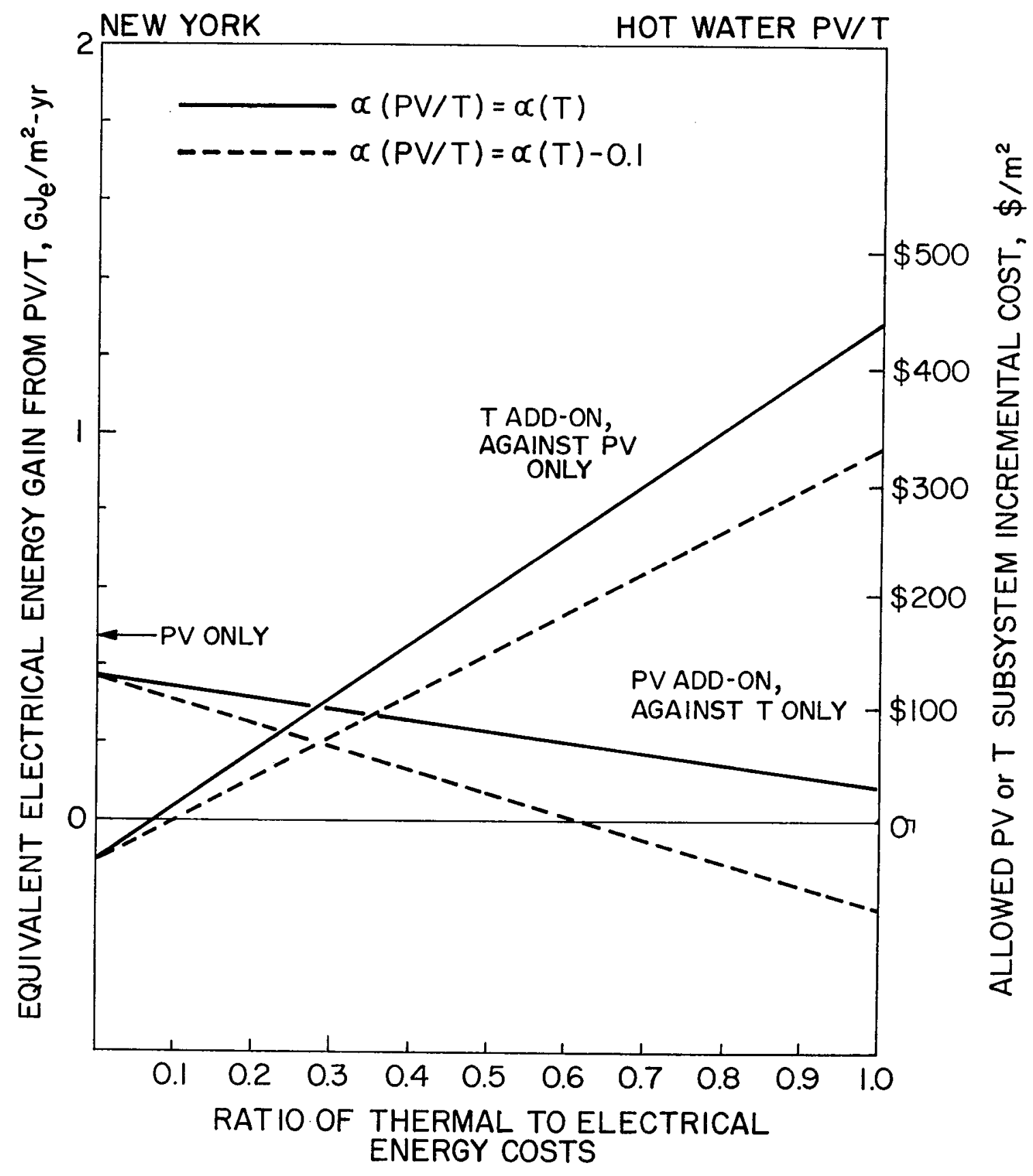

Figure 10. Equivalent electrical energy gain from $\mathrm{PV} / \mathrm{T}$, domestic hot water, New York. 


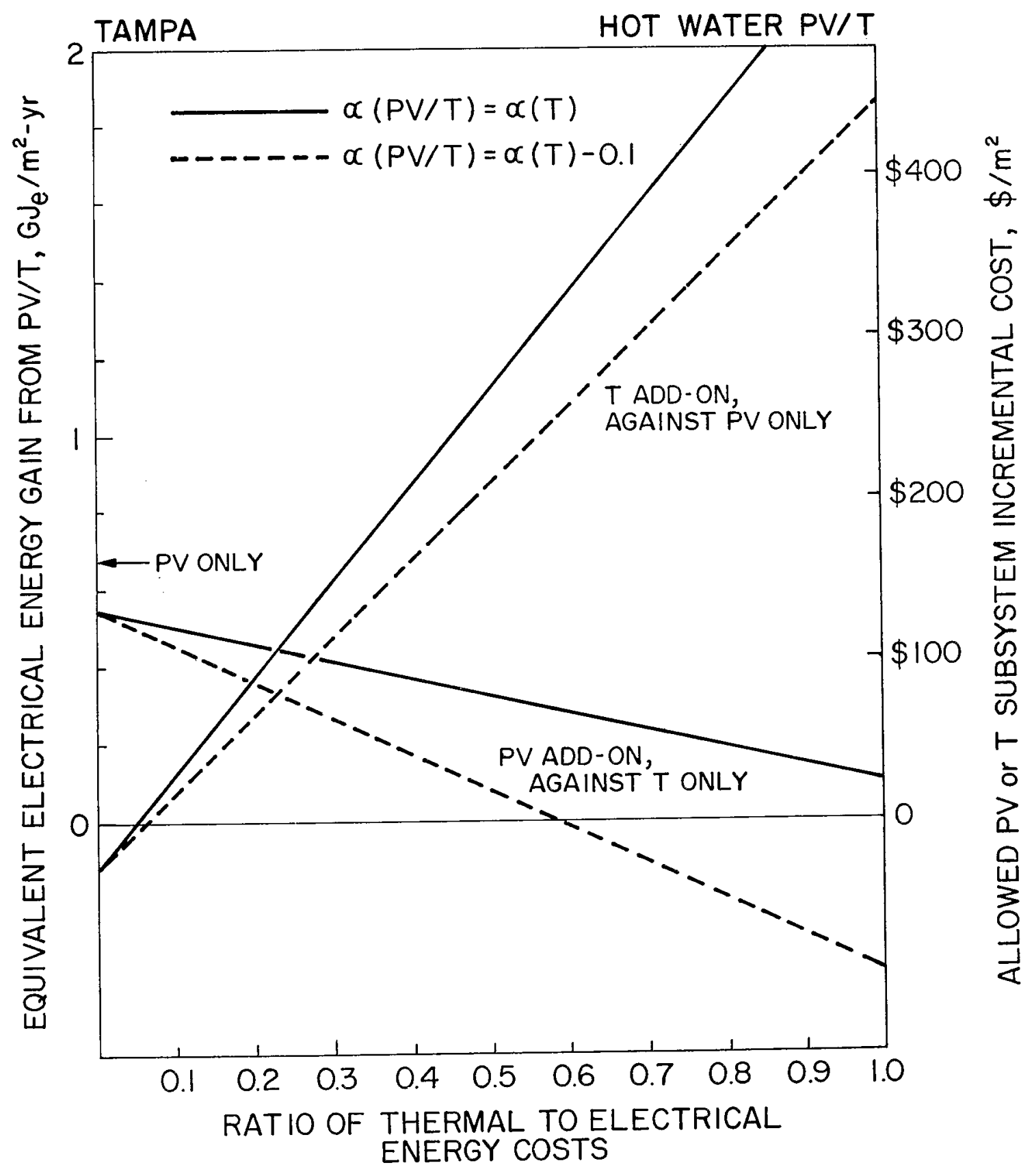

Figure 11. Equivalent electrical energy gain from $P V / T$, domestic hot water, Tampa. 


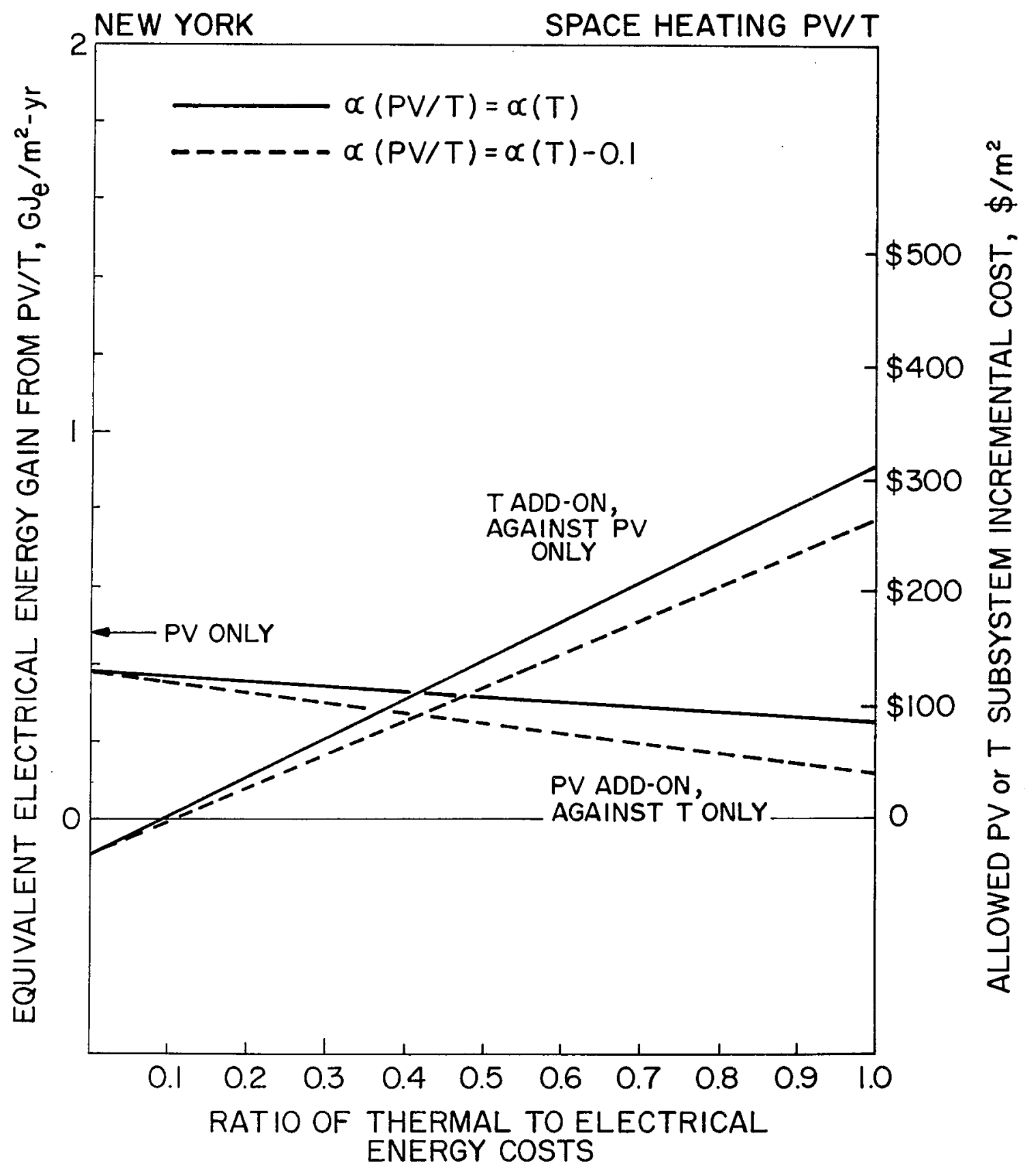

Figure 12. Equivalent electrical energy gain from PV/T, space heating/DHW, New York. 


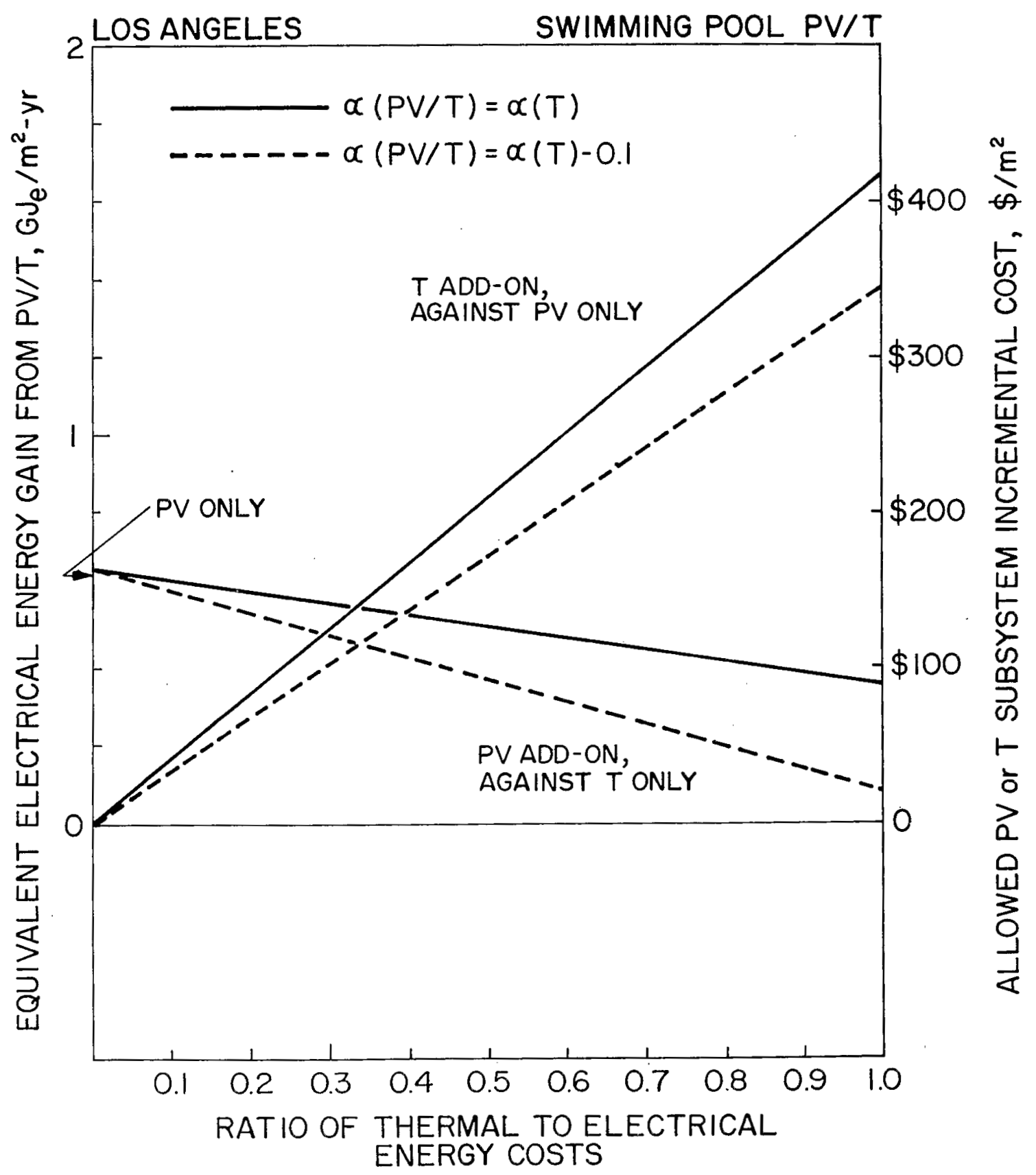

Figure 13. Equivalent electrical energy gain from $P V / T$, swimming pool heating, Los Angeles. 


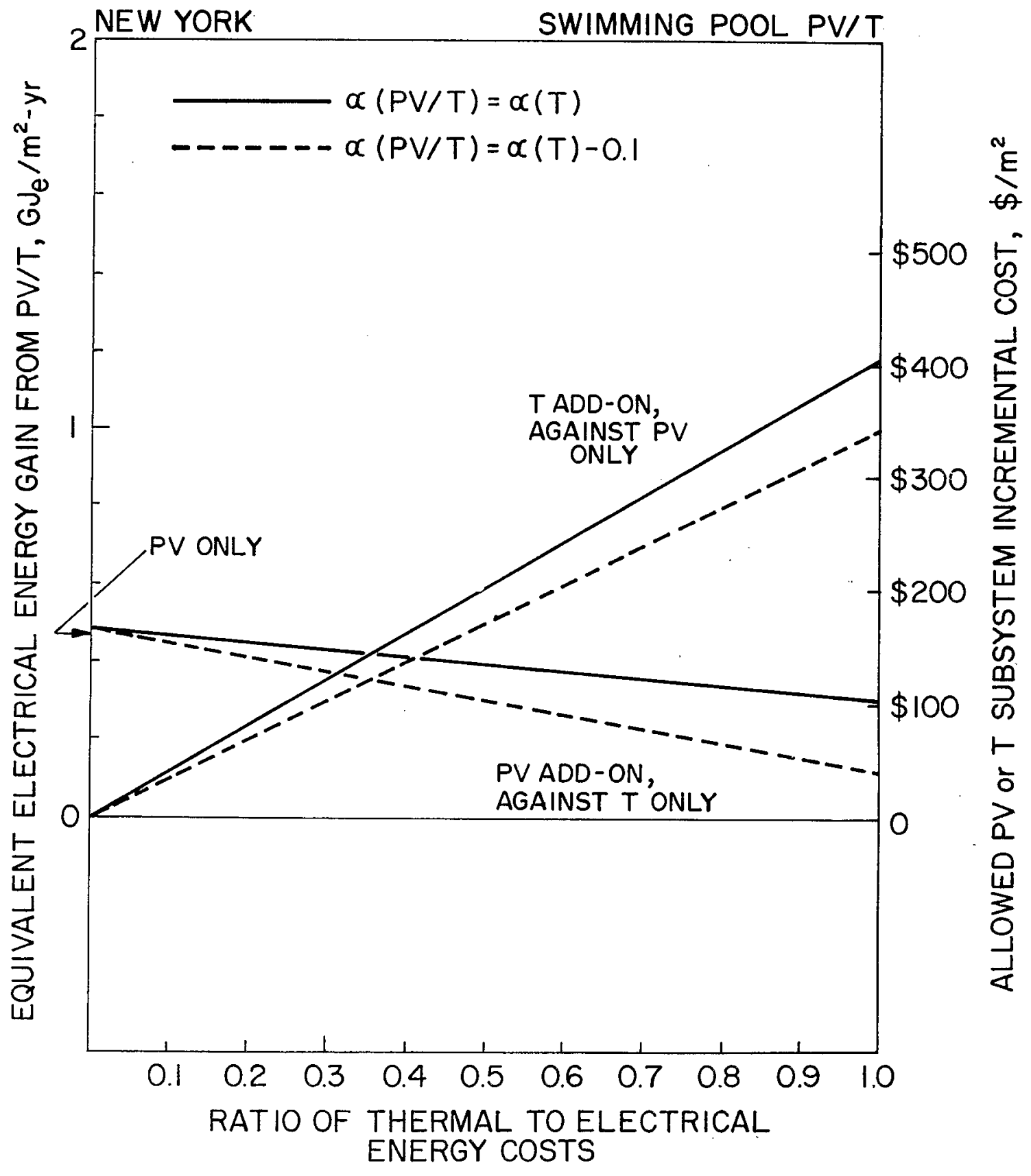

Figure 14. Equivalent electrical energy gain from PV/T, swimming pool heating, New York. 


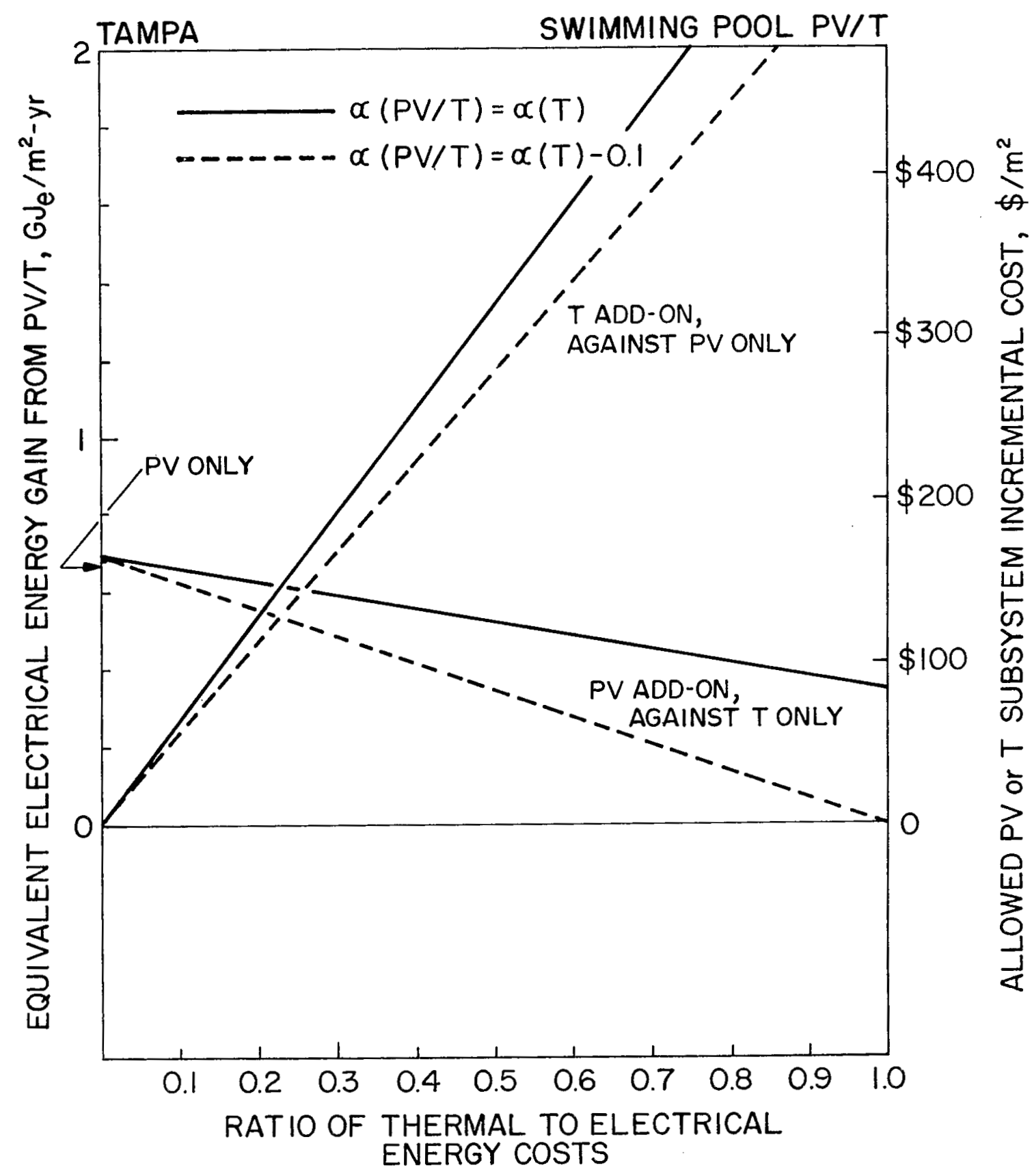

Figure 15. Equivalent electrical energy gain from PV/T, swimming pool heating, Tampa. 
Table 26

Allowed Incremental System Costs for PV/T Against

PV Only (Thermal Add-On) and Against Thermal-Only ( $N$ Add-On).

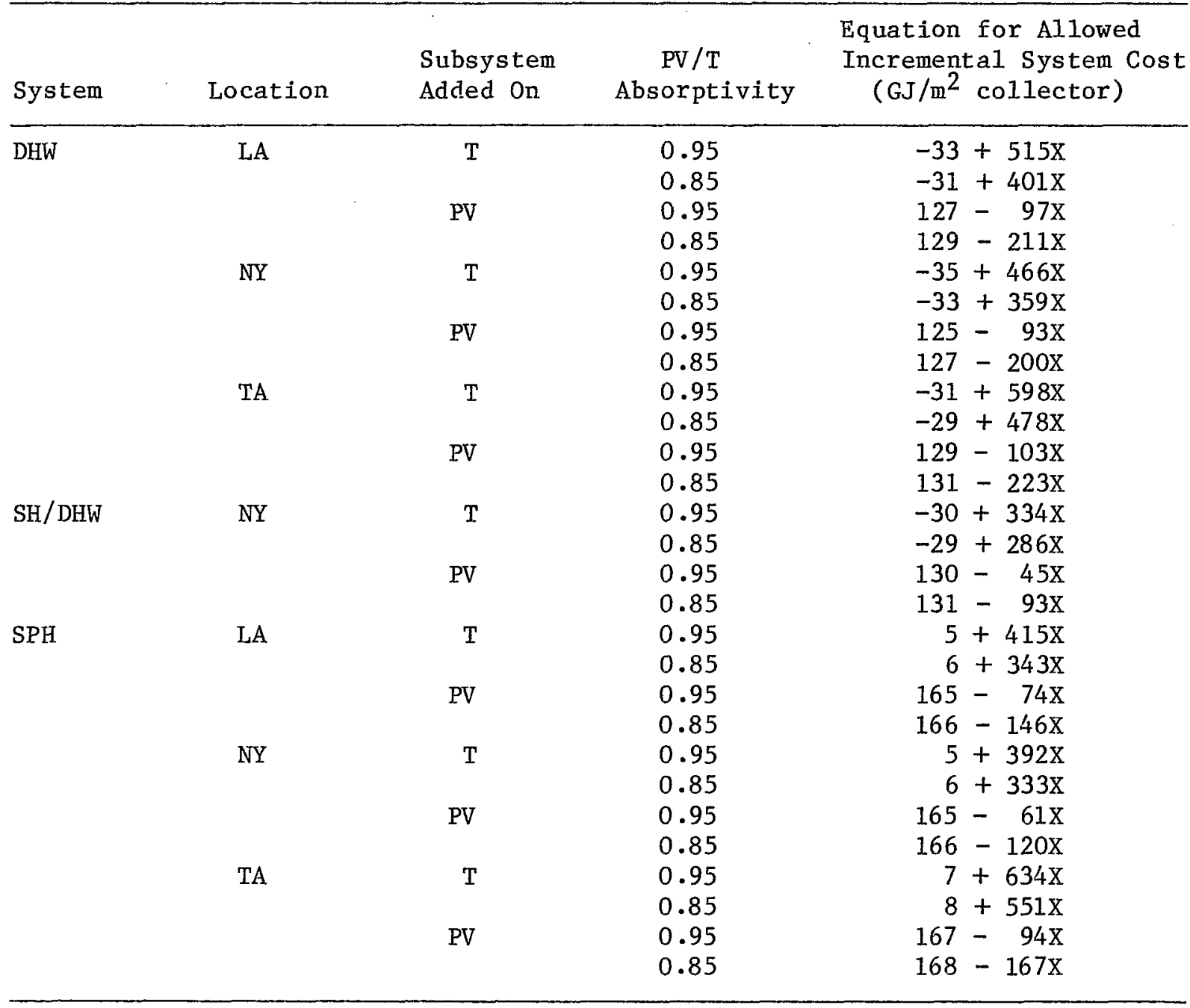

the case in which $P V / T$ absorptivity equals 0.95 . For each system in each city, the objective is to find a set of $X$ values for which both of the following are true:

1. The allowed incremental system cost for the thermal add-on exceeds the projected incremental cost for thermal add-on; and

2. The allowed incremental system cost for PV add-on exceeds the projected incrementa1 system cost for PV add-on. 


\section{Table 27}

Values of Energy Cost Ratio Parameter $X$ for Which the Allowed Incremental System Cost Exceeds the Calculated Incremental System Cost, for PV/T Against PV-Only (Thermal Add-On) and Against Thermal-Only (PV Add-On) $\mathrm{PV} / \mathrm{T}$ Absorbtivity $=0.95$ )

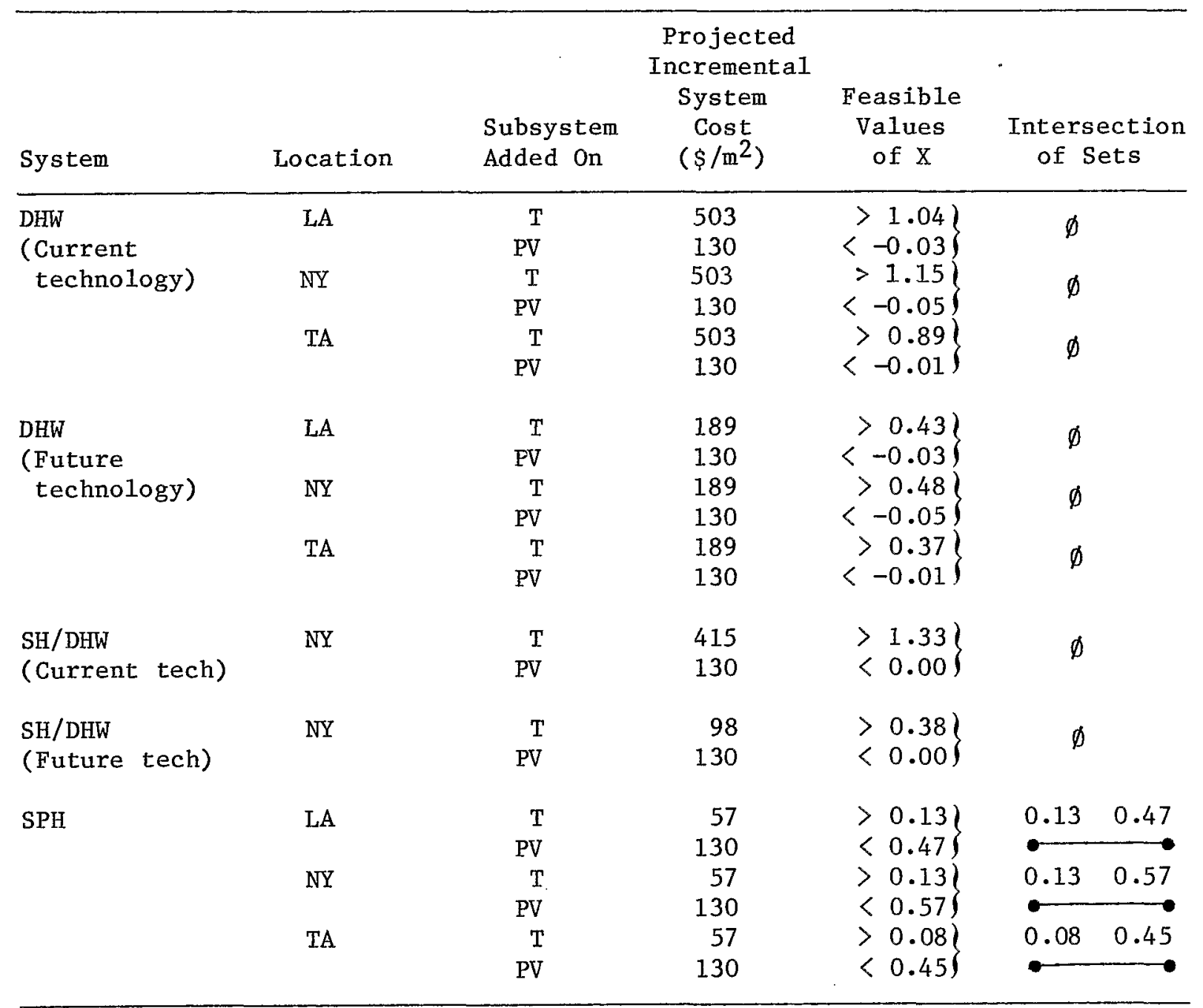

Only values of $X$ between zero and one need be considered. Thermal energy should never be more valuable than electrical energy, since electrical energy can easily be converted into thermal energy, but thermal energy cannot be completely converted to electrical energy. Recall that the most likely values of $\mathrm{X}$ appear to lie in the range $0.25<\mathrm{X}<0.50$ (cf. Section $V$ ). 
For the current-technology medium-temperature systems, there are no values of $X$ which are feasible under both of the above criteria. In fact, except for the values of $\mathrm{X}$ above $0.89 \mathrm{in} \mathrm{Tampa,} \mathrm{neither} \mathrm{criterion} \mathrm{is} \mathrm{satisfied}$ anywhere in the range from zero to one.

For the future-technology systems, Criterion 1 is satisfied for values above 0.4 (actually the lower cutoff varies from 0.37 to 0.48 ). However, Criterion 2 is not satisfied for any values of $X$ above 0 ; and thus $P V / T$ fails the test here also. The value-to-cost ratio of adding $P V$ to the thermal-only system is less than the same ratio for the PV-only system. This is true whether the thermal system is cheap or expensive. Thus, the medium-temperature systems fail the test even if there is no reduction in absorptivity and no increase in collector heat loss due to loss of selectivity.

For the low-temperature swimming pool system, application of Criteria 1 and 2 does yield some feasible values of $\mathrm{X}$. Moreover, these values cover the range of $X$ values which appear reasonable. One can say, then, that the low temperature $\mathrm{PV} / \mathrm{T}$ system passes the test for the case of $\mathrm{PV} / \mathrm{T}$ absorptivity equal to 0.95 .

If $\mathrm{PV} / \mathrm{T}$ absorptivity is as low as 0.85 , the "windows of viability" become narrower. In Los Angeles, the feasible values of $\mathrm{X}$ become 0.15 to 0.25 ; in New York, 0.15 to 0.30 ; in Tampa, 0.09 to 0.23 . This shows that the feasible region is quite sensitive to absorptivity and the latter feasible $X$ values are mostly outside the region 0.25 to 0.50 , which is most likely to be encountered in the real world. The conclusion drawn here is that low-temperature PV/T is marginal as far as these tests of economic attractiveness are concerned.

F. Comparison of $\mathrm{PV} / \mathrm{T}$ to Side-by-Side $\mathrm{PV}+\mathrm{T}$

Figures 16 to 18 show the ratios of energy value derived from a unit area of $\mathrm{PV} / \mathrm{T}$ collector to that derived from a unit area of PV-only plus a unit area of thermal-only. The test of viability here is, "Does this ratio, for a given system in a given location, exceed the corresponding ratio of system costs shown in Tables 17 and 18 (Section VII)?" For the medjum temperature systems, the energy ratio never exceeds 0.85 even under favorable conditions, while the cost ratio is never less than 0.90 even for the advanced-technology thermal subsystem. Thus the medium-temperature $P V / T$ systems fail this test: sideby-side $\mathrm{PV}+\mathrm{T}$ is more attractive. 


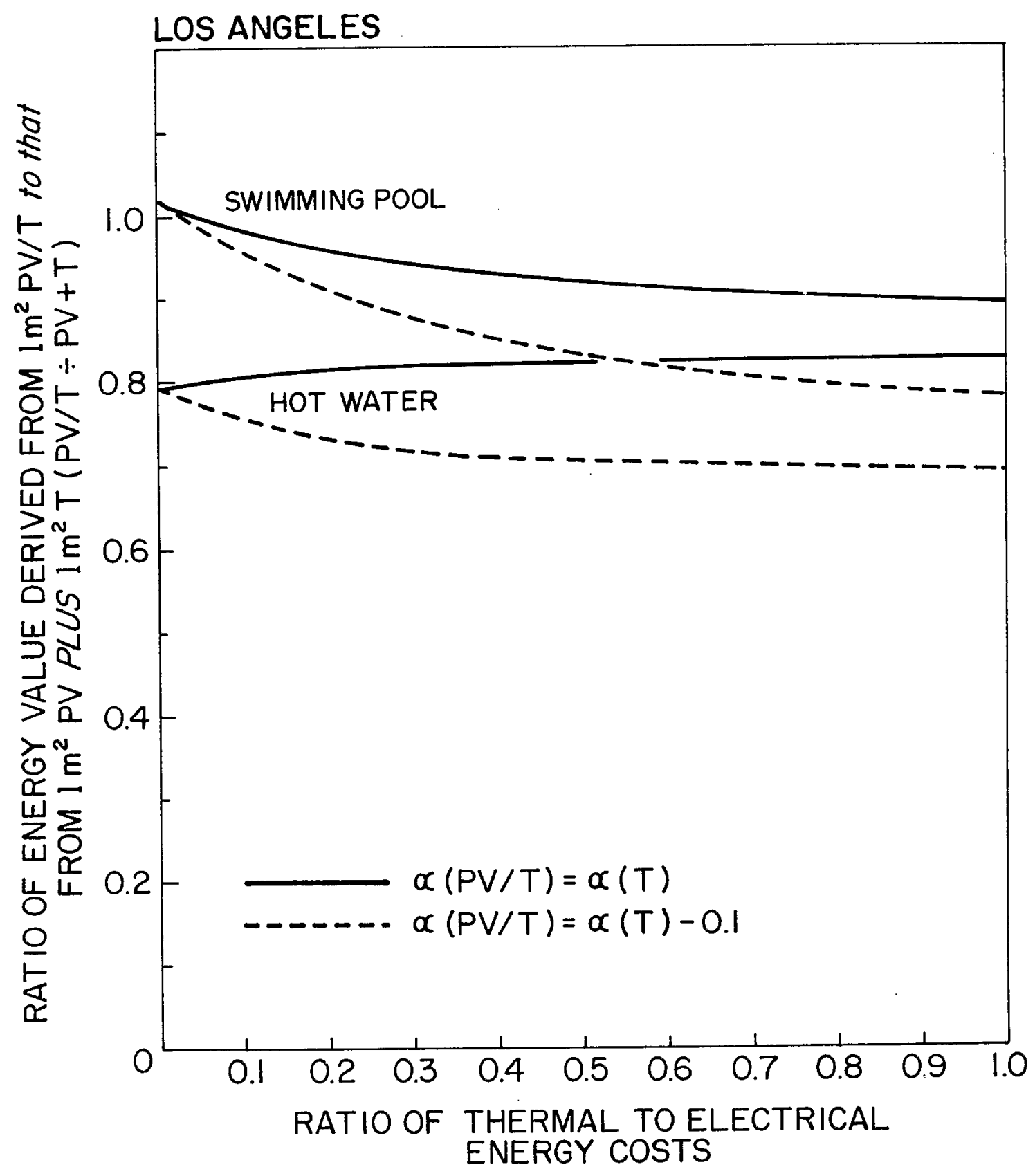

Figure 16. Energy value ratios, $P V / T$ vs. side-by-side $P V+T$, Los Angeles. 


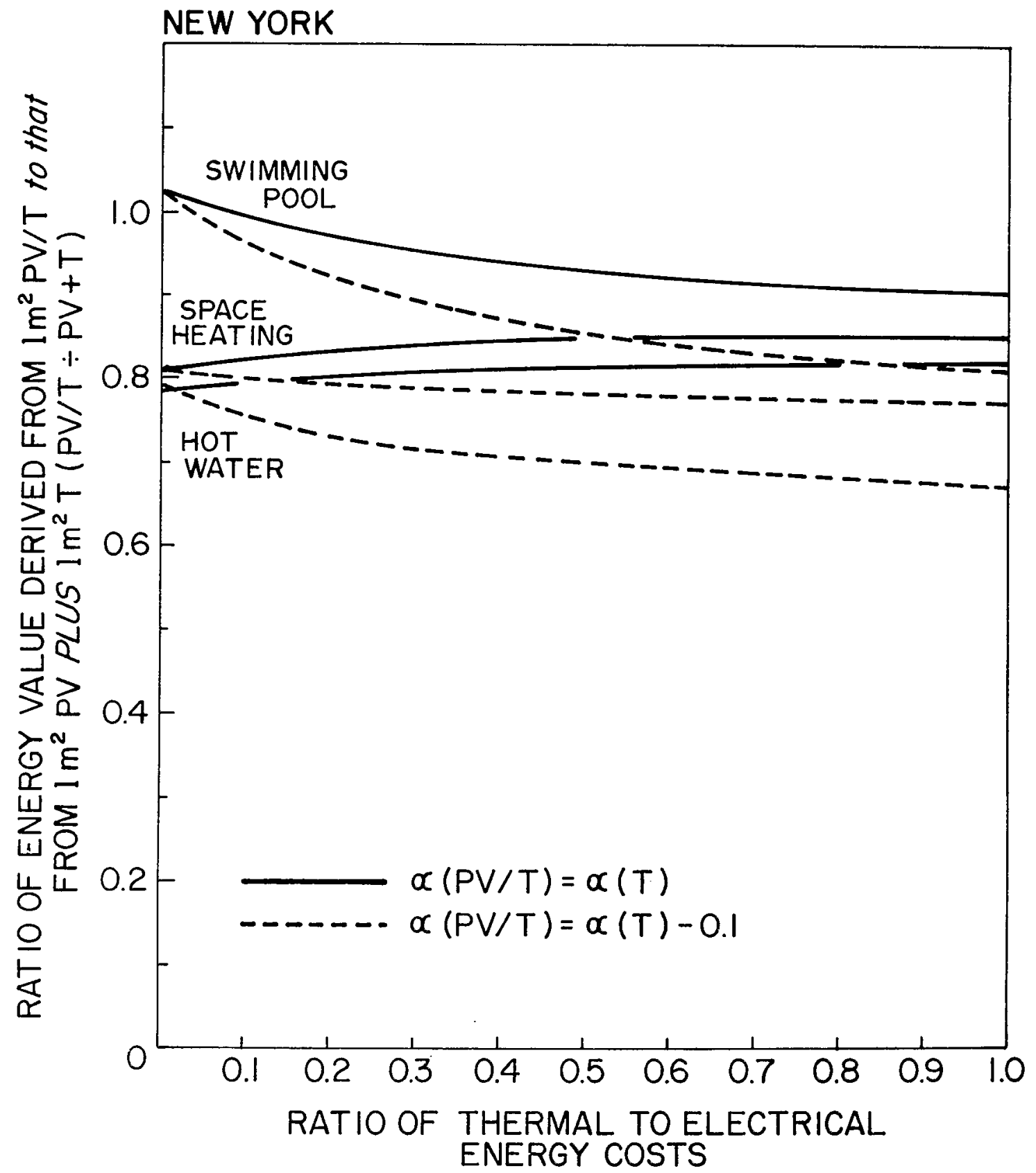

Figure 17. Energy value ratios, PV/T vs. side-by-side PV+T, New York. 


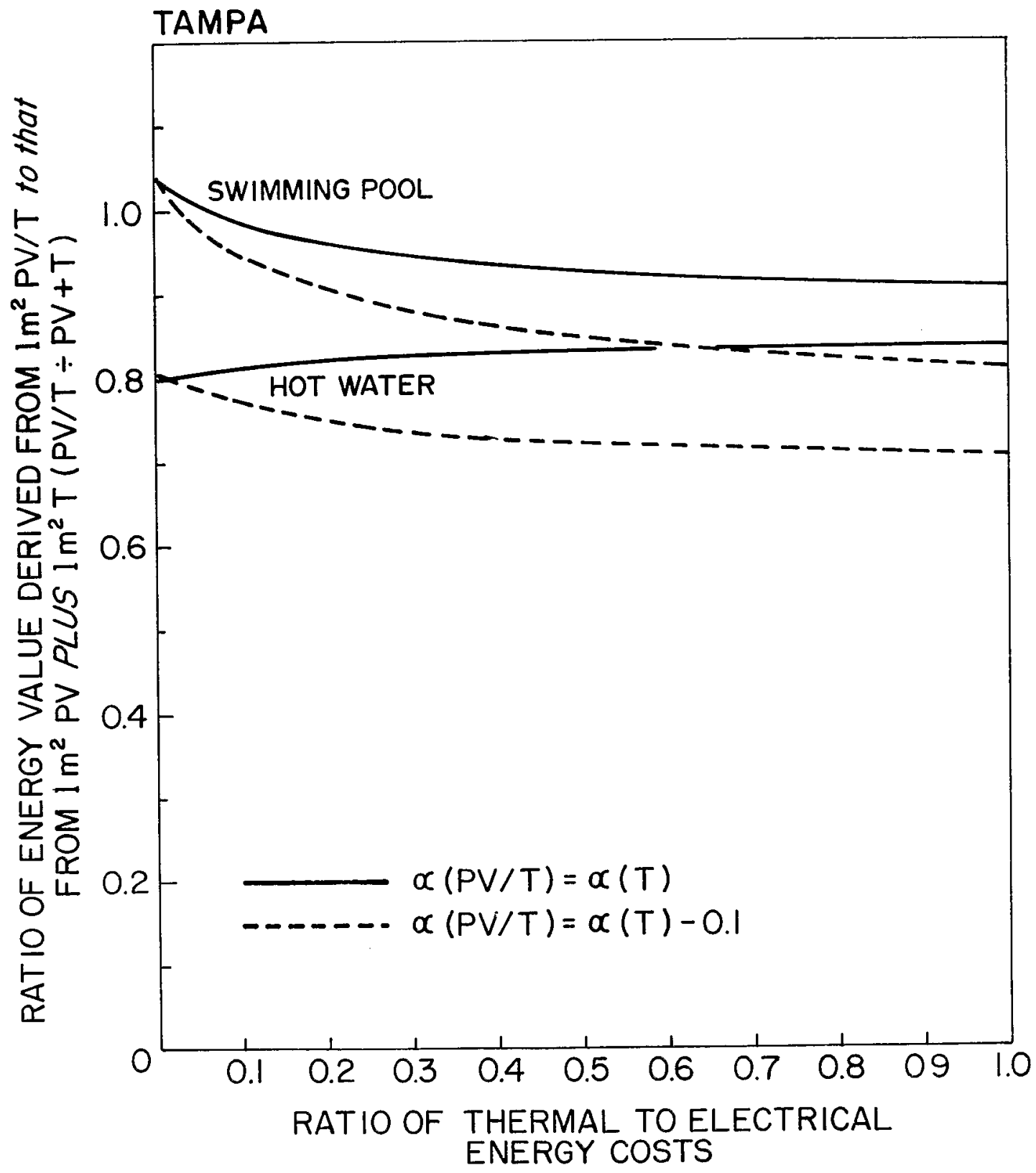

Figure 18. Energy value ratios, $P V / T$ vs. side-by-side $P V+T$, Tampa. 
For the low-temperature systems, the cost ratio may be as low as 0.86 (Table 18), while the energy ratio for $0.95 \mathrm{PV} / \mathrm{T}$ absorptivity is $\sim 0.95$ in the expected range of $X$ values $(0.25$ to 0.50$)$. With $0.85 \mathrm{PV} / \mathrm{T}$ absorptivity the energy ratio in the range $0.25<x<0.50$ drops to within a few percentage points of the cost ratio. Thus it is concluded that the low-temperature swimning pool $\mathrm{PV} / \mathrm{T}$ is at least marginally attractive according to this test.

It should be noted that this is not the most stringent test that could be made, since it compares $\mathrm{PV} / \mathrm{T}$ to a side-by-side system with a fixed collector area ratio $(1: 1)$. In other words, if $\mathrm{PV} / \mathrm{T}$ passes this test, it could still fail a test against a side-by-side system with a different ratio of PV to thermal collector area.

G. Summary

The results of this section are pessimistic for the PV/T systems studied. The medium-temperature applications fail the tests even under assumptions that must be considered favorable. Even the low-temperature applications, which fare better, do not come out as clear winners, unless one assumes no loss of absorptivity in the PV/T system. 


\section{HEAT PUMP APPLICATIONS FOR PHOTOVOLTAICS}

The evaluation of $\mathrm{PV}$ and $\mathrm{PV} / \mathrm{T}$ as collectors for use with heat pumps was carried out as a part of this project. The potential attractiveness of $P V / T$ with a heat pump lies in the ability of the heat pump to make use of relatively low-grade heat (below $\sim 30^{\circ} \mathrm{C}$ ) as a heat source to its evaporator at the same time as it uses the electricity from the PV to drive the compressor motor. operating the collector at these low temperatures also has the advantage of improved cell efficiency over that obtained at higher temperatures in direct space heating and hot water systems. This is the so-called series configuration (Figure 19).

In alternative configuration, the collector feeds heat directly to the load without going through the heat pump, as in a direct heating system. The heat pump then serves as the backup, providing heat to the house with ambient air as the source whenever the solar heat is inadequate. This is the parallel. configuration (Figure 20).

Besides solar heat and ambient air, a third heat source--the ground-should be considered. Ground-coupled heat pumps have been studied during two distinct periods, the decade following World War II and, more recently the past four years. A summary of this work is available (44).

A. Solar Source Heat Pump with $\mathrm{PV} / \mathrm{T}$

Considerable work has been done on series solar heat pump systems with thermal-only collectors $(\underline{35}, \underline{45}-56)$. The basic series system which uses electric resistance backup has the problem of thermal starvation. That is, during periods of high heating load and low insolation, which tend to occur during the coldest months of the year, the available solar heat can be insufficient to meet the heating load, forcing the system to use inefficient electric resistance backup heat. Such systems face the dilemma that, if small collector areas are used, the system is forced onto backup often and its performance suffers; if large collector areas are used to lessen the need for backup, the system costs are forced up. It is thus essential in such systems to find a way to avoid the use of electric resistance (44). This is why ground coupling was first considered for use in solar assisted heat pump 


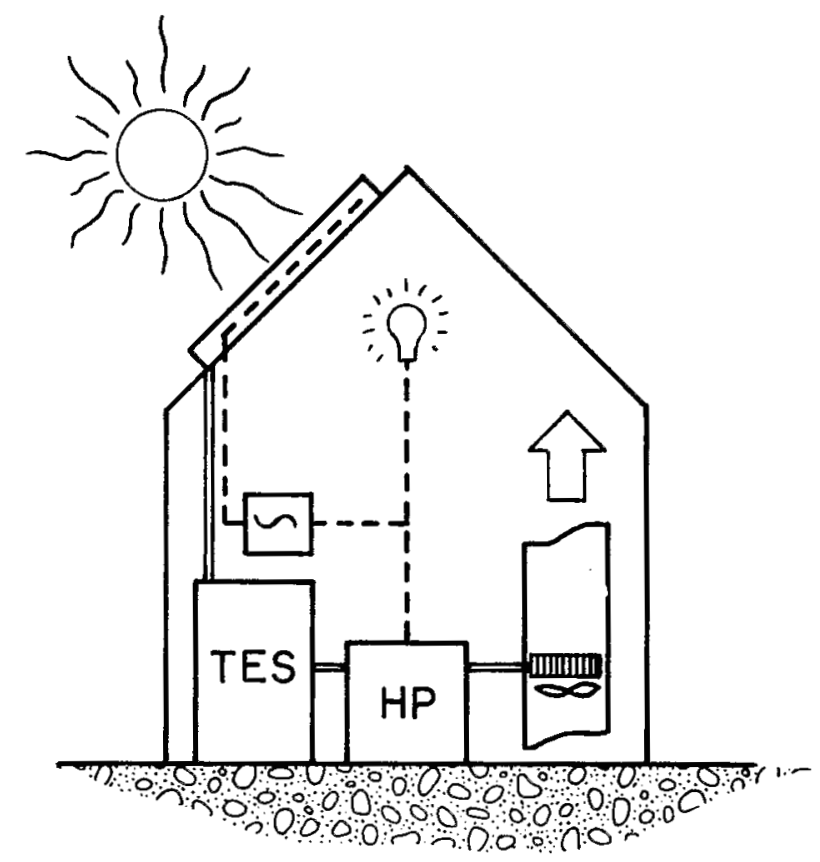

Figure 19. Series solar assisted heat pump configuration, with $\mathrm{PV} / \mathrm{T}$ collectors.

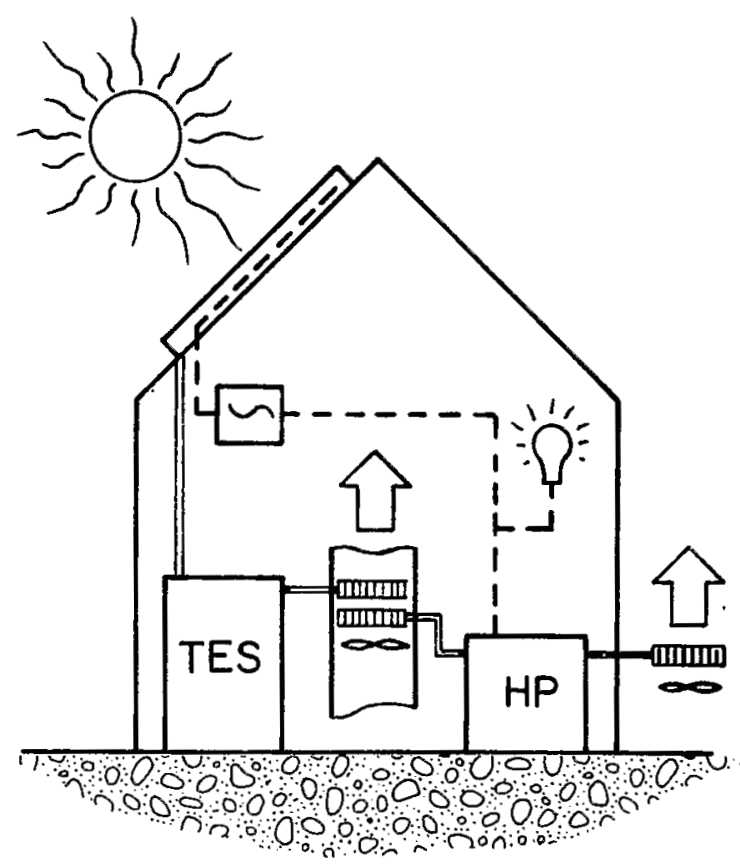

Figure 20. Parallel solar assisted heat pump configuraton, with $P V / T$ collectors. 
systems, although it is now evident that ground coupling can be used by itself, with solar input as an option.

The conclusion that the series system with electric resistance backup is not attractive economically is not likely to be changed by the addition of photovoltaics to the collector. Indeed, because less thermal energy is collected in a PV/T collector than in an equal area of thermal-only collector, thermal starvation will occur sooner, thus calling for more backup heat.

To the first approximation in which the sum of electrical and thermal energy produced by the $\mathrm{PV} / \mathrm{T}$ collector is equal to the thermal energy produced by the thermal-only collector, the increased need for backup due to the reduction in thermal energy collected (in going from thermal only to $P V / T$ ) will just equal the electrical energy produced by the $\mathrm{PV} / \mathrm{T}$. In effect, one can consider the electrical energy as contributing this difference in backup. Thus the electrical energy produced by the PV/T collector is largely degraded to thermal energy. There is then little or no benefit gained in the $\mathrm{PV} / \mathrm{T}$ system over the thermal-only one, in spite of a considerable increase in cost.

B. Air Source Heat Pump with $\mathrm{PV} / \mathrm{T}$

It has been suggested (15) that the parallel solar heat pump configuration with $\mathrm{PV} / \mathrm{T}$ collectors has advantages, especially in cold climates. Since the parallel system is a stand-alone solar heating system which has an air-to-air heat pump as its backup instead of an oil or gas furnace, the analysis of $\mathrm{PV} / \mathrm{T}$ for space heating and domestic hot water carried out in this report is equally applicable to a parallel PV/T solar heat pump system. The results obtained in this analysis were not encouraging, as seen above. From a purely thermal standpoint, the parallel system cannot be said to show much promise at present. One analysis (47) of both series and parallel solar heat pump systems with electric resistance backup concluded that none of these systems was economically viable. Another analysis (57), done by a group reputed to be strong advocates of the parallel system, concluded that even the parallel system, optimally sized economically, would not save energy relative to a 70 to $85 \%$ efficient gas furnace in northern climates. (See Figure 21).

For the above reasons, the parallel $\mathrm{PV} / \mathrm{T}$ heat pump system is given no further consideration here. 


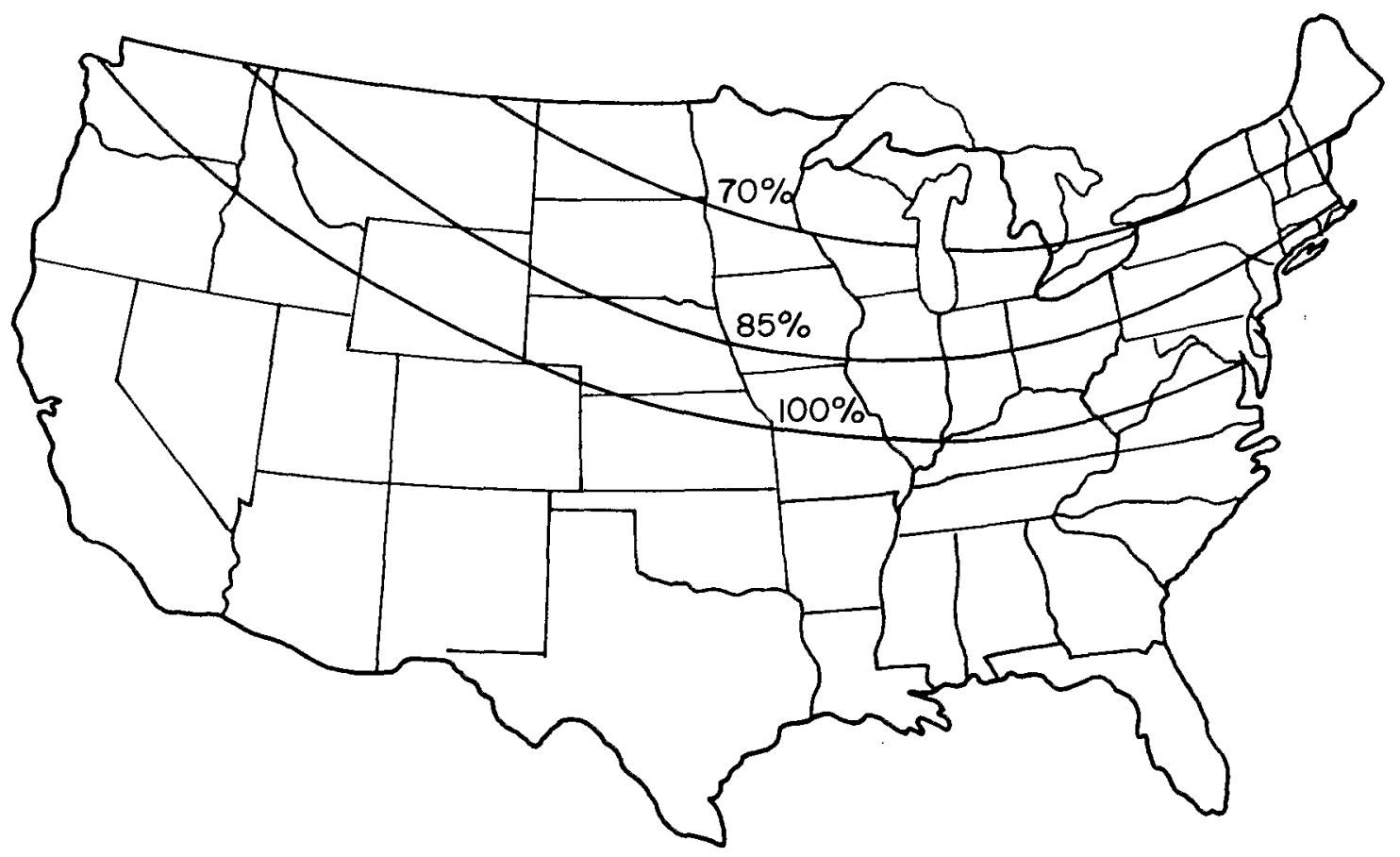

Figure 21. Contours of the conventional gas or oil furnace efficiency required to save more primary energy than the best alternative system (from Ref. (57)).

\section{Ground Source Heat Pump with $\mathrm{PV} / \mathrm{T}$}

A study (25) of various options for combining solar energy with a ground-coupled heat pump system has been carried out at Brookhaven National Laboratory, for systems using thermal-only collectors. Four ways of collecting and using solar energy in such systems were identified (Figure 22):

1. Actively collected solar energy and heat removed from the ground are both used as sources of thermal energy to the heat pump (series/direct heating).

2. Actively collected solar energy is delivered directly to the building load, with the ground-coupled heat pump as backup (direct heating only).

3. Actively collected solar energy preheats the return air stream from the building, and the heat pump raises the air temperature further (if necessary) to the value required for comfort (high side boosting). 


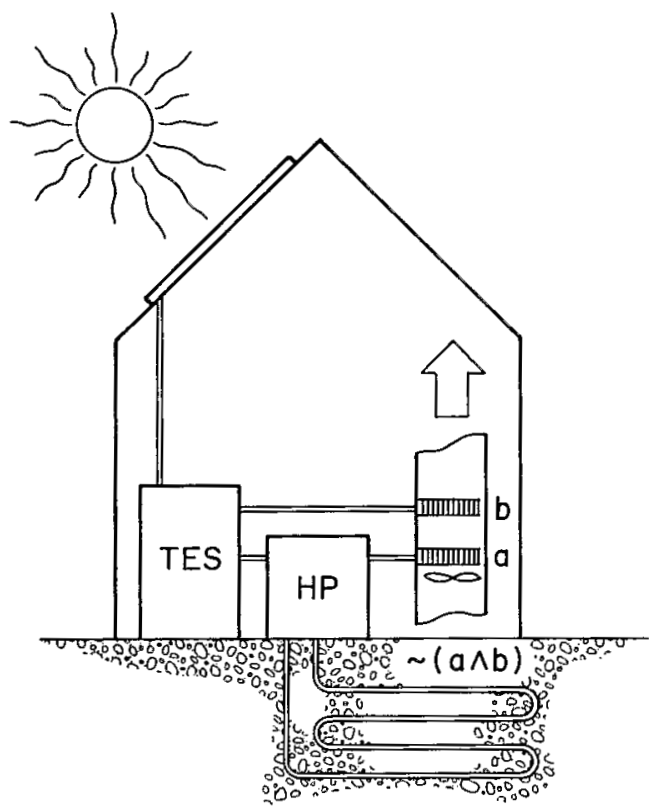

(1)

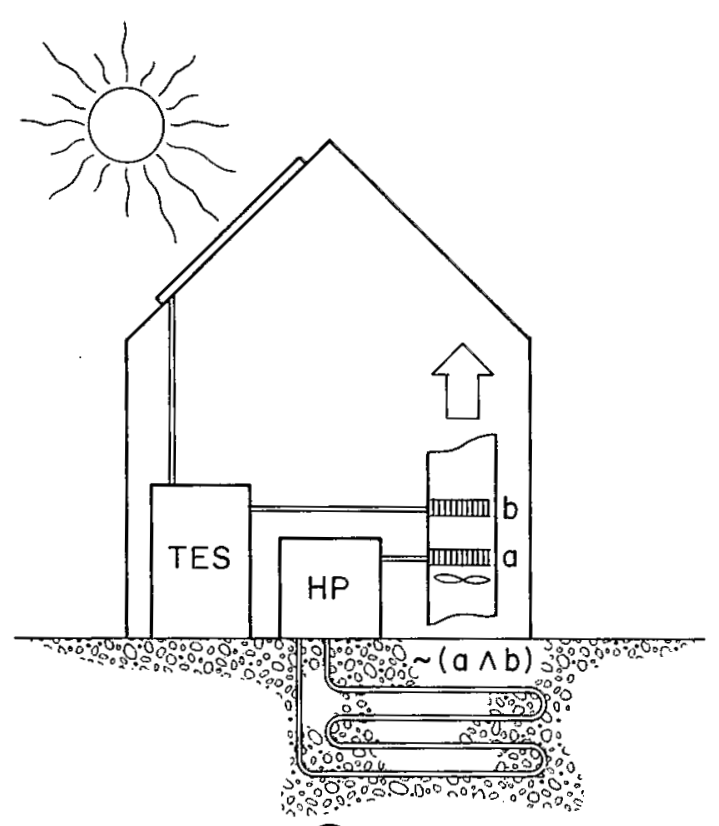

(2)

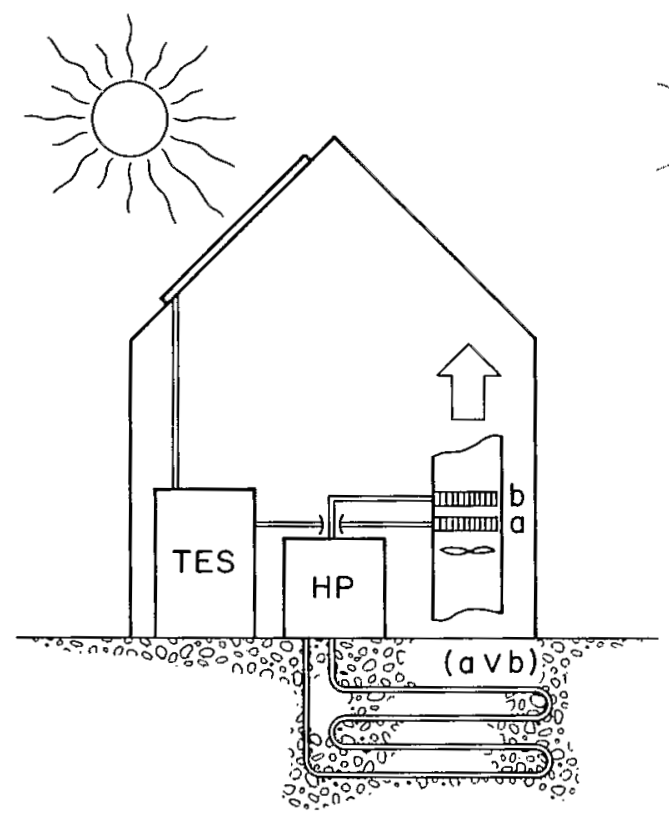

(3)

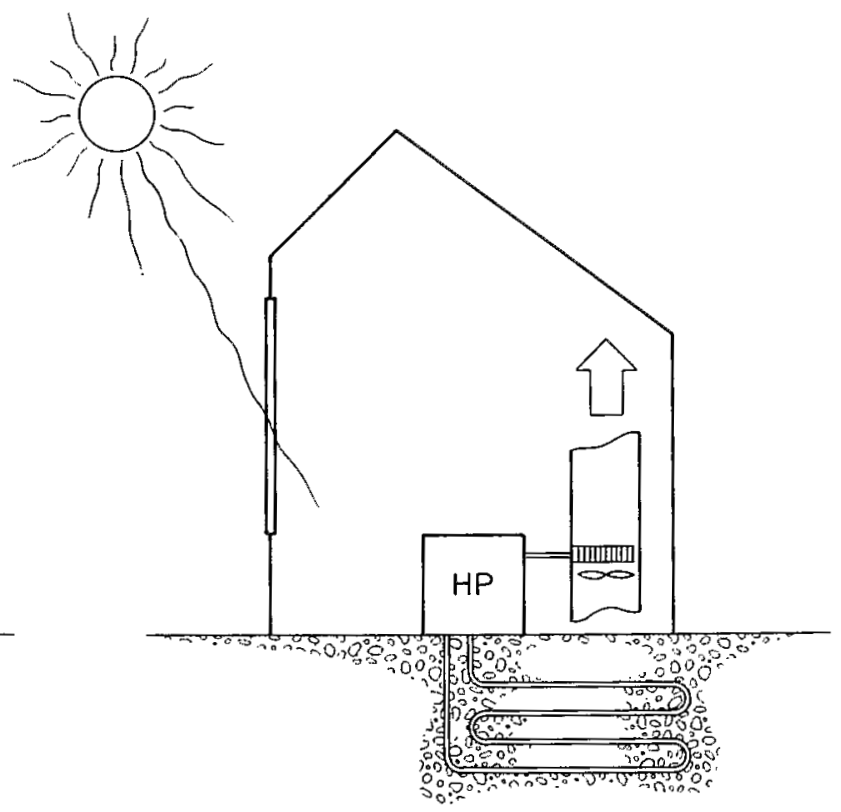

(4)

Figure 22. Ground-coupled solar heat pump: 1) series/direct heating; 2) direct heating only; 3) high side boosting; 4) passive augmentation. 
4. Solar energy collected via direct-gain passive design is used to reduce the building load required to be met by the ground-coupled heat pump.

In systems 1 and 2 the duct coils operate alternately, not simultaneous$1 y$, as indicated by the symbol $\sim(a \wedge b)$. In system 3 the coils can operate individually or together ( $a v b$ ).

In each of the three active solar options the heat pump produces hot water to the extent that solar energy is inadequate. In the passive option all of the hot water is produced via the heat pump. The study was undertaken for three cities (Atlanta, New York, and Madison) providing a range of heating season environments from mild to severe.

The study considered ground-coupled systems in which the ground is used as an alternative heat source but not as a storage element for solar energy. Solar heat (in the active options) is stored in a separate, insulated tank.

Such systems were found to face a dilemma. If the solar energy is collected and used at low temperatures $\left(5^{\circ}\right.$ to $\left.10^{\circ} \mathrm{C}\right)$ then the coefficient of performance (COP) of the heat pump will be only marginally better than what could have been obtained from the ground source alone. This reduces the value of the thermal energy obtained from the collector. On the other hand, if the solar collection temperature is moved higher, say to $\sim 25^{\circ} \mathrm{C}$, then one of two things happens. (1) With collectors of the low-temperature type, the amount of solar energy collected is signficantly reduced in winter, when the heat is needed, relative to what would have been collected at the lower temperature. (2) With the medium-temperature collector, the system performs better if the collector temperature is pushed up to $40^{\circ} \mathrm{C}$ and the heat is used directly, without going through the heat pump.

Thus, the conclusion was that, in a ground-coupled heat pump system where solar energy is not also stored in the ground, the solar energy should not be routed through the heat pump but should be used directly, with the ground used as a backup source for heating and hot water and as a sink for cooling. Another conclusion of this study was that a good way to incorporate solar input at relatively low cost is to make use of a moderate amount of direct-gain passive with night insulation. 
In any event, the use of solar collectors in other than a direct-heating mode did not appear attractive in ground-coupled heat pump systems where the ground is not used to store actively collected solar heat but only as an a1ternative heat source and as a sink.

The idea of using of active solar collectors feeding energy to groundcoupled storage has been seriously considered for specific system configurations ( 58,59 ) but has not been generally evaluated or optimized. If such systems were to use glazed collectors, the $\mathrm{PV} / \mathrm{T}$ option would labor under the same difficulties as the medium-temperature PV/T systems discussed here. That is, although the economic value of adding thermal collection capability to PV may under some circumstances be favorable, the value of adding PV to the thermal system is degraded by the interception of radiation by the glazing, the loss of cell efficiency due to the higher operating temperature, the penalty incurred by the value of the thermal energy given up in order to obtain the electricity, and possible additional penalties caused by lessened absorptivity and loss of selectivity. These effects, as discussed earlier,are sufficient to reduce the marginal value of $P V$ in the system below its cost. If unglazed collectors could be used, the PV/T might be marginally attractive, like the swimming pool PV/T. One report $(\underline{60)}$ has indicated the possibility that unglazed PV/T collectors may be attractive with heat pumps under certain conditions. Further investigations in this area would appear to be warranted. D. PV With Ground Coupling

At least one system configuration involving photovoltaics may have merit. Although it is not a PV/T system, it is included here because readers working in the photovoltaic area may be interested in ground coupling if it can enhance the market potential of photovoltaics in any way.

The proposed system configuration would incorporate the optimized ground-coupled heat pump system with modest passive augmentation which resulted from the study by Andrews (25). However, instead of all the power needed to operate the heat pump being purchased, part of it would be provided by a PV array of modest size $\left(\sim 30 \mathrm{~m}^{2}\right.$ for a moderately well insulated house in New York). The PV array would not need to be grid-compatible. Either the dc 
power from the PV would be fed directly to a dc-driven heat pump, or an inexpensive non-grid-compatible inverter would be used with an ac-driven heat pump. There would be little or no storage of electricity. PV electricity would be used as collected to operate the heat pump, supplemented as needed from the utility grid. Energy storage would be possible in the domestic hot water subsystem; in effect the electricity produced by the $P V$ array would be magnified by the COP of the heat pump and could then be stored as thermal energy.

System schematics are shown for a water-to-air heat pump (Figure 23) and a water-to-water heat pump (Figure 24). The diagram shows the dc option, but the ac option with the low cost non-grid compatible inverter is also worthy of consideration. In both systems the domestic hot water tank shown is a special design which separates the incoming cold water from the hot water which is produced by passing water through a water-refrigerant heat exchanger. This heat exchanger could be used as a desuperheater at low water flow rates and as a condenser at high water flow rates, if a suitably designed heat pump is employed. Desuperheater operation would be used when the heat pump was also needed for space heating. Condenser operation would be used during spring and fall when hot water was required but not space heating. To provide this versatility a variable-capacity heat pump would be needed with provision for refrigerant charge management.

The water-to-air heat pump adheres most closely to current practice for single-family residences. The water-to-water heat pump would probably be more appropriate for multifamily or commercial applications. In the water-to-air heat pump the water circuits are simple but the refrigerant circuit is complex (although no more complex than in a standard air-to-air heat pump). In the water-to-water heat pump the refrigerant circuit is simple but the water circuits are complex. The water-to-water heat pump does provide potential advantages: the evaporator and condenser do not exchange roles as the heat pump goes from heating to cooling, and so their designs can be optimized for their specific roles; water storage allows off-peak operation of the heat pump to the extent that the PV energy is inadequate; and the building can be easily zoned via the use of multiple fan/coil units. 


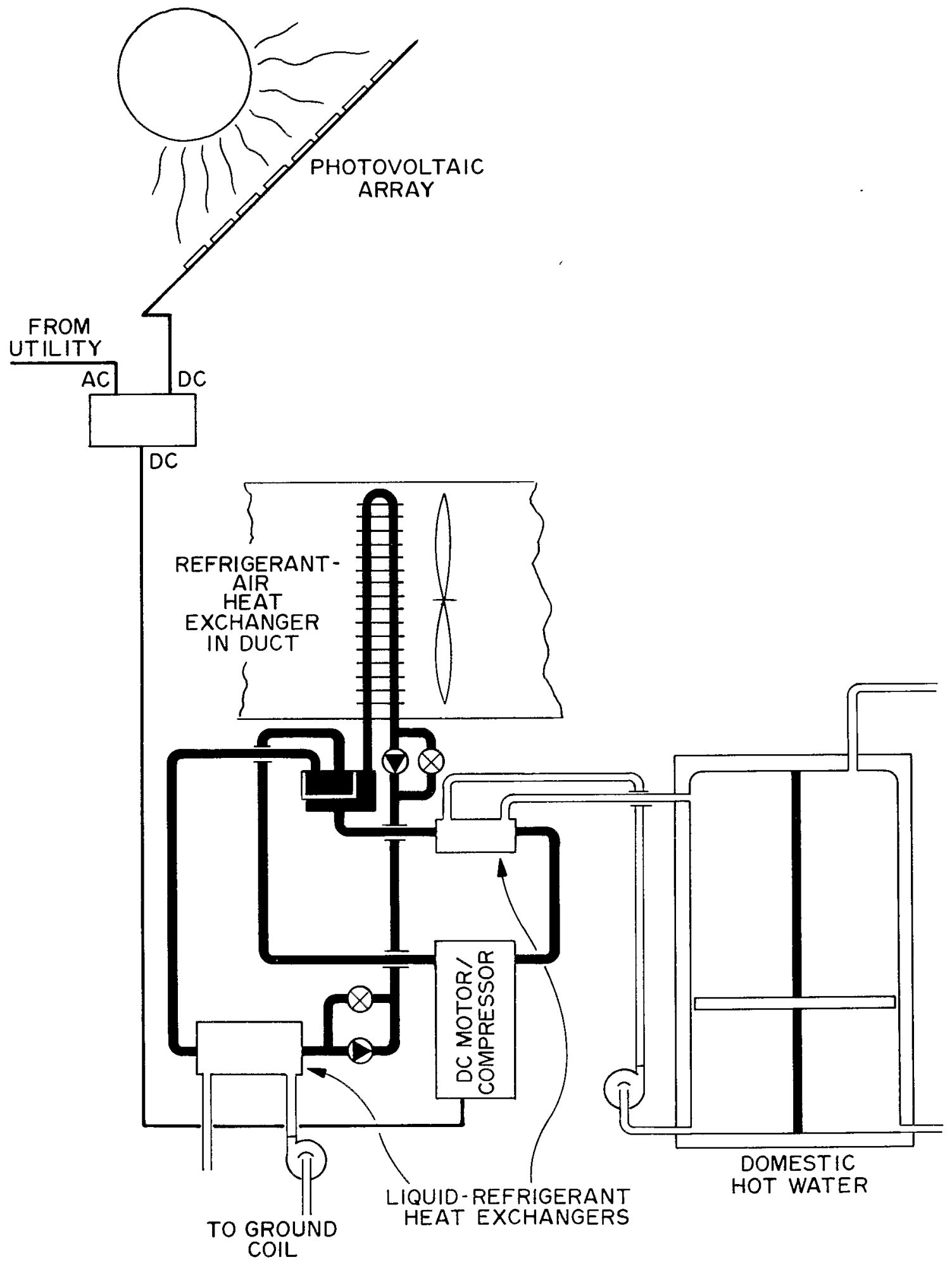

Figure 23. PV-driven ground-coupled heat pump, water-to-air configuration. 


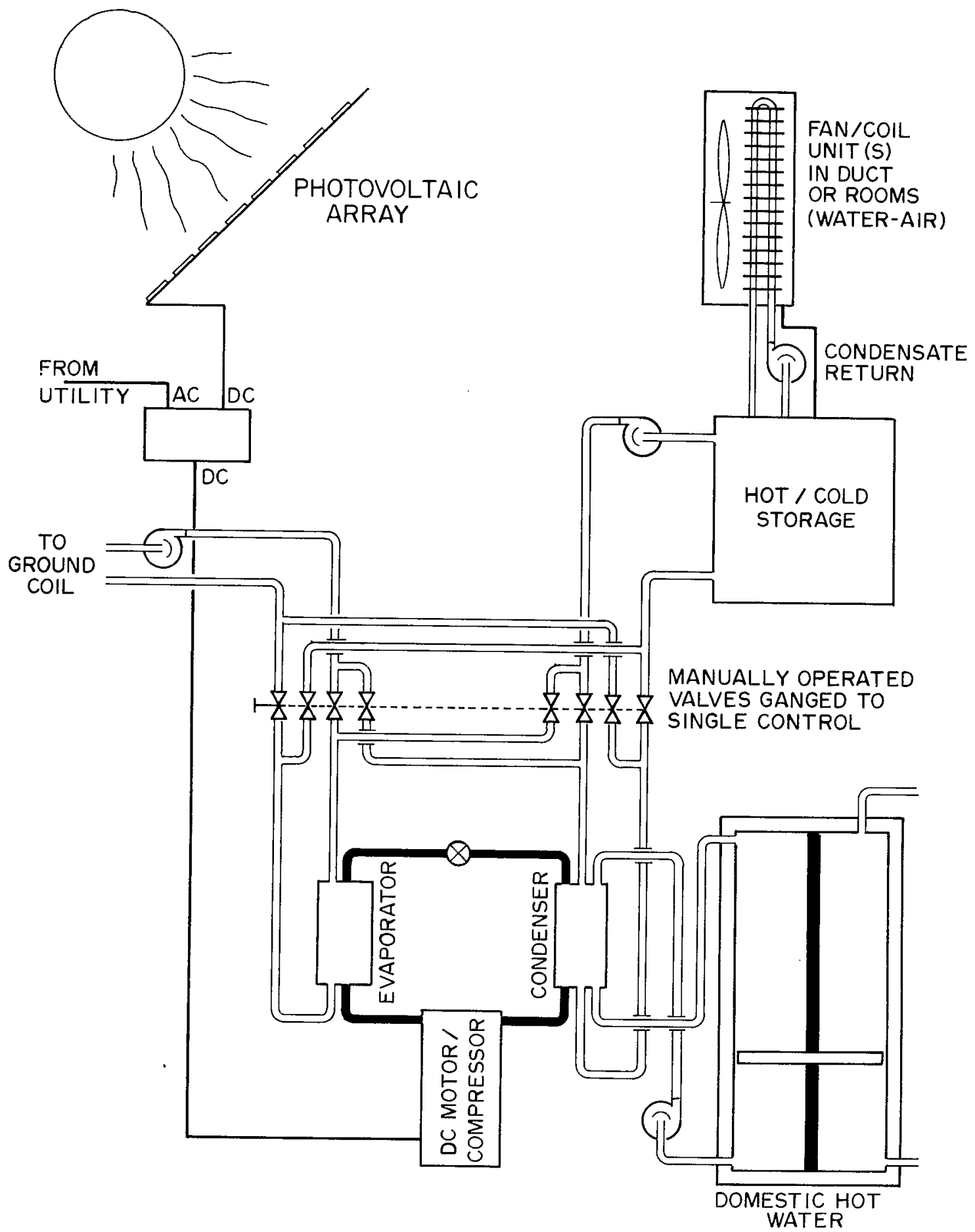

Figure 24. PV-driven ground-coupled heat pump, water-to-water configuration. 
Calculations have been made for an example of the system in New York, and the results are shown in Table 28. The system is that of Andrews (25), a ground-coupled heat pump with $15 \mathrm{~m}^{2}$ of direct-gain passive with movable insulation which is set in place at night (either manually or automatically). The first three columns of Table 28 show the loads and gains involved. The study of (25) did not consider cooling specifically, since all the systems studied were identical in the cooling mode. Here an annual cooling load of 20 GJ is assumed, to give an annual heating/cooling load ratio (61) of 3.0 , and a cooling COP of 2.35 corresponding to an energy efficiency ratio (EER) of 8 for cooling. The cooling season is assumed to run from mid-June to mid-September. During this period, hot water is produced from the air-conditioning reject heat. During the spring and fall, when there is no heating or cooling load, hot water is assumed to be produced with a COP of 2.0, comparable to that obtained from dedicated heat pump hot water heaters (62). During the winter months, when hot water is produced by desuperheating, the hot water COP is assumed to be the same as that obtained by the heat pump for space heating.

A number of annual performance factors (APF) have been calculated for comparison (Table 28). APF is defined as the ratio of total benefits (heating and cooling) divided by the purchased electric energy required. For electric resistance with electric air conditioning $\left(I^{2} R+A / C\right)$ the APF is 1.13. For the air-to-air heat pump with electric hot water and electric air conditioning, the APF is 1.62. For the ground-coupled heat pump with $15 \mathrm{~m}^{2}$ of direct-gain passive with night insulation, and hot water production via the heat pump, the APF rises to 3.51. (Without the passive, the APF is 3.0.) With the addition of photovoltaics, the APF rises to $4.19,5.21,6.42$, and 8.08 , depending on whether $10,20,30$ or $40 \mathrm{~m}^{2}$ of $\mathrm{PV}$ are used. For comparison, a parallel solar/heat pump system (thermal-only collectors) with a solar fraction of $50 \%$ would have an APF of less than 3.0 under similar circumstances (Table 29). 
Table 28

Example of Photovoltaic Ground-Coupled Heat Pump System, New York, Electric Energy Requirements and PV Contributions, (A11 values in $\mathrm{GJ} ; 1 \mathrm{GJ}=278 \mathrm{kWh}$ )

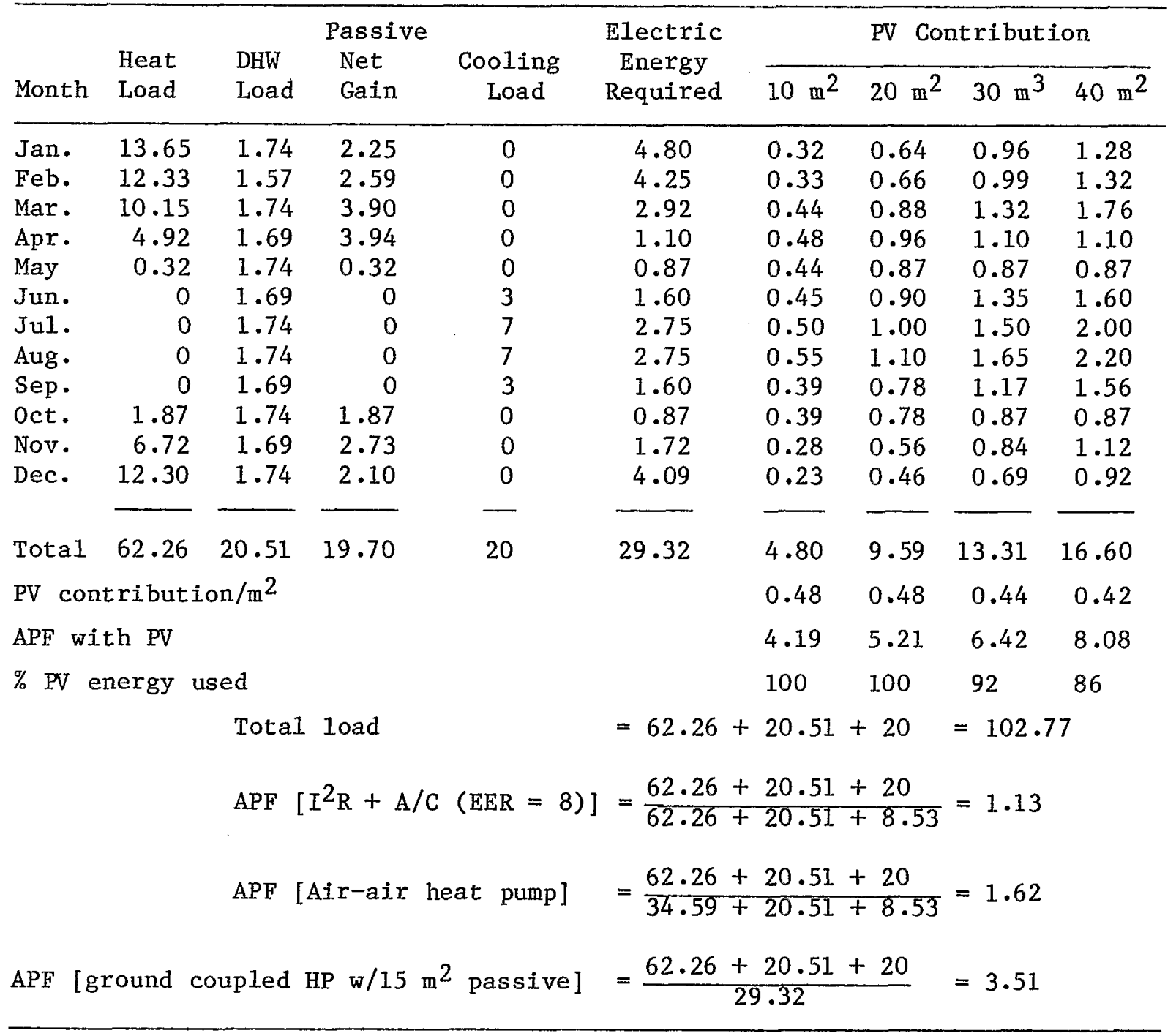


Estimation of Parallel Solar Assisted Heat Pump System Performance ( $50 \%$ Solar Fraction)

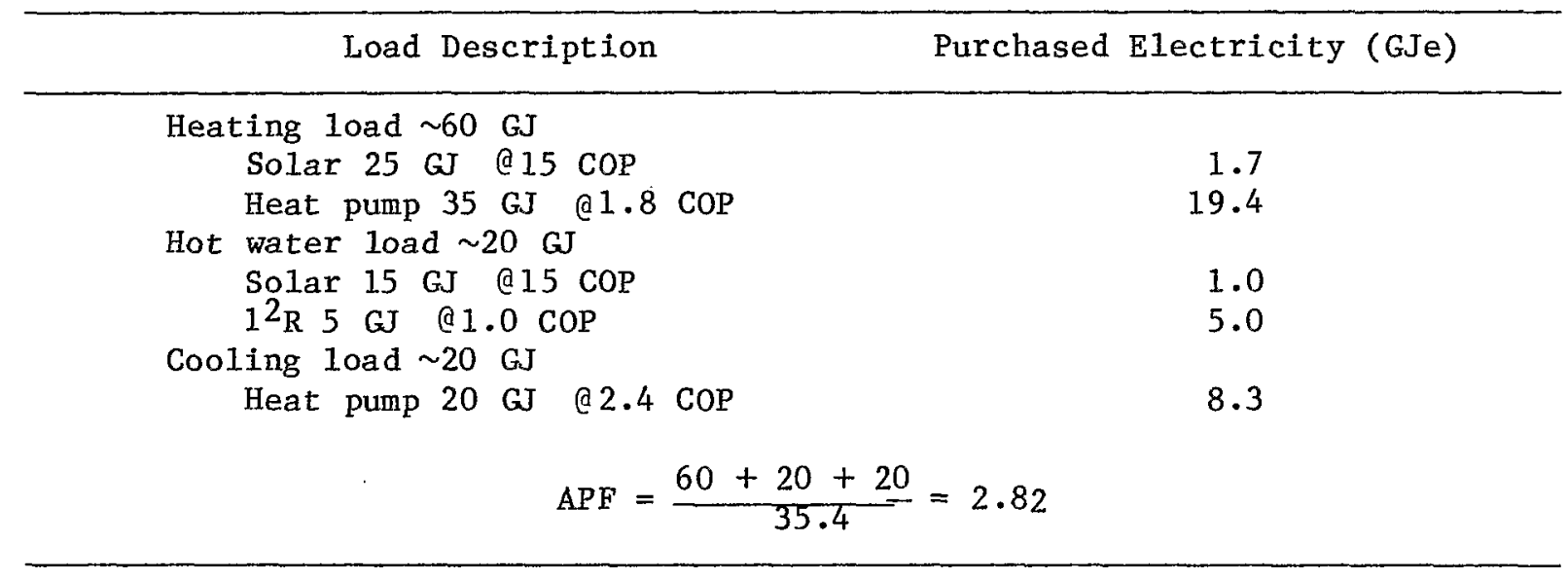




\section{CONCLUSIONS}

This study analyzed the economic attractiveness of flat-plate PV/T systems for hot water heating and space heating (glazed collectors, mediumtemperature applications) and for swimming pool heating (unglazed collectors, low-temperature applications). For medium-temperature applications, PV/T systems were not found to be attractive relative to the three solar alternatives, PV-only, thermal-only, and side-by-side PV plus thermal, in any of the locations studied for any ratio of thermal to electrical energy costs. This conclusion held even under the assumption of greatly reduced thermal energy collection costs. The conclusion resulted largely from the significantly lower marginal value of $P V$ cells in a $P V / T$ collector than in a PV-only system. The marginal value of the $\mathrm{PV}$ cells in the $\mathrm{PV} / \mathrm{T}$ collector is reduced by the glazing interposed between the sun and the cells; by the higher collector operating temperatures, which reduce cell efficiency; and by the reduction in thermal output due to the electrical energy collected. Additional complications that may make the comparison even more unfavorable are possible reduced solar absorptivity and increased infrared emissivitiy relative to a good selective surface, which may be applied to a therma1-on1y collector.

For low-temperature unglazed collectors, $P V / T$ appeared to be marginally attractive. The reasons for this better result include the absence of glazing, improved cell efficiency due to low temperature operation, and the limitation of the need for thermal energy for swimming pool heating to only part of the year so that the electricity collected year-round makes this system more attractive. The use of unglazed $\mathrm{PV} / \mathrm{T}$ collectors with heat pumps warrants further study.

The outlook for $\mathrm{PV} / \mathrm{T}$ could be improved by PV cost reductions to values well below the DOE 1986 program goals, coupled with progress in thermal energy collection consistent with the advanced technology projected in this study.

In view of these results, our recommendation is that further work on $\mathrm{PV} / \mathrm{T}$ hardware await those developments in $\mathrm{PV}$ and thermal energy collection technology which would make the $\mathrm{PV} / \mathrm{T}$ marriage economically attractive. 


\section{REFERENCES}

1. L. W. Florscheutz, "Extension of the Hottel-Whillier model to the analysis of combined photovoltaic/thermal flat plate collectors," Solar Energy 22, 361 (1979).

2. P. Raghuraman, "Analytical prediction of liquid photovoltaic/thermal flat-plate collector performance," DOE CO0-4094-66 (1979).

3. P. Raghuraman, "Analytical prediction of an air photovoltaic/thermal flat-plate collector," DOE/ET/20279-93 (1980).

4. P. Raghuraman and S. D. Hendrie, "Analytica1 predictions of liquid and air photovoltaic/thermal flat-plate collector performance," DOE C00-4094-89 (1980).

5. S. D. Hendrie and P. Raghuraman, "A comparison of theory and experiment for photovoltaic/thermal collector performance," DOE C00-4094-74 (1980).

6. ARCO Solar Inc., "Design and fabrication of combined photovoltaic-thermal collectors," SAIND 79-7008 (1980).

7. C. H. Cox, III, "Design of solar cells for use in photovoltaic/thermal collectors," DOE/ET/20279-97 (1980).

8. J. A. MacMillan et a1., "The role of spectral selectivity in hybrid solar energy conversion," Proc. Ann. Mtg. Am. Sect. Int. Sol. Energy Soc., Denver, CO, August 1978, Vo1. 2.2, p. 300.

9. S. D. Hendrie and P. Raghuraman, "An advanced combined photovoltaic/thermal collector: design and testing," DOE COO-4094-88 (1980).

10. W. A. Aiello and P. Raghuraman, "Performance of a combined photovoltaic/thermal flat-plate liquid collector," Proc. ASME Solar Energy Div. 3rd Ann. Conf., Reno, NV, Apri1 1981, p. 557.

11. J. J. Loferski, "Combined solar therma1-photovoltaic systems demonstration, phase I," Proc. Ann. DOE Active Solar Heating and Cooling Contractors' Rev. Mtg., March 1980, p. 7-6, DOE CONF800340.

12. E. C. Kern, Jr., "On photovoltaic/thermal collectors and heat pumps," DOE CONF-780808-26 (1978).

13. E. C. Kern, Jr. and M. C. Russe11, "Combined photovoltaic and therma1 hybrid collector systems," C00-4577-3, Proc. 13th IEEE Photovoltaic Specialists' Conf., Washington, DC, June 1978. 
14. P. Raghuraman, "Hybrid photovoltaic/thermal solar energy systems," DOE C00-4577-1, p.26 (1978).

15. D. B. Sheldon and M. C. Russell, "A review of combined photovoltaic/ thermal collector - solar assisted heat pump system options," Proc. 5th Ann. Heat Pump Technology Conf., Stillwater, OK, April 1980, p. IX-7.

16. S. R. Venkateswaran and D. K. Anand, "Performance studies of combined photovoltaic/thermal solar heating and cooling systems," Proc. 2nd Ann. Systems Simulation and Economic Analysis Conf., San Diego, CA, January 1980 , p. 119, SERI-TP-351-431.

17. Westinghouse Electric Corporation Research and Development Center, "Regional conceptual design and analysis studies for residential photovoltaic systems," SAND 78-7040 (1978); (a) Vol 1, p. 16.

18. General Electric Corporation Space Division, "Regional conceptual design and analysis studies for residential photovoltaic systems," SAND 78-7039 (1979); (a) Vol II, p. 11-4.

19. E. R. Hoover, "Comparative analysis of combined flat-plate PV/T collectors with separate PV/T collectors," SAND 80-1494 (1980).

20. U.S. Dept. of Housing and Urban Development, "Solar fact sheet," HUD-PDR-492-11 ( July 1980).

21. "EIA survey results on solar pool heating," Solar Engineering (April 1979).

22. "1980 swimming pool industry market report," published by Swimming Pool Week1y/Swimming Pool Age (Ft. Lauderdale, FL), (1980).

23. "Forecasts for solar energy applications in the United States, 19771992," International Business Services, Inc., Economic and Technology Development Division, Washington, DC, (1978).

24. J. W. Andrews, "Optimization of solar assisted heat pump systems via a simple analytic approach," Proc. 2nd Ann. Systems Simulation and Economic Analysis Conf., San Diego, CA, January 1980, p. 361, SERI/TP-351-431

25. J. W. Andrews, "Ground coupled solar heat pump: analysis of four options," Proc. ASME Solar Energy Div. Conf., Reno, NV, April 1980, P. 248 .

26. A. M. Perino, "A methodology for determining the economic feasibility of residential or commercial energy systems," SAND 78-0931, p. 11 (1979); (a) p. 14; (b) p. 12; (c) p. 17 . 
27. "An economic analysis of solar water and space heating," ERDA DSE-2322-1, (1976).

28. Southern California Edison Co., Public Information Office, personal communication.

29. Tampa Electric Co., Public Information Office, personal communication.

30. Long Island Lighting Co., residential electric bills, January-February 1981 .

31. "Photovoltaic program systems development plan," Jet Propulsion Laboratory 5240-5 (1980).

32. Winter 1980-81 fuel oil dealer prices, eastern Long Is land.

33. E. L. Zweigel, "Solar thermal industry market analysis," Corporate Technology Dept., The Continental Group, Inc., (August 1980), (Limited Distribution).

34. "Cost reduction opportunities: residential solar systems," Booz Allen \& Hamilton, Bethesda, MD (1981), (Draft subject to revision).

35. J. W. Andrews, "Heat pump impact upon solar collector design and cost," Proc. Int. So1. Energy Soc. Congr., At lanta, GA, May 1979, p. 792.

36. J. M. Alcone and P. L. Marjon, "Ground coupling and heat pump compatible collectors," Science Applications Inc., Albuquerque, NM (1981), (Draft subject to revision).

37. J. W. Andrews and W. G. Wilhelm, "Thin-film flat-plate solar collectors for low-cost manufacture and installation," BNL 51124 (March 1980).

38. W. D. Mckevey, P. B. Zimmer, and R. J. H. Lin, "Solar selective coating development," Honeywell, Inc., Final Report, DOE Contract No. DE-AC04-78CSA14287 (December 1979).

39. R. C. Bourne, "Membrane-1ined foundations for 1iquid thermal storage;" Proc. Ann. DOE Active Solar Heating \& Cooling Contractors' Rev. Mtg., March 1980, p. 11-30, DOE CONF 800340.

40. D. Leiman, Sun Collector Inc., Commack, NY (Fafco distributor), personal communication (1981).

41. P. J. Lunde and P. S. Brown, Jr., "Solar radiation data on inclined surfaces for selected U.S. locations 1971-1972," Center for the Environment and Man, Inc., Hartford, CT (1977).

42. C. W. Wynn and G. R. Johnson, "Solar energy analysis programs for programmable handheld calculators," SEEC-TR-99, Solar Environmental Engineering Co., Ft. Collins, Co (1976). 
43. J. Backlund, Fafco Inc., Menlo Park, CA, private communication (1981).

44. J. Andrews, "Solar energy and heat pumps: can this marriage be saved?" Proc. 16th Intersoc. Energy Conversion Engineering Conf., Atlanta, GA, August 1981, P. 1691 .

45. J. W. Andrews, E. A. Kush, and P. D. Metz, "A solar assisted heat pump system for year-round space conditioning," Proc. 3rd Workshop Use of Solar Energy for the Cooling of Buildings, February 1978, p. 248, DOE CONF-780249.

46. T. L. Freeman, J. W. Mitchell, and T. E. Audit, "Performance of combined solar heat pump systems," Solar Energy 22, 125-35 (1979).

47. P. J. Hughes and J. H. Morehouse, "Comparison of solar heat pump systems to conventional methods for residential heating, cooling and water heating," Science Applications Inc., McLean, VA, Report 80-906-WA (1979).

48. H. F. Bessler and B. C. Hwang, "Solar assisted heat pumps for residential use," ASHRAE Journal, September 1980, p. 59.

49. W. Kahan and R. C. Estes, "Optimization and comparison strategies for solar energy systems," Am. Soc. Mech. Eng. Pub. 79-WA/SOL-26 (1979).

50. J. W. Andrews, "Solar assisted heat pump overview and summary pf in-house research," Proc. 3rd Ann. Sol. Heating and Cooling Res. and Dev. Branch Contractors' Meeting, September 1978, p. 228, DOE CONF-780983 (1979).

51. E. A. Kush, "Development of a solar assisted heat pump for the heating and cooling of buildings," Ibid., p. 233.

52. J. W. Andrews, "Solar assisted heat pump program overview and summary of work at Brookhaven National Laboratory," Proc. Ann. DOE Active Solar Heating and Cooling Contractors' Rev. Mtg., March 1980, p. 4-1, DOE CONF-800340.

53. E. A. Kush, "Solar assisted heat pump studies: heat pump hardware and experiments, simulations, earth coupling contracts and supporting contracts, Ibid., p. 4-5.

54. E. A. Kush, "The role of the vapor compression cycle in solar energy utilization," Proc. Ann. Mtg. Am. Sect. Int. Sol. Energy Soc., Denver, Co, August 1978, Vol. 2.1, p. 957.

55. E. A. Kush, "Performance of heat pumps at elevated evaporating temperatures, with application to solar input," Am. Soc. Mech. Eng. Pub. 79-WA/SOL-19 (1979). 
56. A. Ecker, "Development of a solar assisted heat pump for the heating and cooling of buildings," Proc. Ann. DOE Active Sol. Heating and Cooling Contractors' Rev. Mtg., March 1980, p. 4-20, DOE CONF-800340.

57. B. E. Manton and J. W. Mitche11, "A regional comparison of solar, heat pump, and solar - heat pump systems," Proc. ASME Solar Energy Div. 3rd Ann. Conf., Reno, NV, Apri1 1981, p. 200.

58. D. M. Jardine, "Extension of Phoenix/City of Colorado Springs solar assisted heat pump project," Draft Final Report (1981), (Subject to revision).

59. T. R. Galloway, "Solar-assisted heat pump and swimming pool synergy for domestic heating," URCL-83458, Rev. 1 (1980).

60. S. Gassner and L. Wen, "Evaluation of Unglazed Flat-Plate PhotovoltaicThermal Collectors in Residential Heat-Pump Applications," to be presented at the ASME Solar Energy Division meeting, Albuquerque, NM, April 1982.

61. W. Kahan, "Analytical selection of marketable SAHP systems," SAN/1467-1, p. 126, The Singer Company, Fairfield, NJ (1980).

62. L. Morrison and J. Swisher, "Analysis of the performance and space conditioning impacts of dedicated heat pump hot water heaters," Proc. ASME Solar Energy Div. Conf., Reno, NV, April 1980, p. 175. 